Di Sanzo, Spengler, et al.

\title{
Mapping sites of carboxymethyllysine modification on proteins reveals its consequences for proteostasis and cell proliferation
}

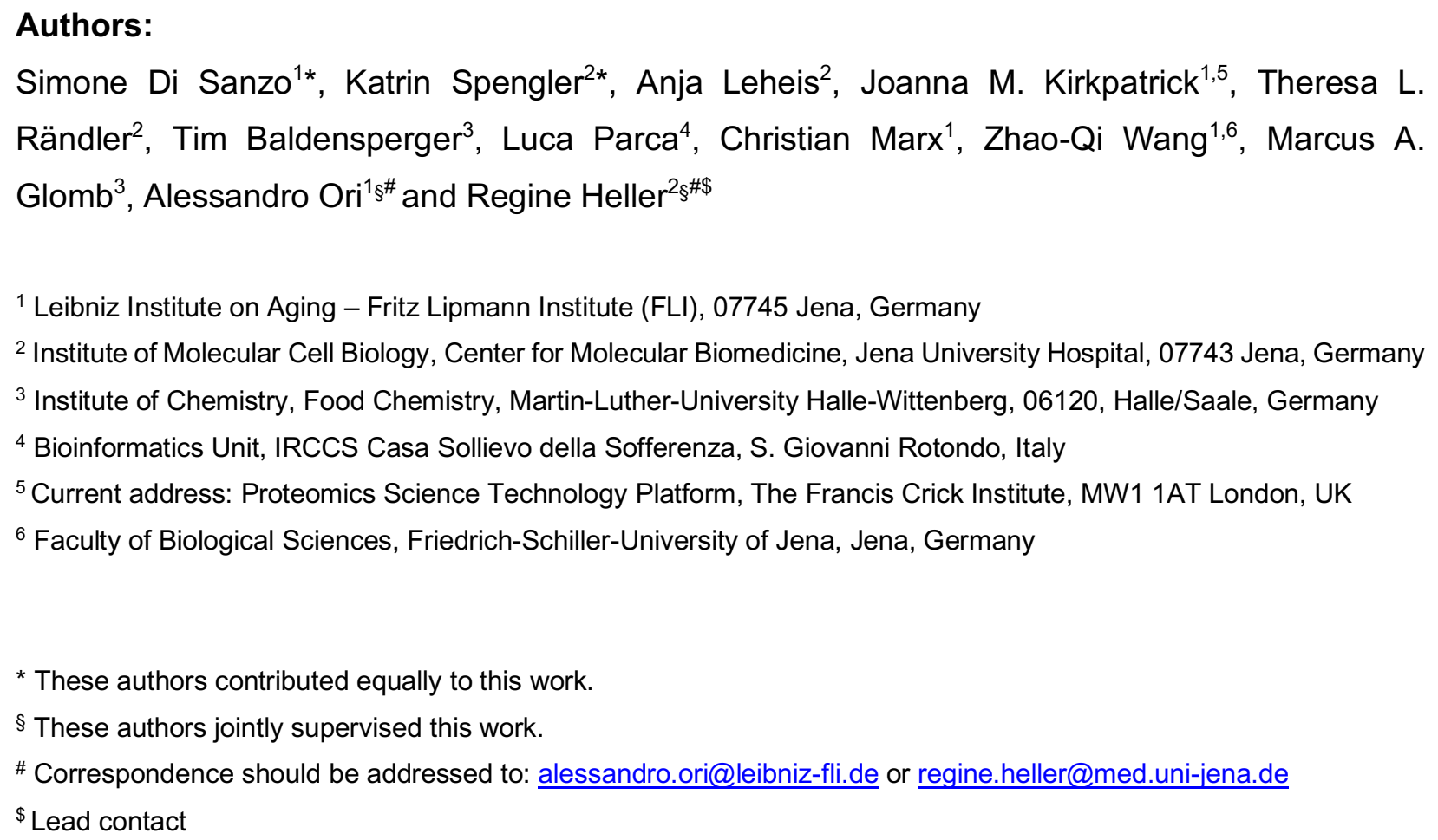

\section{Summary}

Posttranslational mechanisms play a key role in modifying the abundance and function of cellular proteins. Among these, modification by advanced glycation end products (AGEs) has been shown to accumulate during aging and age-associated diseases but specific protein targets and functional consequences remain largely unexplored. Here, we devised a proteomic strategy to identify specific sites of carboxymethyllysine (CML) modification, one of the most abundant AGEs. We identified over 1000 sites of CML modification in mouse and primary human cells treated with the glycating agent glyoxal. By using quantitative proteomics, we found that protein glycation triggers a proteotoxic response and directly affects the protein degradation machinery. We show that glyoxal induces cell cycle perturbation in primary endothelial cells and that CML modification reduces acetylation of tubulins and impairs microtubule dynamics. Our data demonstrate the relevance of AGE modification for cellular function and pinpoint specific protein networks that might become compromised during aging. 
Di Sanzo, Spengler, et al.

1

2 Keywords: advanced glycation end products; carboxymethyllysine; posttranslational modification; aging; proteasome; endothelial cell; cell cycle; tubulin; acetylation; mass spectrometry

\section{Highlights}

- A peptide enrichment strategy allows mapping of CML modification in cells and tissues

- CML modification competes with ubiquitination or acetylation of lysines

- Glyoxal treatment destabilizes the 26S proteasome

- Glyoxal arrests cell cycle and impairs microtubule dynamics via altering the tubulin code

\section{Introduction}

Advanced glycation end products (AGEs) are generated via a non-enzymatic glycation of proteins initiated by the reaction of glucose, fructose or highly reactive dicarbonyls such as methylglyoxal or glyoxal with amino acids (Brownlee, 1995). Glycation is enhanced when glucose levels are high, when dicarbonyls deriving from glycolytic intermediates or lipid peroxidation accumulate (Nigro et al., 2019), or when dicarbonyl detoxification by glyoxalases such as glyoxalase 1 (GLO1) and protein deglycase DJ-1 is low (Nigro et al., 2017). AGE formation may alter structure and function of the targeted proteins and, in addition, AGEs may elicit their effects as ligands of the pro-inflammatory receptor for advanced glycation end products (RAGE) (Teissier and Boulanger, 2019). One of the most abundant AGEs in vivo is $N(6)$-carboxymethyllysine (CML), whose formation is triggered, among other routes, by glyoxal (Brings et al., 2017). CML is known to be chemically stable, to accumulate in human tissues in diabetes, atherosclerosis, neurodegeneration and aging, and thus to be a biomarker of aging (Delgado-Andrade, 2016).

A causal relationship between the buildup of AGEs and individual disease is still under debate, but studies in which AGE levels were modulated via the GLO1 system, provided first evidence. Overexpression of GLO1 increases lifespan in C. elegans (Morcos et al., 2008) and reduces endothelial dysfunction in diabetic mice (Brouwers et al., 2014), while knockdown of GLO1 mimics diabetic nephropathy in non-diabetic mice (Giacco et al., 2014). Glycation of extracellular proteins such as hemoglobin HbA1c (Shapiro et al., 1980) or collagen (Avery and Bailey, 2005) is well described, but reports on glycation of intracellular proteins are still scarce. Examples of those are histones (Ansari et al., 2018; Baldensperger et al., 2020; Galligan et al., 2018; Guedes et al., 2011; Mir et al., 2014; Zheng et al., 2019; Zheng et al., 2020), mitochondrial proteins (Hamelin et al., 2007; Rosca et al., 2005; Wang et al., 2009), the 20S proteasome (Queisser et al., 2010), 
Di Sanzo, Spengler, et al.

1 enzymes involved in energy production (Snow et al., 2007), small heat shock proteins (Oya-Ito et

2 al., 2006; Schalkwijk et al., 2006; Sudnitsyna and Gusev, 2017) and the sodium channel Nav1.8

3 (Bierhaus et al., 2012). Glycation is increasingly seen as a driver of metabolic disease and aging,

4 and it may elicit specific effects by targeting signaling proteins (Chaudhuri et al., 2018; Kold-

5 Christensen and Johannsen, 2020). In this context, glycation of the ryanodine receptor associated

6 with successive $\mathrm{Ca}^{2+}$ leakage and mitochondrial damage (Ruiz-Meana et al., 2019), reversible

7 inhibitory glycation of nuclear factor erythroid 2-related factor 2 (Nrf2) (Sanghvi et al., 2019), and

8 methylglyoxal-induced dimerization of Kelch-like ECH-associated protein 1 (KEAP1) with

9 subsequent activation of the KEAP1/Nrf2 transcriptional program (Bollong et al., 2018) have been

10 reported. The latter may play a role in the upregulation of defense systems, such as GLO1 and

11 the ubiquitin-proteasome system (UPS), and may be involved in the hormetic effect of

12 methylglyoxal (Ravichandran et al., 2018). In contrast to earlier assumptions of irreversible AGE

13 formation, recent studies suggested the possibility of deglycation via DJ-1 or protein arginine

14 deiminase 4 (Zheng et al., 2019; Zheng et al., 2020).

A global characterization of the targeted proteins and pathways, which may significantly contribute pathophysiological effects of AGEs, like CML. Here, we developed a proteomic workflow based on selective enrichment of CML-modified peptides coupled to mass spectrometry for identification and quantification. We applied this approach to two cellular models (mouse embryonic fibroblasts (MEF) and human umbilical vein endothelial cells (HUVEC)), and to tissues of young and chronologically aged mice. This strategy allowed us to identify specific sites of CML modification. We show that CML modification of proteins competes with ubiquitination or acetylation, and that it destabilizes components of the UPS. CML accumulation in primary endothelial cells led to inhibition of proliferation, which was due to both altered expression of cell cycle regulators, and glycation of tubulins associated with impaired microtubule dynamics.

\section{Results}

27 An enrichment strategy for the identification of CML-modified peptides

Aiming to identify sites of CML modification on proteins, we developed a proteomic workflow employing an antibody-based enrichment of CML-modified peptides coupled to mass spectrometry (CMLpepIP). We applied CMLpepIP to MEF and HUVEC treated with different concentrations of glyoxal, a cell-permeable dialdehyde (Fig. 1A). In both cell types, glyoxal treatment led to a dose-dependent increase of total CML levels, as verified by immunoblot (Fig. 
Di Sanzo, Spengler, et al.

1B), and amino acid absolute quantification using liquid chromatography mass spectrometry (LC-

$2 \mathrm{MS})$ (Fig. 1C). To assess the efficiency of our enrichment protocol, we compared the fraction of

3 peptide spectrum matches (PSM) assigned to CML-containing peptides between elutions from

4 the enriched and control samples. When CMLpepIP was applied to glyoxal-treated cells, we

5 achieved up to 7 times more PSM from CML-containing peptides as compared to controls. With

6 a lower concentration of glyoxal, the gain of modified peptides was reduced and, in any case, the

7 fraction of PSM assigned to CML peptides never exceeded 5\% (Fig. 1D). This indicates that

8 CMLpepIP enables reproducible (Fig. S1A and S1B), but only partial, enrichment of CML-modified

9 peptides, especially in high complexity samples where CML peptides occur at low concentration $10(<1 \%)$.

11 Using CMLpepIP, we identified 995 unique CML sites in MEF and 451 in HUVEC of which 941, and 330 were deemed 'highly confident', respectively (see Methods for applied cut-offs) (Fig. S1A and Table S1). Overlapping sets of CML sites were reproducibly identified across conditions and independent experiments (Fig. S1B and S1C). To validate the identified CML peptides, we performed parallel reaction monitoring (PRM) measurements using isotopically labeled spike-in peptide standards derived from our list of identified CML sites (Table S1). Co-elution of endogenous (light) and standard (heavy) peptides validated the identified CML-modified peptides, and it enabled quantitation relative to the spike-in standard across conditions that recapitulated the absolute levels of CML measured by LC-MS (Fig. 1E,F).

A subset of conserved CML sites was found to be modified in both MEF and HUVEC (Fig. 1G). These sites localized on proteins involved in translation, RNA binding and chromatin remodeling at the centromere as well as on structural constituents of the cytoskeleton and mitochondrial proteins (Fig. 1H and Table S1). Since long-lived proteins are postulated to be the main targets of AGEs (Gkogkolou and Bohm, 2012; Smuda et al., 2015; Verzijl et al., 2000), we used published turnover data (Mathieson et al., 2018) and investigated the turnover distribution for modified and non-modified proteins in MEF and HUVEC. In both cell types, proteins with slower turnover were more likely to be affected by CML modification, independently of their subcellular localization (Fig. 1 left - J left), indicating slow turnover as an important determinant of CML modification. Although we were able to detect CML sites across the entire dynamic range of identified proteins in both cell types (Fig. S1D), we noted that protein abundance correlated with CML modifications, with high abundant proteins being more often detected as modified (Fig. 1/ right - J right). 
bioRxiv preprint doi: https://doi.org/10.1101/2020.10.16.342311; this version posted October 19, 2020. The copyright holder for this preprint (which was not certified by peer review) is the author/funder, who has granted bioRxiv a license to display the preprint in perpetuity. It is made available under aCC-BY-NC-ND 4.0 International license.

Di Sanzo, Spengler, et al.

1 Taken together, CMLpepIP enabled us to investigate the CML-modified proteome and to identify

2 specific and conserved targets of AGE-modification in two different primary culture systems.

3 Lower turnover and high abundance appear to be key factors in driving CML modification in vitro.

A

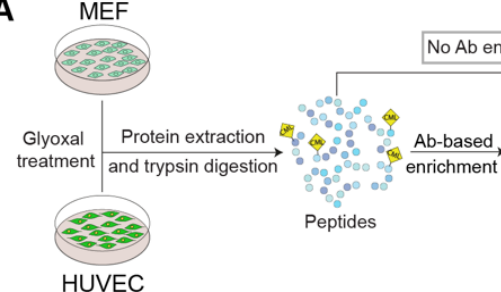

HUVEC

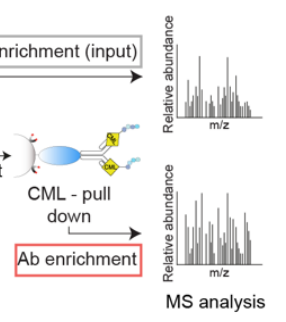

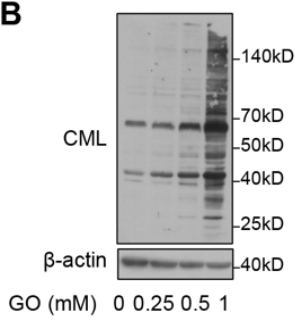

E

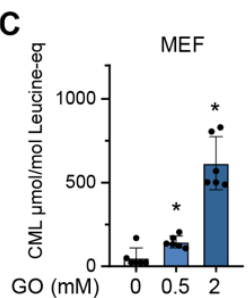

HUVEC
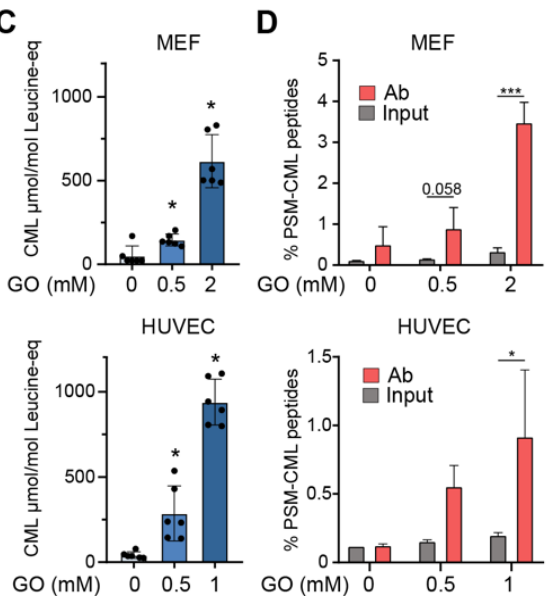

G

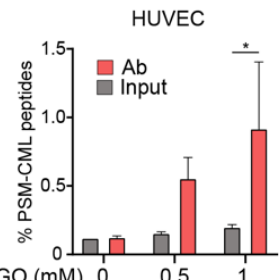

Parallel Reaction Monitoring

Enoyl-CoA hydratase

AFAAGADIK[cml]EMQNR

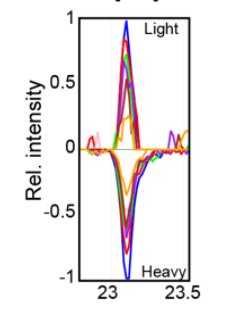

H
Histone $\mathrm{H} 4$

TVTAMDVVYALK[cml]R

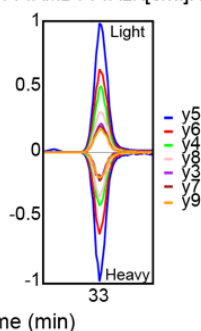

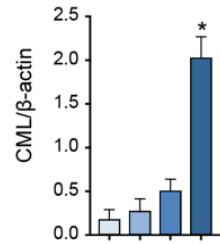

$\mathrm{GO}(\mathrm{mM}) \quad 00.250 .51$

$\mathbf{F}$

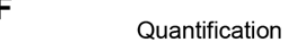

Histone $\mathrm{H} 4$

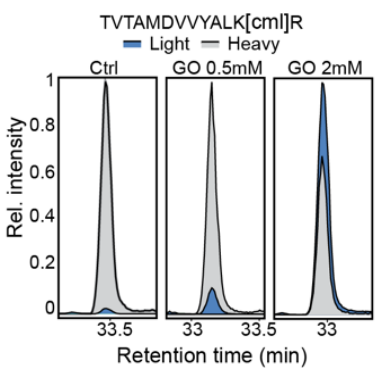
Highly confident CML sites

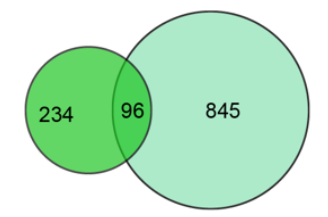

$\square$ MEF (\#unique CML sites $=941$ ) $\square$ HUVEC (\#unique CML sites $=330$ )

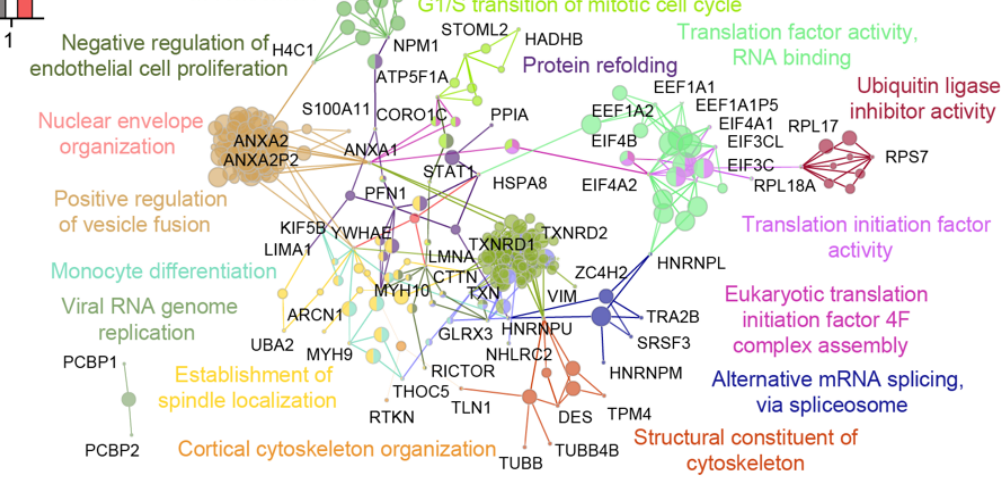

I MEF

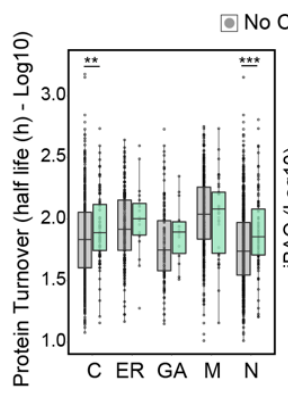
$\square$ No CML $\square \mathrm{CML}$

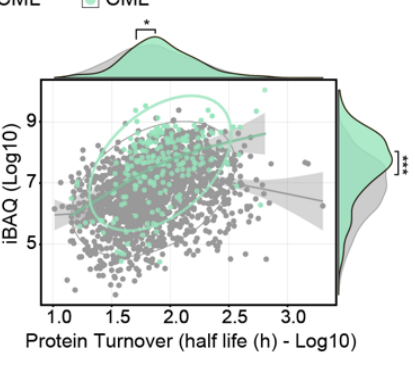

J HUVEC
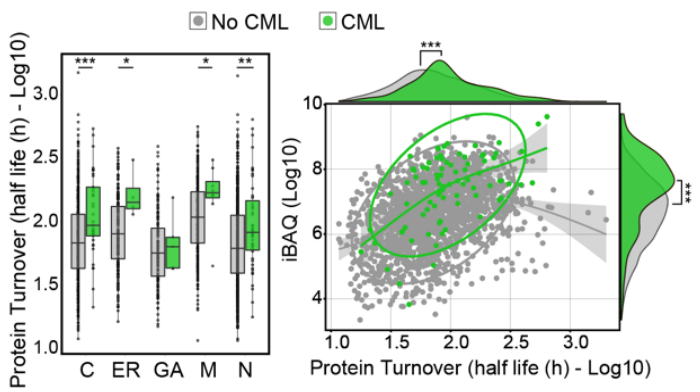

Figure 1. Antibody-based enrichment of CML-modified peptides.

A. Workflow for the identification of CML-modified peptides. Ab: antibody B. Immunoblot (left) and densitometry-based quantification (right) for CML-modified proteins from HUVEC treated with glyoxal (GO) for $48 \mathrm{~h} . n=3,{ }^{*} p<0.05$ vs. control, one-way repeated measurement ANOVA corrected using Holm-Šidák method. C. Quantification of total CML 
Di Sanzo, Spengler, et al.

levels in MEF and HUVEC treated with GO for $8 \mathrm{~h}$ or $48 \mathrm{~h}$, respectively. $n=6,{ }^{*} p<0.05$ vs. control, one-way ANOVA using Geisser-Greenhouse correction. D. Percentage of peptide spectrum matches (PSM) containing CML modification among different conditions. $n=3$ (MEF), $n=2$ (HUVEC), ${ }^{*} p<0.05,{ }^{* * *} p<0.001$. Multiple t-test corrected using Holm-Šidák method. E. Validation of CML-modified peptides by parallel reaction monitoring (PRM) using heavy spike-in peptides. F. Quantification of a CML-modified peptide from histone H4 by PRM in MEF treated with GO for 24h. G. Venn diagram showing the overlap between unique highly confident CML sites identified in MEF and HUVEC. H. Enrichment of Gene Ontology biological processes among CML sites identified in both HUVEC and MEF. The enrichment was performed using the Cytoscape App ClueGO. I-J. Left, protein turnover of CML-modified proteins grouped according to their subcellular localization, as defined by Gene Ontology annotation. Turnover data were taken from (Mathieson et al., 2018). C: cytoplasm; ER: endoplasmic reticulum; GA: Golgi apparatus; M: mitochondria; N: nucleus. Right, scatterplot comparing protein abundance (iBAQ scores, averages of $n=3$ (MEF), $n=2$ (HUVEC)) and protein turnover of CMLmodified proteins. ${ }^{*} p<0.05,{ }^{* *} p<0.01,{ }^{* * *} p<0.001$, Wilcoxon Rank Sum test with continuity correction. Related to Fig. S1 and Table S1.

\section{Sites of CML modification in mouse organs}

Next, we applied CMLpepIP to investigate protein targets of CML in vivo. We analyzed heart, kidney and liver from young (3-4 months) and geriatric C57BL/6J mice (26-33 months), and, in parallel, age-related changes of protein abundance using quantitative MS (Fig. 2A). The selected organs showed a higher basal level of total CML content compared to, e.g., brain (Fig. S2A). We identified 257, 186 and 52 unique CML sites in heart, kidney and liver, respectively, of which 190, 142 and 34 were deemed 'highly confident', respectively (Table S2). Using PRM with spike-in heavy peptides, we validated $16(89 \%)$ out of those $18 \mathrm{CML}$ sites, for which we had successfully developed PRM assays (Fig. S2B-C). CML appeared to target proteins in an organ-specific manner (Fig. 2B). The affected proteins participate in biological processes related to energy production in the heart, cytoskeleton in the kidney, and detoxification in the liver (Fig. 2C). Similar to what we observed in cultured cells (Fig. 1I,J), CML sites in the heart appeared to occur preferentially in proteins with slow turnover (Fig. S2D). Since CML modification occurs on lysines and these residues are targets for other posttranslational modifications (PTM), we assessed the overlap of CML sites and other known PTM. We found that approximately one third of the identified CML sites (97 out of 334 unique highly confident sites) occur on residues that are known to be modified by other PTM, primarily ubiquitination and acetylation (Fig. 2D). These data suggest that modification by CML might interfere with biological processes by impeding other PTM to occur on specific residues.

We next investigated age-related changes of protein abundance in the same tissues using Tandem Mass Tag (TMT)-10plex labeling (Fig. 2A). Principal component analysis could clearly distinguish two different clusters formed by young and old mice for all the three organs (Fig. 2E). 
Di Sanzo, Spengler, et al.

1 By applying gene set enrichment analysis, we identified pathways affected by protein abundance

2 changes in aged organs (Fig. S2E). Among these, a pathway related to AGE signaling was

3 enriched with aging both in heart and kidney. This pathway included components of the fibrotic

4 process such as several types of collagen I and IV, but also proteins mediating signaling

5 downstream of extracellular AGEs via RAGE such as NFאB1, MAPK9 and AKT1. In addition, we

6 specifically queried the data for proteins involved in dicarbonyl detoxification via GLO1 and found

7 a general trend for a decreased abundance of the components of this network in all organs

8 isolated from geriatric mice (Fig. 2F). We validated the functional relevance of decreased GLO1

9 protein levels by confirming a decrease of its activity in old organs (Fig. 2G).

10 Inspired by this and by the well-established increase of total AGE levels in old tissue (Chaudhuri

11 et al., 2018; Delgado-Andrade, 2016; Nigro et al., 2019), we tested whether we could detect an

12 age-dependent elevation of CML modification at specific sites. Using PRM assays on total tissue

13 lysates, we demonstrated an age-dependent raise in the level of CML modification of histone $\mathrm{H} 4$

14 at position $\mathrm{K} 92$ that exceeded the abundance change observed the protein level in heart and

15 kidney (Fig. 2H). However, no age-related changes in the levels of two other CML sites, i.e., K263

16 of adenine nucleotide translocase type 1 and K154 of ATP synthase subunit $\mathrm{\gamma}$, were observed

17 (Fig. 2I).

18 Together, these data show that the targets of AGEs are organ-specific, and that the levels of CML 19 modification increase with aging in a site-specific manner, likely as a consequence of reduced 20 levels and activity of dicarbonyl-detoxifying enzymes in old organs. 
bioRxiv preprint doi: https://doi.org/10.1101/2020.10.16.342311; this version posted October 19, 2020. The copyright holder for this preprint (which was not certified by peer review) is the author/funder, who has granted bioRxiv a license to display the preprint in perpetuity. It is made available under aCC-BY-NC-ND 4.0 International license.

Di Sanzo, Spengler, et al.

A

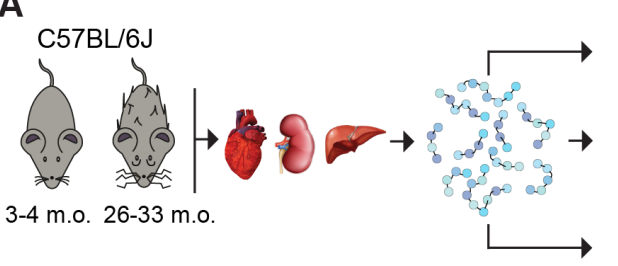

C

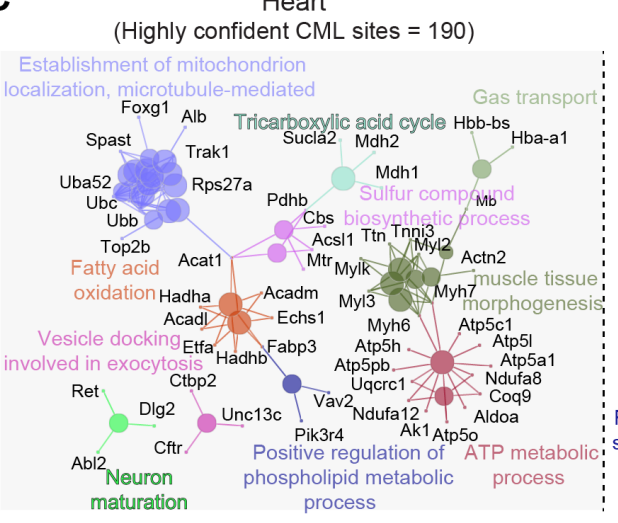

D
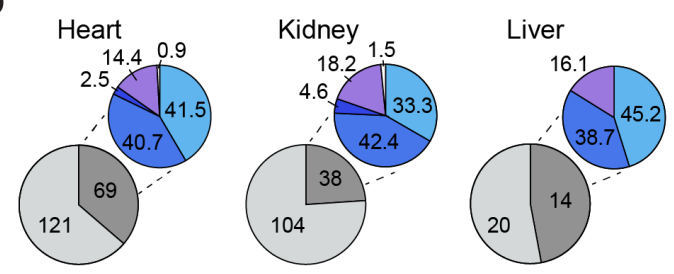

Overlapping PTMs: $\square$ Yes $\square$ No $\square$ Ubiquitination $\square$ Acetylation $\square$ Methylation $\square$ SUMOylation $\square$ Malonylation

$\mathbf{F}$

Glyoxalase 1 network

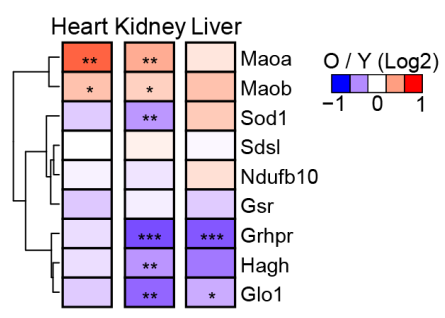

G

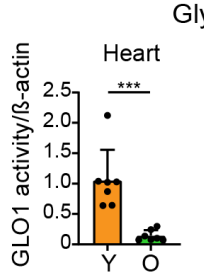

Glyoxalase 1 activity
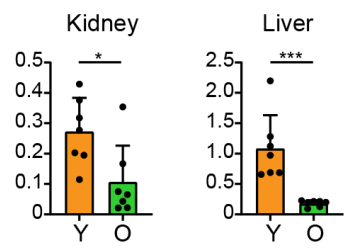

H

I
CMLPeplP

$\rightarrow$ CML site IDs

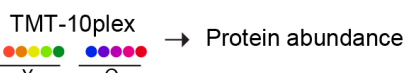

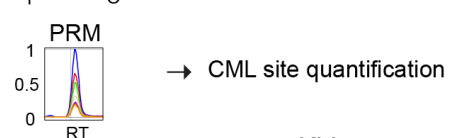

Kidney

(Highly confident CML sites $=142$ )
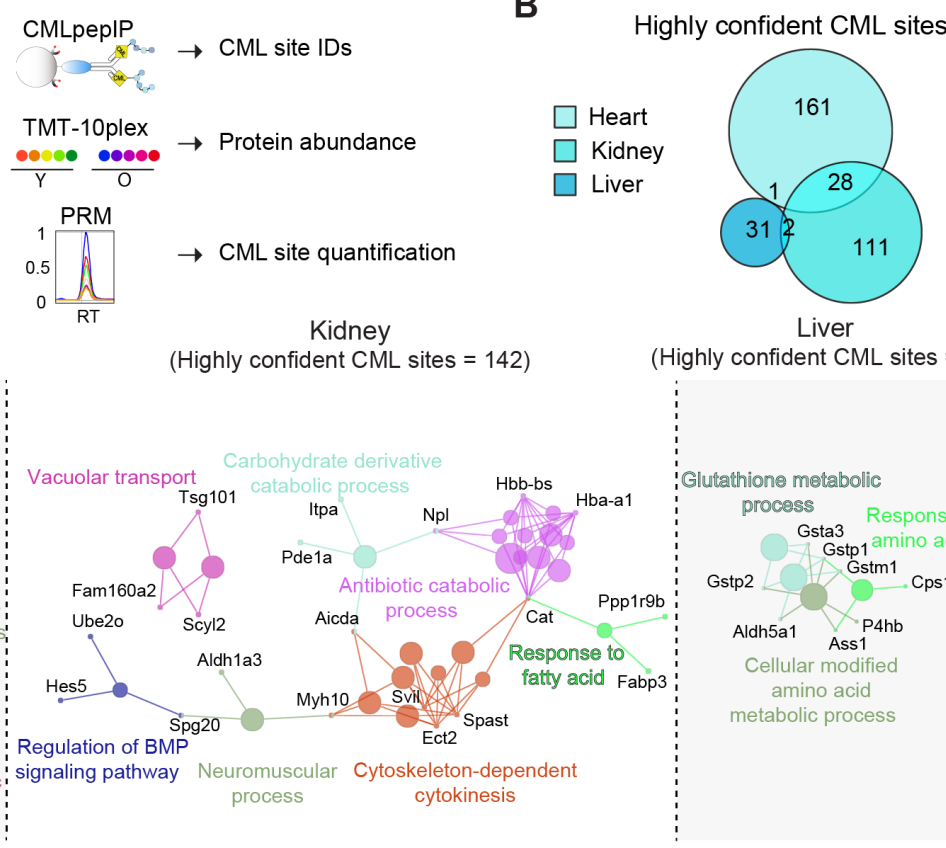

(Highly confident CML sites $=34$ )

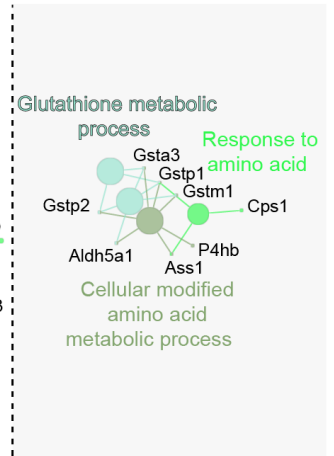

E
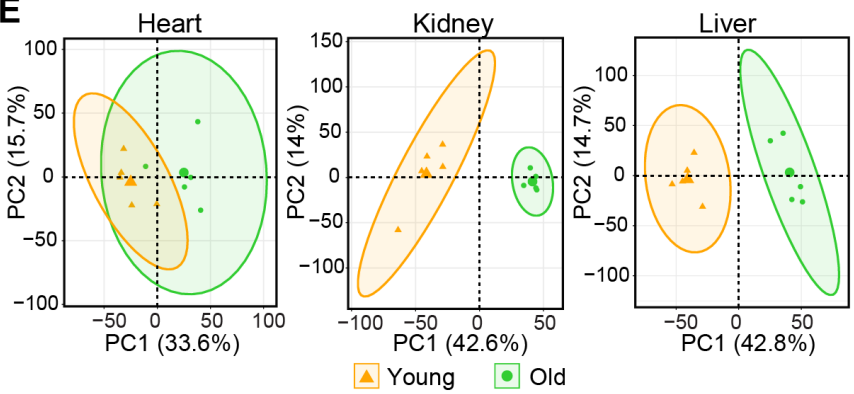
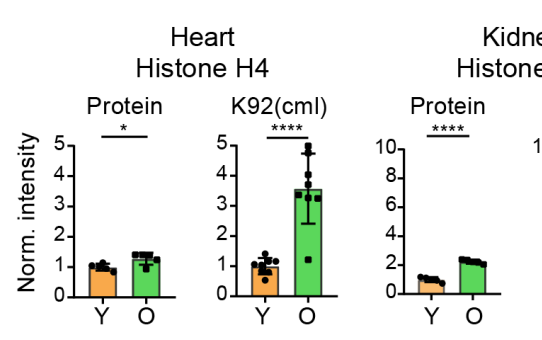

Kidney

44
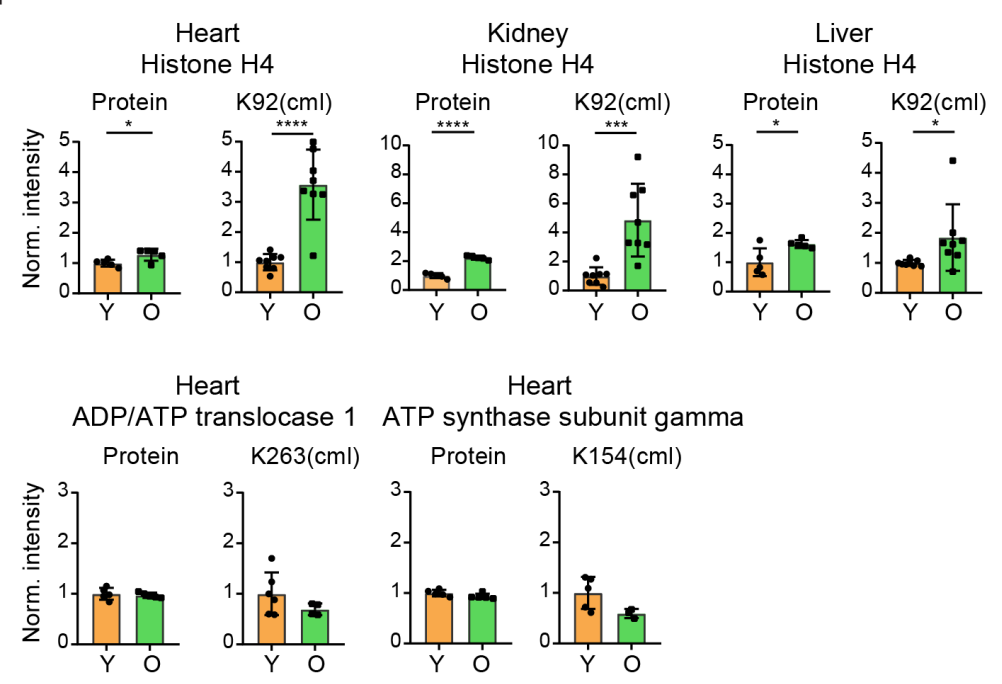

Heart

Heart

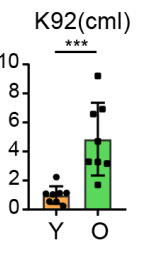

Figure 2. The CML-modified proteome in mouse organs.

A. Workflow for the analysis performed on mouse tissues from young $(\mathrm{Y})$ and old $(\mathrm{O})$ mice. Tandem Mass Tag (TMT) was used for monitoring protein abundance, CMLpepIP for CML site identification and PRM for CML site quantification.

B. Venn diagram of highly confident CML sites identified in heart, kidney and liver. C. Enrichment of Gene Ontology biological processes among CML sites identified from heart, kidney and liver. The enrichment was performed using the 
Di Sanzo, Spengler, et al.

\begin{abstract}
Cytoscape App ClueGO. D. Overlap between CML sites and other PTM. The gray scale pie charts indicate the number of CML sites overlapping with known PTM. The colored pie charts indicate which PTM class overlap with CML sites (shown as percentages). Known PTM were obtained from Minguez et al., 2015; Hornbeck et al., 2015). E. Principal component analysis of proteome data from young and old mice ( $n=5$ per age group). The smaller dots represent individual samples and the larger dots the centroids of each age-matched group. Ellipses represent $95 \%$ confidence intervals. The percentage of variance explained by the first two principle components (PC) axes is reported in the axis titles. F. Effect of aging on the abundance of proteins part of the glyoxalase 1 (GLO1) network. The network was extracted from https://string-db.org using input GLO1. $n=5,{ }^{*}$ adj. $p<0.05,{ }^{* *}$ adj. $p<0.01,{ }^{* * *}$ adj. $p<0.001$, t-test with Benjamini-Hochberg correction for multiple testing, as implemented in limma. G. GLO1 activity tested on heart, kidney and liver lysates from young $(Y)$ and old $(O)$ mice. $n=7,{ }^{*} p<0.05$, ${ }^{* * *} p<0.001$, unpaired t-test, parametric, two-tailed. H-I. Normalized protein intensity of histone H4, ADP/ATP translocase type 1 and ATP synthase subunit $y$ from TMT experiment (Protein - left panel) and intensity of CML-modified peptides from PRM (right panel). $n=5$ for protein abundance, $n=8$ for CML-modified peptides, ${ }^{*} p<0.05$, ${ }^{* * *} p<0.001$, ${ }^{* * * *} p<0.0001$, unpaired t-test. Related to Fig. S2 and Table S2.
\end{abstract}

\title{
CML modification directly targets the ubiquitin-proteasome system
}

To better understand the consequences of increased CML modifications in tissues, we performed experiments to characterize cellular functions in response to glyoxal treatment. Since we observed that some of the CML targets are proteins involved in protein quality control (Fig. S3A), we hypothesized that accumulation of glyoxal impairs proteostasis and triggers cellular responses to counteract proteotoxic stress. To address this question, we applied a data-independent acquisition (DIA) method to monitor proteome-wide changes of protein abundance in MEF treated with different glyoxal concentration for $8 \mathrm{~h}$ and $24 \mathrm{~h}$ (Fig. 3A and S3B). Short treatment ( $8 \mathrm{~h}$ ) with $0.5 \mathrm{mM}$ and $2 \mathrm{mM}$ glyoxal induced only few significant changes of protein abundance, however, a longer treatment $(24 \mathrm{~h})$ triggered a major proteome response that was dose-dependent (Fig. 3B). At this time point, the abundance of CML-modified proteins was significantly increased (Fig. $3 C$ ), while KEGG pathways related to the UPS, especially ubiquitin-conjugating enzymes (E2), were decreased (Fig. 3D and S3C).

Interestingly, we found a significant increase of components of the $26 \mathrm{~S}$ proteasome induced by glyoxal treatment in a dose-dependent manner in both MEF and HUVEC (Fig. 3E left and S3D). However, while $0.5 \mathrm{mM}$ glyoxal also increased proteasomal activity in MEF, the induction of $26 \mathrm{~S}$ proteasome by $2 \mathrm{mM}$ glyoxal was not followed by a corresponding increase of activity (Fig. 3E right). In parallel, we observed a dose-dependent accumulation of ubiquitinated proteins $24 \mathrm{~h}$ after glyoxal treatment (Fig. 3F). We speculated that the lack of proteasome activity increase at high doses of glyoxal might be due to a functional impairment of the proteasome itself. To test this, we evaluated the thermal stability of proteasomal proteins in MEF treated with glyoxal using thermal proteome profiling (Franken et al., 2015). This analysis revealed that glyoxal treatment negatively impacted the thermal stability of most of the $26 \mathrm{~S}$ proteasome subunits in a dose-dependent 
bioRxiv preprint doi: https://doi.org/10.1101/2020.10.16.342311; this version posted October 19, 2020. The copyright holder for this preprint (which was not certified by peer review) is the author/funder, who has granted bioRxiv a license to display the preprint in perpetuity. It is made available under aCC-BY-NC-ND 4.0 International license.

Di Sanzo, Spengler, et al.

1 fashion (Fig. 3G), while the overall thermal stability of proteins remained comparable across the

2 tested conditions (Fig. S3E and Table S3). In addition, we identified a subset of proteasomal

3 proteins and other members of the UPS, including ubiquitin itself, to be directly CML-modified

4 both in cells treated with glyoxal and in organs (Fig. S3A).

5 Taken together these data describe a specific and dose-dependent proteome response to glyoxal

6 exposure. This is characterized by accumulation of CML-modified proteins and an induction of

7 compensatory mechanisms including the UPS. The UPS may become saturated at higher glyoxal

8 concentration due to the accumulation of CML-modified and ubiquitinated proteins, and to a

9 destabilization of the $26 \mathrm{~S}$ proteasome.

A

Glyoxal (GO) treatment - MEF
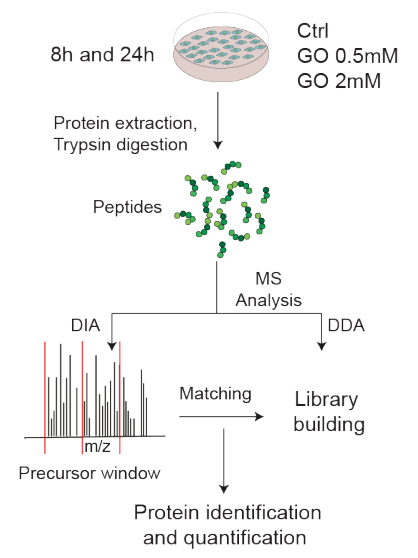

E

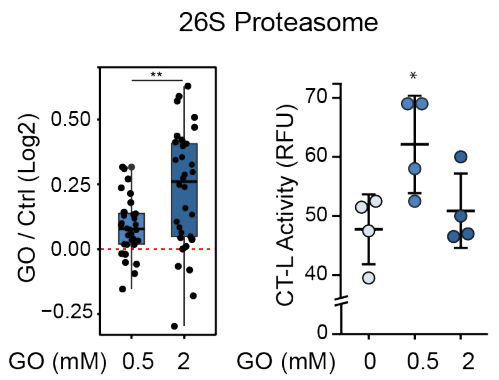

B

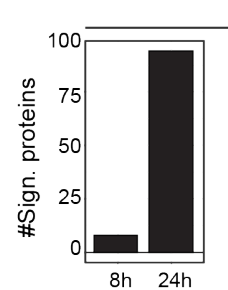

GO $0.5 \mathrm{mM}$

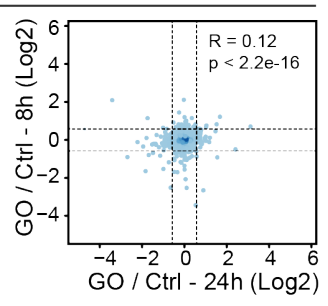

$\mathrm{GO} 2 \mathrm{mM}$

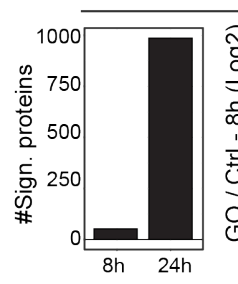

$\mathbf{F}$

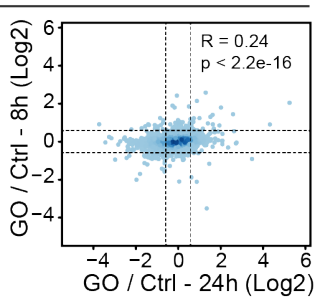

Mono- and polyubiquitinated proteins

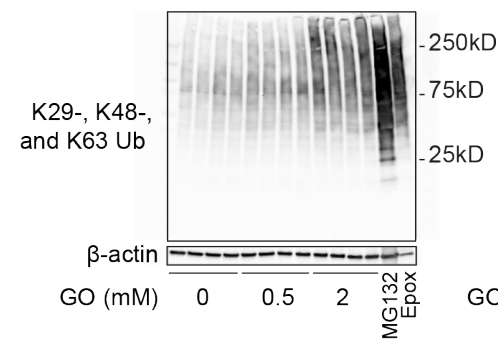

C

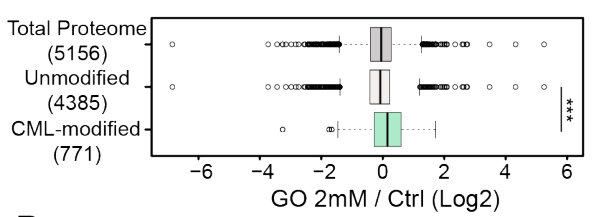

D

KEGG pathways enriched in GO 2mM / Ctrl

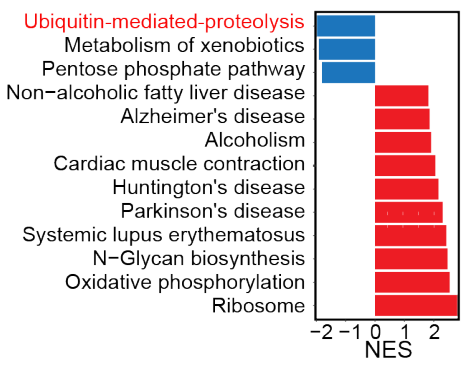

G

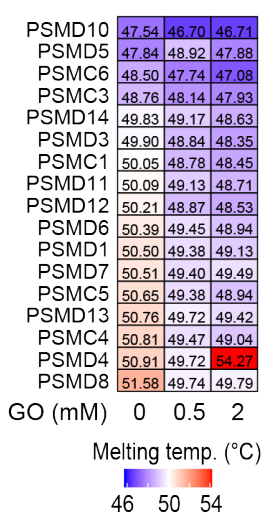

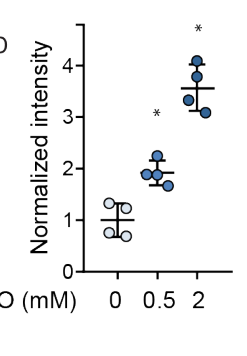

Figure 3. The proteome response to glyoxal (GO) treatment.

A. Workflow for the analysis of proteome changes induced in MEF by GO. B. Left, number of significant proteins (absolute log2 fold change $>0.58$ and $\mathrm{q}<0.05$ ) after 8 and $24 \mathrm{~h}$ GO treatment. Right, scatterplots comparing the log2 fold changes induced by GO at 8 or $24 \mathrm{~h}$. Dashed lines represent the log2 fold change cut-offs used $( \pm 0.58)$. $n=5(8 \mathrm{~h})$, $\mathrm{n}=4$ (24 h). C. Distribution of protein fold changes for $2 \mathrm{mM} \mathrm{GO}$ vs. control (Ctrl) after $24 \mathrm{~h}$ of treatment. Average values of $n=4$ were compared, ${ }^{* * *} p<0.001$, Wilcoxon rank sum test continuity correction with alternative two-sided. D. Gene Set Enrichment Analysis (GSEA) for KEGG pathways based on protein fold changes induced by $2 \mathrm{mM} \mathrm{GO}$ after $24 \mathrm{~h}$ 
Di Sanzo, Spengler, et al.

\begin{abstract}
of treatment. Normalized enrichment score (NES) indicates pathways enriched among proteins that increase (red) or decrease (blue) upon $G O$ treatment (FDR<0.05). All the proteins quantified were ranked according to their log2 fold change and used as input for GSEA. E. Boxplot of fold changes for members of the $26 \mathrm{~S}$ proteasome (left) and proteasome chymotrypsin-like (CT-L) activity (right) in MEF treated with GO for $24 \mathrm{~h}$ compared to Ctrl. $\mathrm{n}=4$, ${ }^{* *} \mathrm{p}<0.01$, Wilcoxon Rank Sum test with continuity correction. F. Immunoblot for mono- and polyubiquitinated proteins from MEF lysates treated with GO for $24 \mathrm{~h}$. Lysates from cells treated with proteasome inhibitors MG132 (20 $\mu \mathrm{M}$ for $6 \mathrm{~h})$ or epoxomicin (Epox, $10 \mathrm{nM}$ for 96h) were loaded as positive controls. $\mathrm{n}=4$, ${ }^{*} \mathrm{p}<0.05$, one-way ANOVA using GeisserGreenhouse correction. G. Heatmap representing the melting point temperature of members of $26 \mathrm{~S}$ proteasome identified in all conditions obtained using thermal proteome profiling. Related to Fig. S3 and Table S3.
\end{abstract}

Glyoxal inhibits proliferation of primary human endothelial cells by inducing cell cycle arrest and inhibiting microtubule dynamics

In endothelial cells, glyoxal-induced CML modifications occurred mainly in proteins of the nucleus, the cytoskeleton and the mitochondria (Fig. 4A and Table S4), while glyoxal-initiated changes in protein abundance comprised an upregulation of stress response proteins, e.g., heme oxygenase 1, and a downregulation of processes related to proliferation and growth (Fig. 4B). In particular, several factors involved in DNA replication were downregulated. This was also reflected on a functional level since glyoxal led to an inhibition of endothelial cell proliferation as demonstrated by reduced cell numbers and lower incorporation of BrdU in the presence of serum or after stimulation with basic fibroblast growth factor (bFGF) (Fig. 4C,D). Furthermore, angiogenic sprouting in response to vascular endothelial growth factor (VEGF) was impaired (Fig. 4E). Glyoxal-treated cells did not show signs of apoptosis (Fig. S4A).

Since mitochondrial proteins, e.g., ATP synthase subunit $\gamma$, were found to be CML-modified (Fig. $1 \mathrm{H}$ ), we asked whether alterations in cellular energy production would underlie the observed inhibition of cell proliferation. Seahorse analyses revealed a decrease in basal respiration and mitochondrial ATP production in HUVEC treated with glyoxal (1 mM, 48 h) (Fig. 4F and Fig. S4B) as well as an upregulation of glycolysis (Fig. 4G and Fig. S4C). The latter, together with an increased mitochondrial biogenesis (Fig. $4 \mathrm{H}$ ), likely compensated the reduction of mitochondrial ATP production, since total cellular ATP was not altered (Fig. 4I). These data show that the cellular energy homeostasis was maintained despite the exposure of cells to dicarbonyl stress and that reduced cell proliferation was not due to metabolic limitations. 
bioRxiv preprint doi: https://doi.org/10.1101/2020.10.16.342311; this version posted October 19, 2020. The copyright holder for this preprint (which was not certified by peer review) is the author/funder, who has granted bioRxiv a license to display the preprint in perpetuity. It is made available under aCC-BY-NC-ND 4.0 International license.

Di Sanzo, Spengler, et al.

A
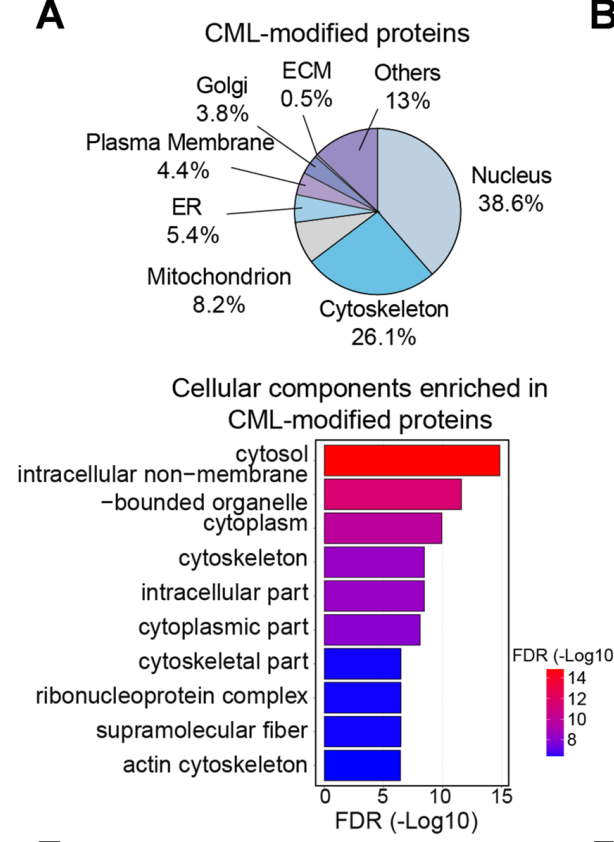

E

Angiogenic sprouting
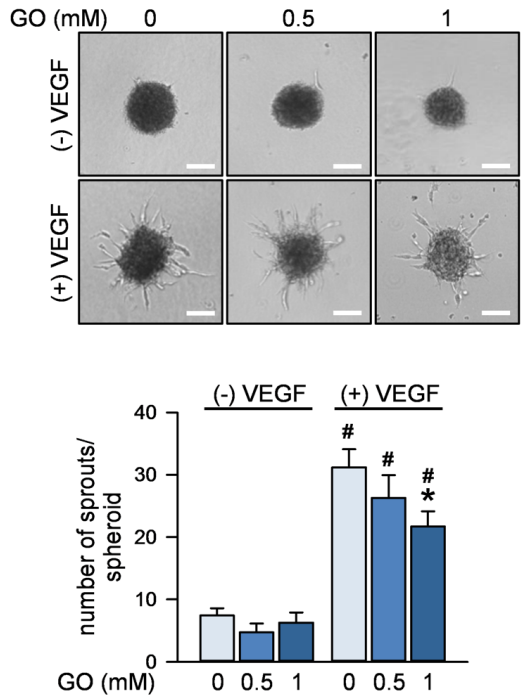

B

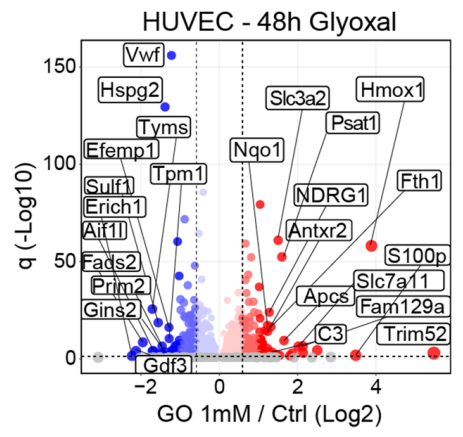

Biological process enriched in GO $1 \mathrm{mM} / \mathrm{Ctrl}$

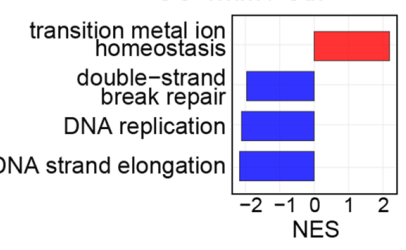

C

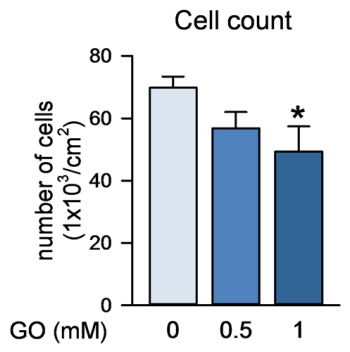

D

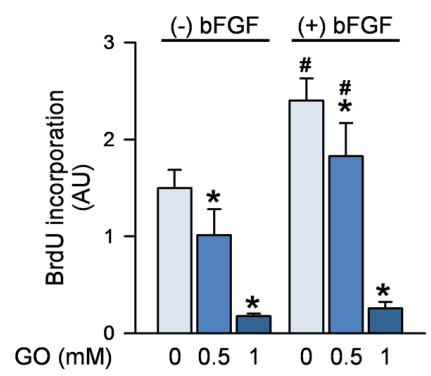

$\mathbf{F}$

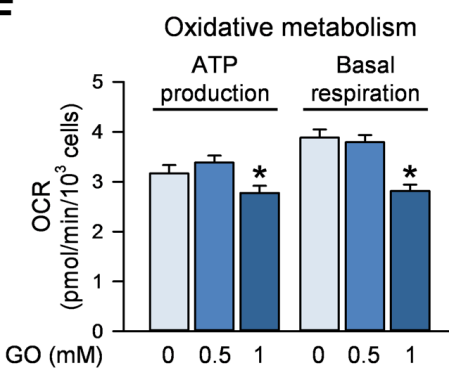

H

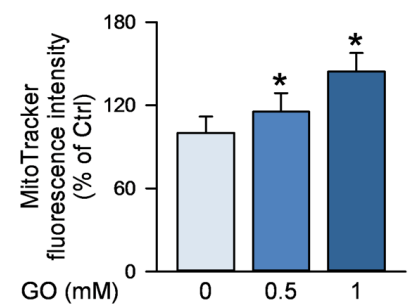

G

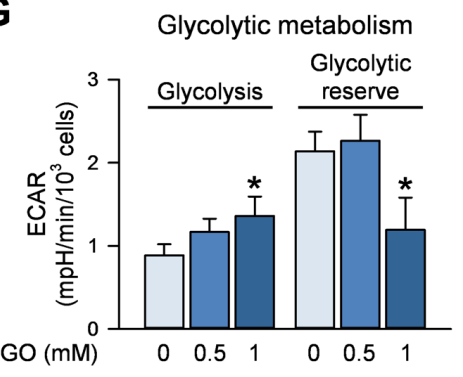

I

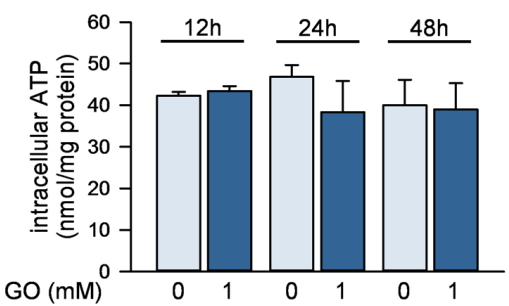

Figure 4. Glyoxal (GO) impairs the proliferation of HUVEC.

A. Upper panel: CML-modified proteins annotated to different cellular compartments according to Gene Ontology annotation after GO treatment (1 mM, 48 h). Lower panel: Gene Ontology cellular component terms enriched in CMLmodified proteins. False Discovery Rate (FDR) <0.05. B. Upper panel: volcano plot depicting proteins that significantly increase (red) or decrease (blue) abundance upon GO treatment $(1 \mathrm{mM}, 48 \mathrm{~h}$ ) or remain unchanged (gray). Horizontal dashed line indicates a significance cut-off of $\mathrm{q}<0.05$ and vertical dashed lines an absolute fold change (log2) $>0.58$. Lower panel: gene set enrichment analysis for Gene Ontology biological process terms based on protein fold changes. Terms enriched among increased (red) or decreased (blue) proteins are shown. FDR<0.05; NES: normalized enrichment score. C-H. HUVEC were treated with $\mathrm{GO}$ for $48 \mathrm{~h}$. C. Cell numbers were determined. $\mathrm{n}=5$. D. Cells were stimulated with bFGF $(50 \mathrm{ng} / \mathrm{ml}, 24 \mathrm{~h})$ and BrdU incorporation was measured. $\mathrm{n}=5$. E. Spheroids were generated, embedded and stimulated with VEGF $(50 \mathrm{ng} / \mathrm{ml}, 24 \mathrm{~h})$. Representative pictures and sprout numbers per spheroid are shown. Scale bar=100 um. n=4. F-G. Oxygen consumption rate (OCR) (F) and extracellular acidification rates (ECAR) 
Di Sanzo, Spengler, et al.

(G) were measured via Seahorse technology and mitochondrial and glycolytic parameters calculated. $\mathrm{n}=6$. $\mathbf{H}$. Cells were stained with MitoTracker and analyzed by flow cytometry. $\mathrm{n}=5$. I. HUVEC were treated with $1 \mathrm{mM}$ GO and intracellular ATP levels were measured in cell extracts. $n=3$. C-I. Data are represented as mean \pm SEM. Statistical significance was analyzed using one-way or two-way repeated measurement ANOVA corrected using Holm-Šidák method. * $p<0.05$ vs. control, \# $p<0.05$ vs. respective non-bFGF or non-VEGF-treated sample. Related to Fig. S4 and Table S4.

To further clarify the mechanisms underlying inhibition of cell proliferation by glyoxal, we analyzed its effect on the cell cycle. Applying a triple staining method, we found that treating endothelial cells with glyoxal for $24 \mathrm{~h}$ triggered an arrest in G0/G1 and G2 phases, while the percentage of cells in the $S$ and $M$ phases was significantly decreased (Fig. 5A). Some of these alterations, especially the decrease in mitosis, were already seen after $4 \mathrm{~h}$ of glyoxal treatment, although at a lower degree. In accordance with the lower entry of cells into $S$ and $M$ phases, we observed a decrease of the cell cycle markers cyclin A (S phase) and phosphorylated H3(S10) ( $\mathrm{p}-\mathrm{H} 3(\mathrm{~S} 10)$, M phase) (Fig. S5A). In addition, tracking cell proliferation dynamics revealed a slower proliferation in response to the high dose of glyoxal (Fig. 5B).

We hypothesized that the observed cell cycle arrest induced by glyoxal was due to altered expression of cell cycle regulators plus to specific glycation of proteins involved in cell cycle control, which were both identified in glyoxal-treated cells (Fig. 5C). Interestingly, alteration of protein expression was mainly related to proteins involved in the regulation of S and G1 phases, while glycation was mostly observed in proteins controlling G2 and M phases, for instance, in tubulin $\alpha$ and $\beta$ chains (Fig. 5C). Strikingly, 8 out of 10 subunits of the replicative helicase MCM27/GINS/CDC45 and several factors involved in lagging strand DNA synthesis such as subunits of DNA polymerases $\alpha$ and $\delta$, FEN1 and DNA ligase 1 were downregulated, whereas the cyclindependent kinase inhibitor 1A (CDKN1A)/p21 was upregulated.

One pathway through which the expression of cell cycle regulators is affected is the DNA damage response. Glyoxal triggered phosphorylation of the checkpoint kinase 1 (CHK1) and led to an increased percentage of cells with $\mathrm{YH} 2 \mathrm{AX}$ foci (Fig. 5D,E). As a consequence, and in line with the 28 proteomics data, the p53/p21 pathway was upregulated by glyoxal (Fig. 5F and S5B).

29 Immunoblotting experiments showed that especially with the higher dose of glyoxal the 30 abundance and, additionally, the phosphorylation of p53 as well as the expression of its target 31 CDKN1A/p21 increased. The expression of another inhibitor of cyclin-dependent kinases, p16, 32 was enhanced, too (Fig. 5F). We also found that after treatment with $1 \mathrm{mM}$ glyoxal a small proportion of cells $(\sim 12 \%)$ acquired a senescent phenotype, as shown by positive staining for senescence-associated beta-galactosidase (SA- $\beta-$ Gal) (Fig. S5C). This may be related to 
bioRxiv preprint doi: https://doi.org/10.1101/2020.10.16.342311; this version posted October 19, 2020. The copyright holder for this preprint (which was not certified by peer review) is the author/funder, who has granted bioRxiv a license to display the preprint in perpetuity. It is made available under aCC-BY-NC-ND 4.0 International license.

Di Sanzo, Spengler, et al.

1 persistent dicarbonyl and oxidative stress since glyoxal led to increased mitochondrial and

2 cytosolic formation of reactive oxygen species (ROS) (Fig. 5G).

A
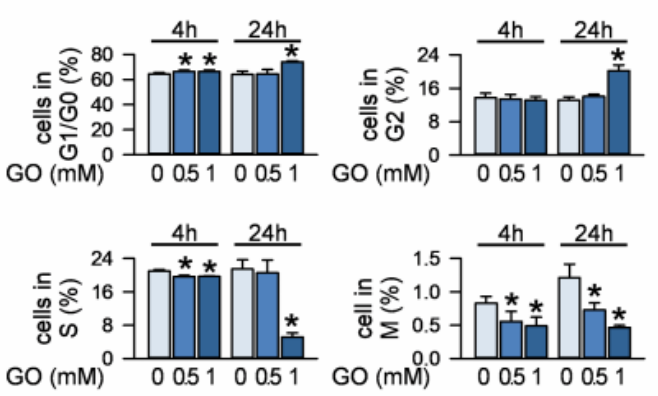

C Expression and glycation of cell cycle proteins

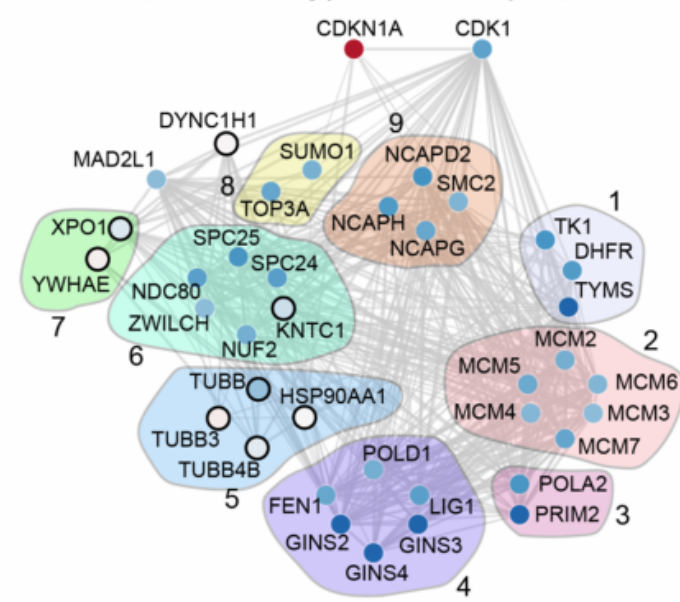

E
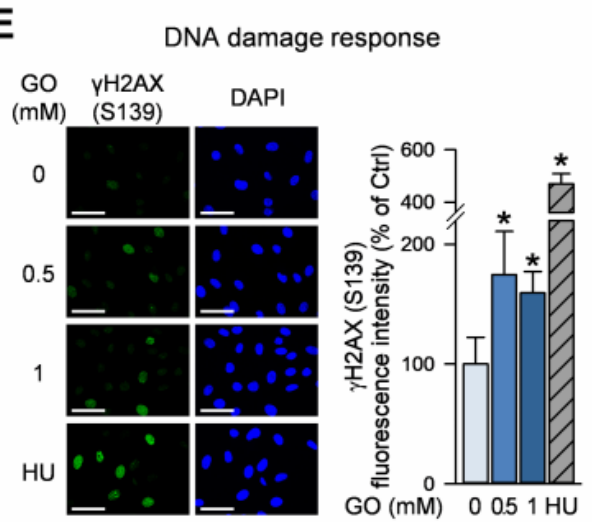

$\mathbf{F}$
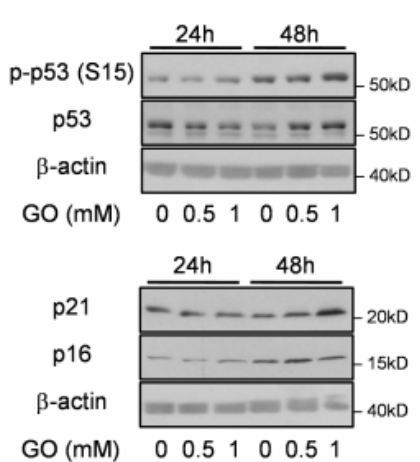

B

Proliferation dynamics
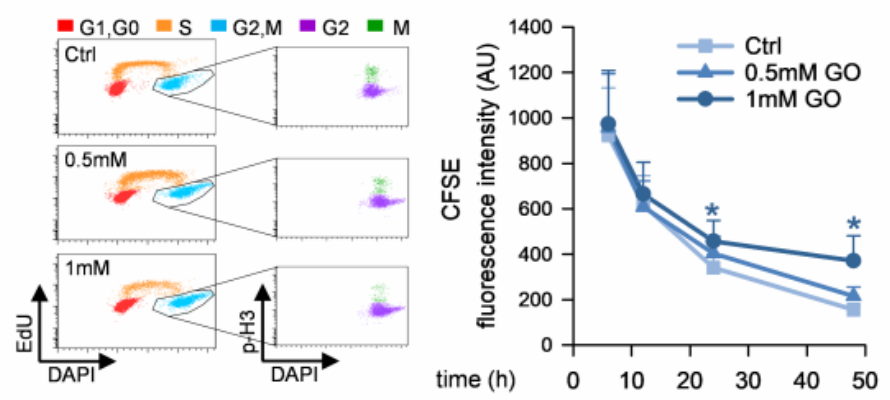

D DNA damage response

1. G1 G1/S Phase

2. G1 G1/S Phase, G2/M

Checkpoints, S Phas

3. G1 G1/S Phase, S

4. S Phase

5. G2 G2/M Phase, M

Phase

6. M Phase, Spindle

7. G2 G2/M Phase, G2/M

7. G2 G2/M Phase, G2/M
Checkpoints, M Phase

8. $\mathrm{G} 2 / \mathrm{M}$ Checkpoints

9. $M$ Phase

Avg FC (Log2)

$\begin{array}{lc}-1 & 0 \\ \text { O Modified }\end{array}$

Not modified
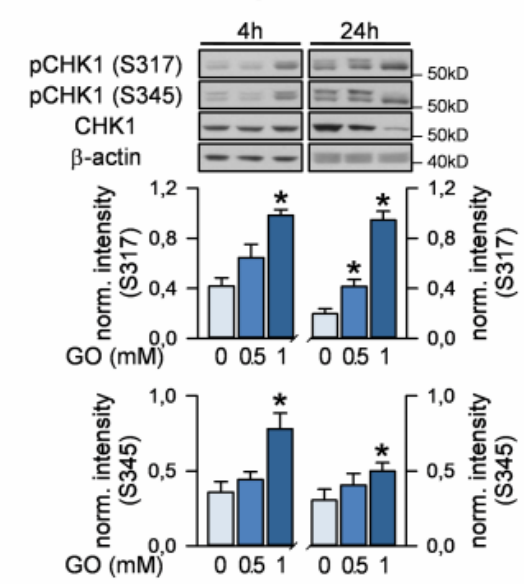

G
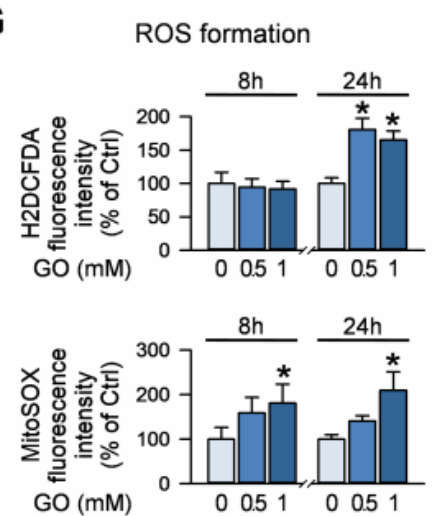

Figure 5. Perturbation of the cell cycle induced by glyoxal (GO).

A. HUVEC were treated with $G O$ as indicated and subjected to cell cycle analysis applying a triple staining method (EdU, p-H3 (S10), DAPI). Ratio of cells in the respective cell cycle phases (left) and representative dot plots (right) are shown. $n=4$. B. HUVEC were stained with carboxyfluorescein succinimidyl ester (CFSE) and treated with GO. CFSE staining was quantified by flow cytometry. $n=4$. C. Cell cycle proteins were chosen according to Reactome annotation divided by their specific role in each phase. Only proteins with significantly altered expression (absolute fold change $>0.58$ and $\mathrm{q}<0.05$ ) or modified by $\mathrm{CML}$ are shown. Each dot represents the protein fold change and the black edge signifies proven CML modification. D. GO-treated HUVEC were lysed and subjected to immunoblot analysis. $n=5$ 
Di Sanzo, Spengler, et al.

(4 h), $n=6$ (24 h). E. Following GO treatment of HUVEC (8h), immunofluorescence staining of $\mathrm{YH} 2 \mathrm{AX}$ (S139) and DAPI was performed. Hydroxyurea (HU, $2 \mathrm{mM}, 1 \mathrm{~h}$ ) served as positive control. Representative pictures and quantification of $\mathrm{yH} 2 \mathrm{AX}$ (S139)-positive nuclei are shown. Scale bar=50 $\mu \mathrm{m} . \mathrm{n}=3$. F. HUVEC were treated with GO, lysed and subjected to immunoblot analysis. Densitometric quantification is shown in figure S5B. $n=6$. G. HUVEC were treated with $G O$ and intracellular (H2DCFDA) and mitochondrial ROS (MitoSOX) were measured by flow cytometry. $n=4$. Statistical significance was analyzed using one-way or two-way repeated measurement ANOVA corrected using Holm-Šidák method. ${ }^{*} p<0.05$ vs. respective control. Related to Fig. S5 and Table S5.

To understand how, on the other hand, glycation of proteins may affect cell cycle progression, we focused on tubulins, which exhibited CML modification of different lysines upon glyoxal treatment and in tissues from old mice (Fig. 6A and S6). CML-modified tubulin showed more strongly structured tubulin filaments when compared to tubulin in control cells (Fig. 6B), and an increased stability against the depolymerizing agent nocodazole (Fig. 6C). These data point to an impairment of microtubule dynamics upon glyoxal treatment, which may affect mitosis and contribute to the observed reduction of cell proliferation. To check this, we compared mitosis in glyoxal-treated and control cells independent from $G 1$ and G1/S transition. We performed a double thymidine block to synchronize cells in early $S$ phase, treated them with glyoxal thereafter and monitored time-dependent expression of the mitotic marker p-H3(S10) in immunoblotting experiments. In control cells, $\mathrm{p}-\mathrm{H} 3(\mathrm{~S} 10)$ signals were detected between $16 \mathrm{~h}$ and $18 \mathrm{~h}$ after releasing the cell cycle block, while glyoxal-treated cells showed reduced intensity of p-H3(S10) signals indicating a lower number of mitotic cells (Fig. 6D).

CML modification of tubulin may directly affect microtubule dynamics but may also compete with other lysine modifications, thereby affecting tubulin functionality. Since the lysine residues of tubulin, which are modified by CML, are also known to be acetylated (Sadoul and Khochbin, 2016) (Fig. 6A), we hypothesized that CML modification may impede tubulin acetylation. Indeed, glyoxal treatment of HUVEC led to reduced tubulin acetylation at lysine 40 (K40) (Fig. 6E-F), which is known to protect microtubules from mechanical damage and to facilitate self-repair (Portran et al., 2017; Xu et al., 2017). Of note, we were able to demonstrate a direct competition of CML modification and acetylation at K58 of the tubulin $\beta-4 B$ chain in glyoxal-treated cells. Glyoxal induced a significant CML modification of $\mathrm{K} 58$ and at the same time, $\mathrm{K} 58$ acetylation was reduced (Fig. 6G). Together, these data suggest that CML modification of tubulin is likely to have an impact on acetylation and may thereby affect its interactions with microtubule-binding proteins and regulatory enzymes. 
bioRxiv preprint doi: https://doi.org/10.1101/2020.10.16.342311; this version posted October 19, 2020. The copyright holder for this preprint (which was not certified by peer review) is the author/funder, who has granted bioRxiv a license to display the preprint in perpetuity. It is made available under aCC-BY-NC-ND 4.0 International license.

Di Sanzo, Spengler, et al.

A

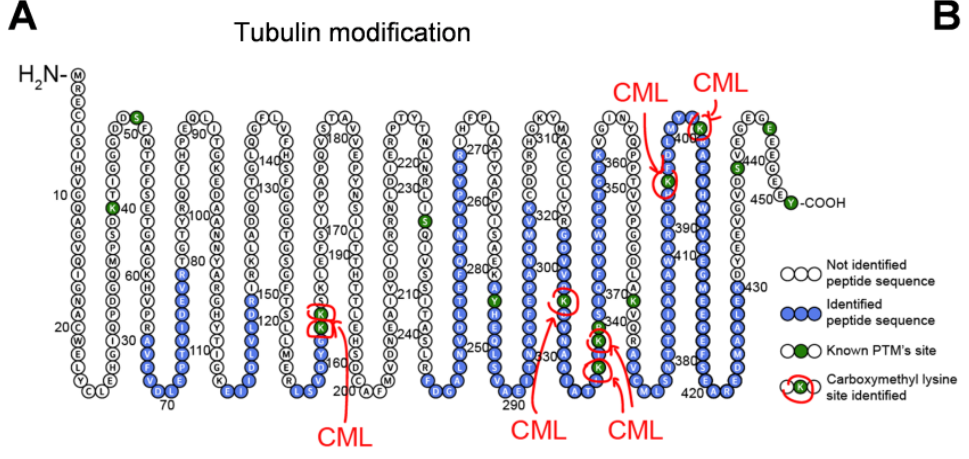

C
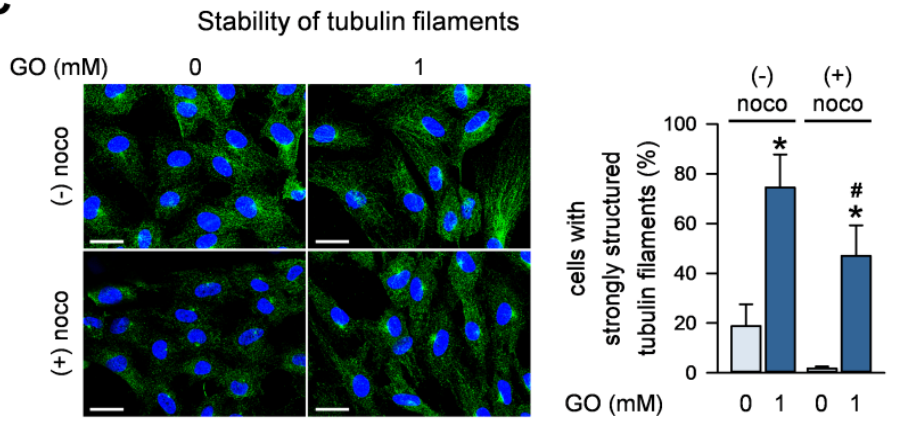

D

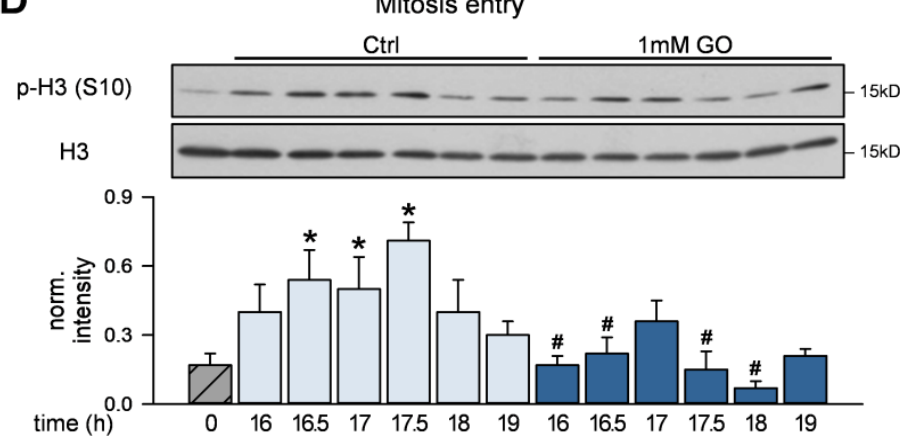

$\mathbf{F}$

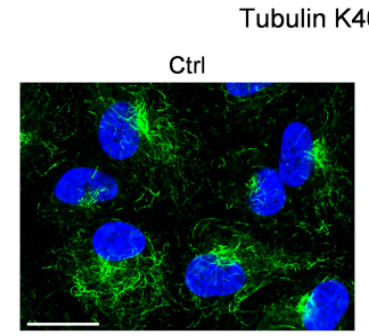

B

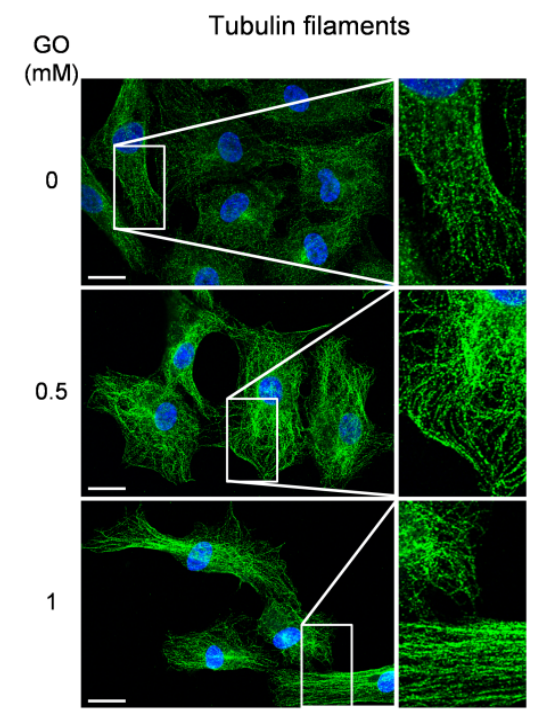

$\mathrm{GO}(\mathrm{mM})$

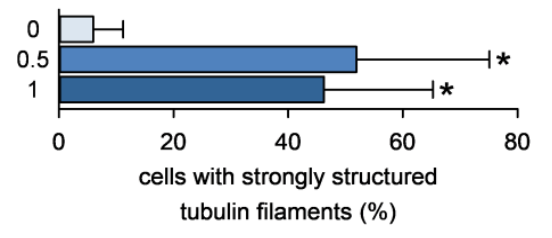

E

Tubulin K40 acetylation
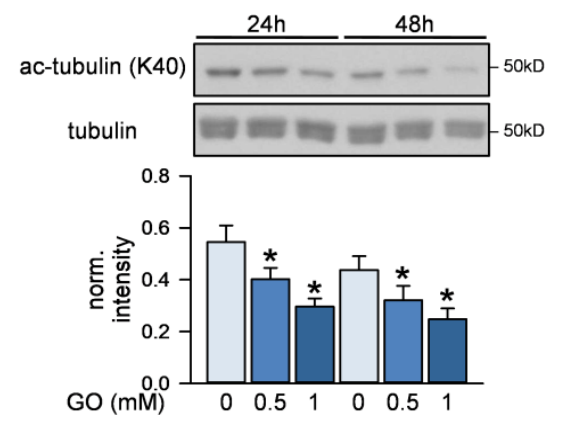

Figure 6. Glyoxal (GO) affects dynamics and post-translational modification of tubulins.

A. Scheme of detected CML modification sites for tubulin $\alpha-1 B$ chain. B. HUVEC were treated with $G O$ for $48 \mathrm{~h}$ and stained against $\alpha / \beta$-tubulin and DAPI. Representative immunofluorescence pictures (upper panel) and the percentage of cells with strongly structured tubulin filaments per high-power field (lower panel) are shown. Scale bar=20 $\mu \mathrm{m}$. $\mathrm{n}=4$. C. HUVEC were treated with GO (1 mM, $48 \mathrm{~h}) .10 \mu \mathrm{M}$ nocodazole was added for $2 \mathrm{~min}$ and $\alpha / \beta$-tubulin and DAPI were stained. Representative pictures (left) and the percentage of cells with strongly structured tubulin filaments per highpower field (right) are shown. Scale bar $=20 \mu \mathrm{m}$. $n=5$. D. HUVEC were synchronized via a double thymidine block and treated with $\mathrm{GO}$ subsequent to releasing the block. Cells were lysed and subjected to immunoblot analysis $\mathrm{n}=5$. $\mathrm{E}$. HUVEC were treated with GO, lysed and subjected to immunoblot analysis. $n=6$. F. HUVEC were treated with $G O$ for 
Di Sanzo, Spengler, et al.

\begin{abstract}
$24 \mathrm{~h}$ and stained against ac-tubulin (K40) and DAPI. A representative picture out of $\mathrm{n}=3$ is shown. G. HUVEC were treated with GO for $48 \mathrm{~h}$. Tubulin modifications were detected by mass spectrometry after respective enrichment of CML-modified or acetylated lysines. Barplot shows the intensity of tubulin $\beta$ acetylated (left panel) or CML-modified at K58 (right panel). The peptide used for the barplot is _INVYYNEATGGK*YVPR_. Statistical significance was analyzed using one-way or two-way repeated measurement AN̄OVA corrected using Holm-Šidák method. * $p<0.05$ vs. control, \# p<0.05 vs. respective non-nocodazole-treated cells (C) or vs. respective non-GO-treated cells (D). Related to Fig. S6.
\end{abstract}

\title{
Discussion
}

The impairment of protein homeostasis is a hallmark of aging and age-associated diseases (Hipp et al., 2019; Ori et al., 2015; Santos and Lindner, 2017). While age-related changes in protein abundance and turnover have been described across tissues and in different species, less is known about the extent and potential functional impact of PTM. Here, we focused on CML modification of proteins, a non-enzymatic PTM belonging to the class of AGEs (Delgado-Andrade, 2016). We developed an antibody-based method for the enrichment of CML-modified peptides coupled to mass spectrometry for identification and quantification. The mapping of CML sites together with studying the total proteome in cultured cells and aging mouse organs allowed us to link CML modifications to cellular functions and to better understand how these processes may contribute to aging and age-associated metabolic diseases.

We validated our method in cultured cells treated with the glycating agent glyoxal and identified over 1000 specific sites of CML modification. CML occurs more often in high abundant proteins that display slower turnover across different cellular compartments. This corresponds to previous studies showing that global AGEs accumulate particularly in tissues characterized by slow protein turnover, such as crystallin lens, cartilage and skin (Gkogkolou and Bohm, 2012; Smuda et al., 2015; Verzijl et al., 2000). Interestingly though, we detected CML-modified peptides across proteins that spanned four orders of magnitude of protein abundance and, conversely, we did not identify CML modifications for all of the most abundant proteins. Keeping in mind potential biases due to limited sensitivity and specific protein sequences not amenable to enzymatic digestion that are inherent to any proteomic analysis, our data suggest the existence of a subset of proteins that are more prone to CML modification than others.

We extended our analysis to primary organs collected from young and old mice and showed that our enrichment strategy is able to identify hundreds of physiologically occurring CML sites, some of these previously reported in an independent study in the mouse heart (Ruiz-Meana et al., 2019). The modified proteins were enriched for mitochondrial proteins, histones, cytoskeletal proteins and enzymes involved in detoxification. We additionally developed targeted proteomics 
Di Sanzo, Spengler, et al.

1 assays that enable the quantification of a subset of CML sites in tissues without prior peptide

2 enrichment. These analyses revealed that the level of CML modification for some sites, i.e.,

3 histone H4-K92 (corresponding to K91 in the mature protein), increased with aging in different

4 organs, while others remained constant. Thus, while global AGE levels increase with age,

5 preferential modification of certain proteins occurs, as previously suggested in plants (Bilova et

6 al., 2017), illustrating the need for targeted investigation of AGE modification sites. Interestingly,

7 increased CML modification in old mice was paralleled by downregulation of the glyoxalase

8 network in all the investigated organs, which may, at least in part, explain the observed increase

9 of CML-modified proteins in old mice. A similar age-associated decline of glyoxalases in rodents and humans has been reported earlier (Kuhla et al., 2006; Sharma-Luthra and Kale, 1994).

Our data reveal a substantial overlap between the identified CML sites and other PTM, particularly acetylation and ubiquitination, suggesting that CML modification may interfere with biological processes mediated by these PTM. For instance, K92 on histone H4, which became substantially more modified with CML during aging, has been reported to be also a target of acetylation and glutarylation, which are both involved in the regulation of chromatin structure and dynamics in response to DNA damage (Bao et al., 2019; Ye et al., 2005). Furthermore, global glycation of histone 3 has been shown to compete with acetylation and methylation thereby disrupting chromatin architecture (Zheng et al., 2019; Zheng et al., 2020). Thus, the age-dependent increase in CML modification of histone H4-K92 as seen in our study may contribute to alteration of chromatin and DNA damage responses in old tissues via interfering with other PTM.

21 In order to investigate other potential mechanisms by which AGEs might affect cellular 22 phenotypes, we focused on perturbation of proteostasis. We show that glyoxal specifically affects 23 the proteostasis network in MEF by increasing the abundance of UPS components and eliciting 24 a hormetic effect on proteasome activity. Low doses of glyoxal increased the activity of the 25 proteasome, while high doses did not alter proteasomal activity and led to an accumulation of ubiquitinated proteins. These data are in agreement with earlier reports showing that methylglyoxal is able to upregulate the protein quality control system (Zemva et al., 2017), and to impair the UPS at high levels leading to accumulation of toxic aggregates (Bento et al., 2010). In line with this, low doses of methylglyoxal led to an increased lifespan of $C$. elegans, while high doses (>1 mM) decreased lifespan (Ravichandran et al., 2018). Inhibition of proteasomal activity by dicarbonyls might be related to a direct modification of the $20 \mathrm{~S}$ proteasome, as previously shown (Queisser et al., 2010). Here, we provide evidence for an interference of high AGEs with the stability of the proteasome by showing reduced thermal stability of proteasomal proteins in 
Di Sanzo, Spengler, et al.

1 glyoxal-treated cells and identifying direct sites of CML modification of proteasomes both in cells

2 treated with glyoxal as well as in organs obtained from mice. Interestingly, we also identified

3 several enzymes involved in the ubiquitin cycle, including ubiquitin itself, to be direct targets of

4 CML modification, suggesting that the interference of AGEs might extend to other components of

5 the UPS beyond the proteasome. Thus, given that the proteasome activity is known to decrease

6 across tissues during aging (Friguet et al., 2000; Hipp et al., 2019; Kelmer Sacramento et al.,

7 2020; Saez and Vilchez, 2014), increased CML levels during aging might contribute to

8 proteostasis impairment via alteration of the UPS.

9 Finally, we investigated the impact of glyoxal on the functional phenotype of endothelial cells, which are well known to be involved in the pathogenesis of age-associated metabolic diseases

11 (Gimbrone and Garcia-Cardena, 2016; Sena et al., 2013). In line with our initial proteomic 12 analysis, we found that glyoxal triggered a proliferation inhibition phenotype characterized by 13 reduced cell proliferation in the presence of serum or bFGF and by lower sprouting in response 14 to VEGF. Glyoxal had only minor effects on endothelial energy metabolism without changes in 15 cellular ATP levels and did not induce cytotoxic effects, as shown by the absence of apoptosis. 16 Our data are in line with previous studies showing that dicarbonyls induce endothelial dysfunction 17 via oxidative stress, inflammatory responses, senescence or apoptosis (Jang et al., 2017; Liu et 18 al., 2012; Navarrete Santos et al., 2017; Sliman et al., 2010; Wang et al., 2019; Yamawaki and Hara, 2008) and that AGEs interfere via RAGE-dependent signaling processes in endothelial cells

20 (Chen et al., 2020; Li et al., 2018; Ravi et al., 2020). Until now, however, the impact of dicarbonyl21 induced changes of protein abundance and intracellular protein modifications on endothelial 22 function has not been thoroughly investigated.

23 To unravel mechanisms underlying the glyoxal-induced proliferation inhibition phenotype, we 24 looked at differentially expressed and/or CML-modified proteins related to cell cycle control. We 25 found that various cell cycle regulators were downregulated in glyoxal-treated cells, particularly proteins involved in DNA replication, likely because CDKN1A/p21 was strongly upregulated and thus restricted $S$ phase entry. This pattern was underlined by growth arrest in G0/G1 and G2 phases and by activation of a DNA damage response as possible underlying mechanism (Ciccia and Elledge, 2010; Shaltiel et al., 2015). We were able to detect phosphorylation of CHK1 as a marker for an activated $\mathrm{G} 1$ and $\mathrm{S}$ phase checkpoint and $\mathrm{YH} 2 \mathrm{AX}$ foci as indicator of DNA damage, likely DNA double strand breaks (Kuo and Yang, 2008; Zhang and Hunter, 2014). This was

32 paralleled by an upregulation of the p53/p21 pathway, a major DNA damage response effector 33 known to prevent G1/S transition (Abbas and Dutta, 2009; Helton and Chen, 2007). Glyoxal may 34 cause DNA damage by glycation of DNA leading to so-called nucleotide AGEs (Pischetsrieder et 
Di Sanzo, Spengler, et al.

1 al., 1999; Rabbani and Thornalley, 2015; Thornalley, 2008; Waris et al., 2015) or by triggering the 2 formation of ROS (Ahmad et al., 2018). The latter may have contributed to DNA damage in our 3 study, since both mitochondrial and cytosolic ROS levels were enhanced by glyoxal. In addition 4 to the p53/p21 pathway, the enhanced expression of p16, another inhibitor of cyclin-dependent 5 kinases preventing G1/S transition, is likely to contribute to the observed sustained growth arrest 6 (Rayess et al., 2012). Upregulation of p16 may be linked to increased ROS levels induced by 7 glyoxal (Sasaki et al., 2014; Takahashi et al., 2006). Both, p53/p21 and p16 pathways are known 8 to play a role in the induction of premature senescence dependent on the extent and persistence 9 of stress (Campisi and d'Adda di Fagagna, 2007) and may thus also be involved in mediating the 10 moderate senescence response occurring in glyoxal-treated endothelial cells.

11 In addition to changes in protein abundance of cell cycle proteins induced by glyoxal, we observed 12 CML modification of several proteins mainly involved in G2 and M phases of cell cycle. To 13 understand how glycation of specific proteins may add to the glyoxal-induced inhibition of 14 proliferation in endothelial cells, we focused on tubulin, whose $\alpha$ and $\beta$ chains exhibited several 15 CML modifications. Tubulin chains form protofilaments, which then associate to microtubules. The 16 latter are major constituents of the cytoskeleton and form the mitotic spindle, whose function is to 17 segregate chromosomes during cell division (Goodson and Jonasson, 2018). A major 18 characteristic of tubulin polymers is their dynamic instability, i.e. the rapid transition between growth and shrinkage, which allows rapid reorganization of the cytoskeleton (Brouhard and Rice, 2018). Microtubule dynamics is known to be regulated by various PTM such as detyrosination, polyglutamination or acetylation (Song and Brady, 2015). Our data reveal glycation as a previously unknown tubulin modification, which has an impact on microtubule dynamics. We show that glyoxal treatment of endothelial cells triggered the formation of strongly structured tubulin filaments compared to fewer and thinner filaments in control cells, similar as observed with microtubule-stabilizing agents (Berges et al., 2017; Wang et al., 2017). Accordingly, our data reveal an increased stability of CML-modified microtubules. While the depolymerizing compound nocodazole completely dissolved the tubulin filaments in control cells, its effect was significantly reduced in cells pretreated with glyoxal. Microtubule dynamics may not only be affected by CML modification of tubulin but also by competition of glycation with other PTM. As shown in our proteomic analysis of mouse tissues, CML modification often occurs on residues that are known to be modified by other PTM. Accordingly, we found four CML-modified sites on a-tubulin (K326, K336, K394, K401) and three CML sites on $\beta$-tubulin (K58, K324, K379), which overlap with previously described acetylation sites (Sadoul and Khochbin, 2016). Moreover, we were able to demonstrate a direct competition between glycation and acetylation for K58 of $\beta$-tubulin indicating 
Di Sanzo, Spengler, et al.

1 that exposure of endothelial cells to glyoxal may alter the tubulin code (Ferreira et al., 2018; Janke

2 and Magiera, 2020). The latter refers to the concept that PTM of tubulin modulate the composition

3 of individual microtubules and program them for specific functions, for instance by regulating the

4 interaction with microtubule-binding proteins (Janke and Magiera, 2020). While the functional

5 impact of most acetylation marks is not yet understood, acetylation of $\mathrm{K} 40$ within the microtubule

6 lumen is suggested to protect microtubules from mechanical stress, possibly through affecting

7 interaction between tubulin protofilaments (Portran et al., 2017; Xu et al., 2017). We found a

8 decrease in K40 acetylation in glyoxal-treated cells, which adds to the alteration of the tubulin

9 code although CML modification was not detected at this site. To address the question of whether

10 the observed alteration of microtubule dynamics may affect mitosis, we compared mitosis in

11 control and glyoxal-treated cells by employing a model, in which cells were treated with glyoxal

12 after synchronization at the G1/S transition point. We found a lower expression of the mitotic

13 marker $\mathrm{p}-\mathrm{H} 3(\mathrm{~S} 10)$ in the presence of glyoxal indicating inhibition of mitosis which may be

14 attributable to impaired microtubule dynamics and contribute to the antiproliferative effect of

15 glyoxal. Together, these data describe a novel potential mechanism of cell cycle inhibition via posttranslational CML modification of tubulin.

17 The described proliferation inhibition phenotype of endothelial cells induced by glyoxal is likely to 18 be of pathophysiological relevance. It is well known that CML accumulates in tissues in patients with diabetes and/or cardiovascular diseases as well as in aging (Delgado-Andrade, 2016). On

20 the other hand, reduced angiogenesis leading to impaired wound healing is one of the hallmarks 21 of diabetes (Okonkwo and DiPietro, 2017) and also observed in aging (Hodges et al., 2018; 22 Moriya and Minamino, 2017). It is also known that only fully functional endothelial cells are able 23 to generate new blood vessels (Boodhwani and Sellke, 2009; Sun et al., 2009). Thus, the 24 formation of glyoxal and its effect on endothelial cell proliferation may be one of the factors linking 25 metabolic alterations to disturbed angiogenesis in diabetes and aging and promote pathogenetic 26 processes via this mechanism.

27 Together, the data presented in this study are based on a novel enrichment strategy coupled to 28 mass spectrometry, which allowed the identification of proteins susceptible to CML modification 29 and their respective CML sites in cells treated with a glycating agent and in organs from mice. 30 Our data unravel subsets of proteins prone to CML modification as well as a proteotoxic response 31 characterized by a dysfunction of the UPS. Exposure of endothelial cells to glycative stress 32 triggers a proliferation inhibition phenotype, in which altered expression of cell cycle regulators 33 induced via the DNA damage response as well as CML modification of tubulin contribute to growth 34 arrest. The observations of this study expand our understanding of vascular dysfunction in aging 
bioRxiv preprint doi: https://doi.org/10.1101/2020.10.16.342311; this version posted October 19, 2020. The copyright holder for this preprint (which was not certified by peer review) is the author/funder, who has granted bioRxiv a license to display the preprint in perpetuity. It is made available under aCC-BY-NC-ND 4.0 International license.

Di Sanzo, Spengler, et al.

1 and age-related metabolic disease and pave the way for further studies to link CML modifications 2 to functional phenotypes.

3 
Di Sanzo, Spengler, et al.

1 Acknowledgments: The authors gratefully acknowledge support from the FLI Core Facilities

2 Proteomics, FACS, functional genomics and the Mouse Facility. The authors acknowledge

3 Helmut Pospiech and Johannes Jungwirth (FLI, Jena) for providing advice and tools for cell cycle

4 analysis, Elke Teuscher (Institute of Molecular Cell Biology, Jena) for her excellent technical

5 assistance and the isolation and culture of HUVEC, Claudia Ender and Amod Godbole (Institute

6 of Molecular Cell Biology, Jena) for taking immunofluorescent pictures, Titus Lohfink (Institute of

7 Chemistry-Food Chemistry, Halle) for CML analysis in HUVEC, Max Tiessen and Domenico Di

8 Fraia (FLI Jena) for implementing the R shiny webserver, and Julia Heiby and Ellen Späth (FLI

9 Jena) for proofreading the manuscript. $\mathrm{RH}$ receives funds from the Deutsche

10 Forschungsgemeinschaft (DFG, RTG1715 and RTG2155). AO acknowledges funding from the

11 DFG (RTG2155), the Else Kröner Fresenius Stiftung (award number: 2019_A79), the Deutsches

12 Zentrum für Herz-Kreislaufforschung (award number: 81X2800193) and the Fritz-Thyssen

13 foundation (award number: 10.20.1.022MN). This research was also supported by the European

14 Regional Development Fund (Grant ID: EFRE HSB 2018 0019) and the federal state of Thuringia

15 providing technical equipment. The FLI is a member of the Leibniz Association and is financially supported by the Federal Government of Germany and the State of Thuringia.

Author contributions: Conceptualization: SDS, AO, RH. Investigation: SDS, KS, JMK, AL, TLR, TB, LP and ZQW.

Declaration of interests: Authors declare no competing interests. 
Di Sanzo, Spengler, et al.

\section{Material and Methods}

\section{Chemicals}

M199 was purchased from Lonza (Verviers, Belgium). Fetal calf serum (FCS), human serum, endothelial growth supplement (ECGS), glyoxal (HUVEC studies), hydroxyurea, nocodazole, antimycin A, thymidine, 2-deoxy-D-glucose, trypsin inhibitor, thrombin, aprotinin, 5-bromo-4chloro-3-indolyl $\beta$-D-galactopyranoside (X-Gal), 4',6-diamidino-2-phenylindole (DAPI), octyl $\beta$-Dglucopyranoside, iodoacetamide (IAA), aqueous $\mathrm{NH3}, \mathrm{ATP}$, cOmplete ${ }^{\mathrm{TM}}$, EDTA-free protease inhibitor cocktail, HEPES, MOPS, NP40 and PonceauS were purchased from Sigma (Taufkirchen, Germany). Protease inhibitor mixture complete, EDTA-free was obtained from Roche Diagnostics (Mannheim, Germany), fibrinogen from Merck/Millipore (Darmstadt, Germany) and Fluoromount-G® from Southern Biotech (Birmingham, AL, US), respectively. Bovine serum albumin-C (BSA-C) was from Aurion (Wageningen, The Netherlands) and goat serum from Cell Signaling Technology (Frankfurt, Germany). D-glucose, L-glutamine, sodium pyruvate, 5-ethynyl2'-deoxyuridine, Trypsin-EDTA and anhydrous dimethylsulfoxide (DMSO) derived from Thermo Fisher Scientific (Waltham, MA, USA). Oligomycin and carbonyl cyanide-4(trifluoromethoxy)phenylhydrazone (FCCP) came from Abcam (Cambridge, UK). Carboxyfluorescein succinimidyl ester (CFSE) was purchased from Invitrogen (Carlsbad, CA, US). Glyoxal (MEF studies), glycerine, $\beta$-mercaptoethanol, glucose, dithiothreitol (DTT), EDTA, formic acid, ammonium bicarbonate, Tris, bovine serum albumin, Tween-20 and Triton X-100 were obtained from Carl Roth $\mathrm{GmbH}$ (Karlsruhe, Germany). Trifluoroacetic acid, acetonitrile and 2-propanol were from Biosolve BV (Valkenswaard, The Netherlands) and glycine was from VWR International (Radnor, PA, USA).

\section{Antibodies}

Antibodies raised against $\beta$-actin (HUVEC studies), cleaved caspase 3 (D175), caspase 3 , cleaved PARP (D214), PARP, histone 3, p-Chk1 (S317), p-Chk1 (S345), Chk1, yH2A.X (S139), p-p53 (S15), p53, p21, p16, a/ $\beta$-tubulin and ac-tubulin (K40) were obtained from Cell Signaling Technology (Frankfurt, Germany). Antibodies against CML (western blot) and p-H3 (S10) (western blot) were from Abcam (Cambridge, UK). The antibody against p-H3 (S10) for flow cytometry was obtained from Merck/Millipore (Darmstadt, Germany) and cyclin A antibody was from Santa Cruz Biotechnology (Dallas, TX, US). The CML antibody used for enrichment was purchased from ImmuneChem Pharmaceuticals Inc. (Burnaby, Canada). Antibodies against mono- and K29-, K48-, and K63-linked mono- and polyubiquitinylated proteins were from Enzo 
Di Sanzo, Spengler, et al.

1 Life Sciences (Farmingdale, NY, USA) and the antibody against $\beta$-actin (MEF studies) was from

2 Sigma (Taufkirchen, Germany). Peroxidase-labeled anti-mouse and anti-rabbit IgG were from

3 Kirkegaard and Perry Laboratories, Inc. (Gaithersburg, MD, USA) or from Dako GmbH (Hamburg,

4 Germany). AlexaFluor®647-conjugated azide (AF647 azide) and secondary AlexaFluor®488-

5 conjugated goat anti-rabbit IgG were from Thermo Scientific (Waltham, MA, USA).

7 Mice

8 All wild-type mice were C57BL/6J obtained from Janvier Labs (Le Genest-Saint-Isle, France) or

9 from internal breeding at FLI. All animals were kept in a specific pathogen-free animal facility with

10 a $12 \mathrm{~h} \mathrm{light/dark} \mathrm{cycle.} \mathrm{Young} \mathrm{mice} \mathrm{were} \mathrm{aged} \mathrm{3-4} \mathrm{months,} \mathrm{old} \mathrm{mice} \mathrm{were} \mathrm{aged} \mathrm{26-33} \mathrm{months.}$

11 Mice had unlimited access to food (ssniff, Soest, Germany)) during the experiment. For the

12 analysis of total proteome, CMLpepIP and glyoxalase activity measurements only male mice were

13 used. Mice were euthanized and organs were isolated, washed in PBS, weighted and immediately

14 snap-frozen in liquid nitrogen before storage in $-80^{\circ} \mathrm{C}$.

MEF cell culturing and treatments

17 SV40-immortalized mouse embryonic fibroblasts (MEF, a kind gift of K. L. Rudolph) were grown 18 in high glucose DMEM medium (Sigma, D6429) until they reached 70 \% confluency. For glyoxal 19 treatment, DMEM medium was removed, cells were washed with PBS and live cell imaging 20 medium (140 mM NaCl; 2.5 mM KCl; 1.8 mM CaCl$; 1.0$ mM MgCl ), 20 mM HEPES; 4500 mg/l 21 glucose and $\mathrm{pH}$ 7.4) was added. Subsequently, glyoxal diluted in the same medium was added 22 at final concentrations of 0.5 or $2 \mathrm{mM}$ for $8-24 \mathrm{~h}$, as notified in figures. For all treatments, cells were snap-frozen in liquid nitrogen and stored at $-80^{\circ} \mathrm{C}$ until further processing.

HUVEC cell culture and treatment

HUVEC were isolated from anonymously acquired human umbilical cords according to the Hospital Ethics Committee. The donors were informed and gave written consent. Briefly, after rinsing the cord veins with $0.9 \% \mathrm{NaCl}$, endothelial cells were detached with collagenase $(0.01 \%$, 3 min at $37^{\circ} \mathrm{C}$ ), suspended in M199/10 \% FCS, washed once (500 x g, 6 min) and seeded on a cell culture flask coated with $0.2 \%$ gelatin. Full growth medium (M199, 17.5 \% FCS, $2.5 \%$ human serum, $7.5 \mu \mathrm{g} / \mathrm{ml}$ ECGS, $7.5 \mathrm{U} / \mathrm{ml}$ heparin, $680 \mu \mathrm{M}$ glutamine, $100 \mu \mathrm{M}$ vitamin $\mathrm{C}, 100 \mathrm{U} / \mathrm{ml}$ penicillin, $100 \mu \mathrm{g} / \mathrm{ml}$ streptomycin) was added $24 \mathrm{~h}$ later. HUVEC from the second passage were 
Di Sanzo, Spengler, et al.

1 detached with trypsin/EDTA after two washes in PBS and the reaction was stopped with HEPES

2 buffer (10 mM HEPES (pH 7.4), $145 \mathrm{mM} \mathrm{NaCl}, 5 \mathrm{mM} \mathrm{KCl}, 1 \mathrm{mM} \mathrm{MgSO}$, $1.5 \mathrm{mM} \mathrm{CaCl}_{2}, 10 \mathrm{mM}$

3 glucose) containing $10 \%$ FCS (HEPES/FCS). Cells were counted using a Neubauer chamber.

4 Seeding was carried out at densities between $23,000 / \mathrm{cm}^{2}$ and $27,500 / \mathrm{cm}^{2}$ dependent on whether

5 experiments were performed 48 or $72 \mathrm{~h}$ after seeding, respectively. For senescence and growth

6 experiments, the seeding density was lower $\left(8,000 / \mathrm{cm}^{2}\right.$ (senescence-associated $\beta$-galactosidase

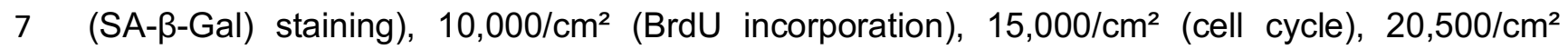

8 (thymidine block)). If not otherwise indicated, $30 \mathrm{~mm}$-dishes were used for experiments. For mass

9 spectrometry-based proteomics, detachment of HUVEC from $90 \mathrm{~mm}$-dishes was performed with

10 trypsin/EDTA and the reaction was stopped by an equal amount of trypsin inhibitor $(1 \mathrm{mg} / \mathrm{ml}$ in

11 PBS). Then, cells were washed twice in M199 (500 x g, $3 \mathrm{~min}$ ) and snap-frozen in liquid nitrogen.

12 Treatment of HUVEC with glyoxal was performed in experimental medium (i.e. full growth medium

13 without vitamin C) and started 48 - $72 \mathrm{~h}$ after seeding. Incubations were performed with glyoxal

14 concentrations of 0.5 or $1 \mathrm{mM}$ for $4-48 \mathrm{~h}$, as notified in figures. Thereafter, cells were stimulated

15 with growth factors if indicated and processed as described below.

Sample preparation for quantitation of total CML levels

MEF and mouse organs were lysed and proteins acetone precipitated as described in Sample preparation for mass spectrometry-based proteomics. HUVEC were detached by trypsin/EDTA, transferred to HEPES/FCS, centrifuged (500 x g, $6 \mathrm{~min}$ ), washed twice in $2 \mathrm{ml}$ PBS and subjected to one freezing/thawing cycle in liquid nitrogen. Pellets were resuspended in $200 \mu$ ice-cold Tris buffer (50 mM Tris (pH 7.4), 2 mM EDTA, 1 mM EGTA, $50 \mathrm{mM} \mathrm{NaF,} 150 \mathrm{mM} \mathrm{NaCl,} 10 \mathrm{mM}$ $\mathrm{Na}_{4} \mathrm{P}_{2} \mathrm{O}_{7}, 1 \mathrm{mM} \mathrm{Na}_{3} \mathrm{VO}_{4}, 1$ \% Triton $\mathrm{X}-100,0.1 \%$ SDS, $0.5 \%$ sodium deoxycholate, $1 \mathrm{mM}$ PMSF, $10 \mu \mathrm{l} / \mathrm{ml}$ protease inhibitor cocktail) and incubated on ice for $30 \mathrm{~min}$. After homogenization using a tissue homogenizer, proteins were precipitated by adding TCA to a final concentration of $10 \%$. Samples were centrifuged $\left(4000 \times \mathrm{g}, 5 \mathrm{~min}, 4^{\circ} \mathrm{C}\right)$, pellets were washed twice in ice-cold $80 \%$ acetone and stored at $-80{ }^{\circ} \mathrm{C}$ until further processing.

\section{Quantitation of total CML levels by HPLC-MS/MS}

30 Protein pellets were reconstituted in PBS and $250 \mu \mathrm{l}$ aliquots of protein extracts $(1 \mathrm{mg} / \mathrm{ml})$ were reduced by addition of $100 \mu \mathrm{IaBH}_{4}$ solution $(15 \mathrm{mg} / \mathrm{ml}$ in $0.01 \mathrm{M} \mathrm{NaOH})$ and were shaken for 1

$32 \mathrm{~h}$ at room temperature. Samples were dried in a vacuum concentrator (Savant-Speed-Vac Plus SC 110 A combined with a Vapor Trap RVT 400, Thermo Fisher Scientific, Bremen, Germany). $800 \mu \mathrm{l}$ of $6 \mathrm{M} \mathrm{HCl}$ was added and the solution was heated $20 \mathrm{~h}$ at $110^{\circ} \mathrm{C}$ under an argon 
Di Sanzo, Spengler, et al.

atmosphere. Volatiles were removed in a vacuum concentrator and the residue was dissolved in $300 \mu \mathrm{l}$ of ultra-pure water. Samples were filtered through $0.45 \mu \mathrm{m}$ cellulose acetate Costar SpinX filters (Corning Inc., Corning, USA). After complete hydrolysis, the amount of amino acids in

4 hydrolysates was determined by ninhydrin assay and referenced to a calibration of L-leucine

5 concentrated between 5 and $100 \mu \mathrm{M}$ as described previously (Smuda et al., 2015). The 6 absorbance was determined at $546 \mathrm{~nm}$ with an Infinite M200 microplate reader (Tecan, 7 Männedorf, Switzerland) using 96-well plates.

8 Chromatographic separations were performed on a stainless-steel column (XSelect HSS T3, $9250 \times 3.0 \mathrm{~mm}, \mathrm{RP} 18,5 \mu \mathrm{m}$, Waters, Milford, USA) using a flow rate of $0.7 \mathrm{ml} / \mathrm{min}$ and a column temperature of $25^{\circ} \mathrm{C}$. Eluents were ultra-pure water $(A)$ and a mixture of methanol (Biosolve, 0013684102BS) and ultra-pure water (7:3, (v/v); B), both supplemented with $1.2 \mathrm{ml} / \mathrm{l}$ heptafluorobutyric acid. Samples were injected (10 $\mu \mathrm{l})$ at $2 \% \mathrm{~B}$ and run isocratic for $2 \mathrm{~min}$, gradient was changed to $14 \% \mathrm{~B}$ within $10 \mathrm{~min}$ (held for $0 \mathrm{~min}$ ), $87 \% \mathrm{~B}$ within $22 \mathrm{~min}$ (held for $0 \mathrm{~min}$ ), $100 \% \mathrm{~B}$ within $0.5 \mathrm{~min}$ (held for $7 \mathrm{~min}$ ) and $2 \% \mathrm{~B}$ within $2.5 \mathrm{~min}$ (held $8 \mathrm{~min}$ ). A PU-2080 Plus quaternary gradient pump with degasser and an AS-2057 Plus autosampler (Jasco, Gross-Umstadt, Germany) were used. The mass analyses were performed using an API 4000 quadrupole instrument (Applied Biosystems, Foster City, USA) equipped with an API source using electrospray ionization. The HPLC system was connected directly to the probe of the mass spectrometer. Nitrogen was used as sheath and auxiliary gas. To measure CML the scheduled multiple-reaction monitoring (SMRM) mode of HPLC-MS/MS was used. Quantitation was based on the standard addition method using known amounts of pure CML standard to compensate for matrix effects. The authentic reference compound was added at $0.5,1,2$, and 4 times the concentration of the analyte in the sample and correlation coefficients were 0.9 or higher.

\section{Thermal Proteome Profiling (TPP)}

MEF were grown in $150 \mathrm{~mm}$-dishes until they reached $70-80 \%$ confluence. They were treated at different concentration of glyoxal $(0,0.5 \mathrm{mM}$ and $2 \mathrm{mM})$ for $8 \mathrm{~h}$ in imaging medium (as described in "MEF cells culturing and treatments"). Cells were harvested using Trypsin-EDTA phenol red $(0.05 \%)$ and counted in order to have $10^{6}$ cells per condition in PBS. Thereupon, cell suspensions were split into 10 individual $0.2 \mathrm{ml} \mathrm{PCR}$ tubes in equal volumes (100 $\mu$ l each tube) and quickly span down to reach a final volume of $20 \mu \mathrm{l}$ of cell suspension in each tube. Tubes were heated

32 at different temperatures for 3 min using a 96 well dry bath ThermoQ (Hangzhou Bioer 33 Technology, Hangzhou, China). Temperatures were: 37, 41, 44, 47, 50, 53, 56, 60, 63 and $67^{\circ} \mathrm{C}$. 
Di Sanzo, Spengler, et al.

1 snap-frozen in liquid nitrogen. Cells were lysed by a thaw-freeze-thaw cycle composed of an

2 incubation step for $5 \mathrm{~min}$ at $25^{\circ} \mathrm{C}$, followed by snap freezing, and an additional incubation at 25

$3 \quad{ }^{\circ} \mathrm{C}$ for $5 \mathrm{~min}$. Lysates were transferred to $7 \times 20 \mathrm{~mm}$ polycarbonate thick-wall tubes (Beckman

4 Coulter, Krefeld, Germany) for ultra-centrifugation (centrifuge Optima TLX with rotor TLA 100,

5 Beckman Coulter), which was carried out at $100,000 \times g$ for 20 min at $4{ }^{\circ} \mathrm{C}$. Identical volumes of

6 the resulting supernatants were then taken $(32 \mu \mathrm{l})$ estimated to correspond to approximately 30

$7 \mu \mathrm{g}$ of protein extract for the $37^{\circ} \mathrm{C}$ sample. Samples were reduced with $10 \mathrm{mM}$ DTT for $15 \mathrm{~min}$ at

$845^{\circ} \mathrm{C}$ and cysteine alkylated with freshly prepared $15 \mathrm{mM} \mathrm{IAA}$ for $30 \mathrm{~min}$ at $25{ }^{\circ} \mathrm{C}$, in the dark.

9 Following reduction and alkylation, proteins were precipitated with ice-cold acetone and digested

10 into peptides, as described in "Sample preparation for mass spectrometry-based proteomics".

\section{Sample preparation for mass spectrometry-based proteomics}

HUVEC and MEF cell pellets (300k and 100k respectively) were thawed, reconstituted in $50 \mu$ of ice-cold PBS and lysed by addition of $50 \mu \mathrm{l} 2$ x lysis buffer (2\% SDS, 100 mM HEPES pH 8, 20 mM DTT). Mouse organs were thawed and transferred into Precellys ${ }^{\circledR}$ lysing kit tubes (Keramikkit 1.4/2.8 mm, $2 \mathrm{ml}(\mathrm{CKM})$ ) containing $1 \mathrm{ml}$ of PBS supplemented with 1 tab of cOmplete ${ }^{\mathrm{TM}}$, Mini, EDTA-free Protease Inhibitor per $50 \mathrm{ml}$. For homogenization, tissues were shaken twice at 6000 rpm for 30 s using Precellys ${ }^{\circledR} 24$ Dual (Bertin Instruments, Montigny-le-Bretonneux, France) and the homogenate was transferred to new $2 \mathrm{ml}$ Eppendorf tubes. Based on estimated protein content ( $5 \%$ of fresh tissue weight for liver and $8 \%$ for heart and kidney), $100 \mu \mathrm{g}$ of protein was processed for further analyses. Volumes were adjusted using PBS and one volume equivalent of 2x lysis buffer was added.

Samples were sonicated in a Bioruptor Plus (Diagenode, Seraing, Belgium) for 10 cycles with 1 min ON and $30 \mathrm{~s}$ OFF with high intensity at $20^{\circ} \mathrm{C}$. Samples were quickly centrifuged and a second sonication cycle was performed as described above. The lysates were centrifuged at 18,407 $\times g$ for $1 \mathrm{~min}$ and transferred to new $1.5 \mathrm{ml}$ Eppendorf tubes. Subsequently, samples were reduced using $10 \mathrm{mM}$ DTT for $30 \mathrm{~min}$ at room temperature, and alkylated using freshly made $15 \mathrm{mM}$ IAA for $30 \mathrm{~min}$ at room temperature in the dark. Subsequently, proteins were acetone precipitated and digested using LysC (Wako sequencing grade) and trypsin (Promega sequencing grade), as described in (Buczak et al., 2020). The digested proteins were then acidified with $10 \%(\mathrm{v} / \mathrm{v})$

31 trifluoracetic acid and desalted using Waters Oasis ${ }^{\circledR}$ HLB $\mu$ Elution Plate $30 \mu m$ following manufacturer instructions. The eluates were dried down using a vacuum concentrator, and reconstituted samples in $5 \%(\mathrm{v} / \mathrm{v})$ acetonitrile, $0.1 \%(\mathrm{v} / \mathrm{v})$ formic acid. For Data Independent Acquisition (DIA) based analysis, samples were transferred to an MS vial, diluted to a 
Di Sanzo, Spengler, et al.

1 concentration of $1 \mu \mathrm{g} / \mu \mathrm{l}$, and spiked with iRT kit peptides (Biognosys, Zurich, Switzerland) prior

2 to analysis by LC-MS/MS. For Tandem Mass Tags (TMT) based analysis, samples were further

3 processed for TMT labelling as described below.

TMT labelling and high $\mathrm{pH}$ peptide fractionation for organ aging proteome and TPP

6 Reconstituted peptides (at $1 \mu \mathrm{g} / \mu \mathrm{l}$ ) were buffered using $100 \mathrm{mM} \mathrm{HEPES}$ buffer $\mathrm{pH} 8.5$ (1:1 ratio)

7 for labelling. 10-20 $\mathrm{gg}$ peptides were taken for each labelling reaction. TMT-10plex reagents

8 (Thermo Scientific, Waltham, MA, USA) were reconstituted in $41 \mu 100 \%$ anhydrous DMSO.

9 TMT labeling was performed by addition of $1.5 \mu$ of the TMT reagent. After 30 min of incubation

10 at room temperature with shaking at $600 \mathrm{rpm}$ in a thermomixer (Eppendorf, Hamburg, Germany),

11 a second portion of TMT reagent $(1.5 \mu \mathrm{l})$ was added and incubated for another $30 \mathrm{~min}$. After

12 checking labelling efficiency, samples were pooled (45-50 $\mu \mathrm{g}$ total), desalted with Oasis ${ }^{\circledR} H L B$

$13 \mu$ Elution Plate and subjected to high $\mathrm{pH}$ fractionation prior to MS analysis.

14 Offline high $\mathrm{pH}$ reverse phase fractionation was performed using a Waters XBridge C18 column $15(3.5 \mu \mathrm{m}, 100 \times 1.0 \mathrm{~mm}$, Waters) with a Gemini C18, 4 × $2.0 \mathrm{~mm}$ SecurityGuard (Phenomenex) 16 cartridge as a guard column on an Agilent 1260 Infinity HPLC, as described in (Buczak et al., 17 2020). Forty-eight fractions were collected along with the LC separation, which were subsequently 18 pooled into 16 fractions (for liver and kidney) and 24 fractions (heart). Pooled fractions were dried 19 in a vacuum concentrator and then stored at $-80^{\circ} \mathrm{C}$ until LC-MS/MS analysis.

\section{LC-MS/MS based on Data Independent Acquisition (DIA) for MEF and HUVEC}

22 Peptides (approx. $1 \mu \mathrm{g}$ ) were separated using a nanoAcquity UPLC M-Class system (Waters 23 Milford, USA) with a trapping (nanoAcquity Symmetry C18, $5 \mu \mathrm{m}, 180 \mu \mathrm{m} \times 20 \mathrm{~mm}$ ) and an 24 analytical column (nanoAcquity BEH C18, $1.7 \mu \mathrm{m}, 75 \mu \mathrm{m} \times 250 \mathrm{~mm}$ ). The outlet of the analytical 25 column was coupled directly to a Q-exactive HF-X (Thermo Fisher, Waltham, MA, USA) using the 26 Proxeon nanospray source. Solvent A was water, $0.1 \%$ formic acid and solvent B was acetonitrile, $0.1 \%$ formic acid. The samples (approx. $1 \mu \mathrm{g}$ ) were loaded onto the trapping column with a constant flow of solvent $A$ at $5 \mu \mathrm{l} / \mathrm{min}$. Trapping time was $6 \mathrm{~min}$. Peptides were eluted via the analytical column with a constant flow of $0.3 \mu \mathrm{l} / \mathrm{min}$. During the elution step, the percentage of solvent B increased in a non-linear fashion from $0 \%$ to $40 \%$ in $90 \mathrm{~min}$. Total runtime was 115 min, including clean-up and column re-equilibration. The peptides were introduced into the MS via a Pico-Tip Emitter $360 \mu \mathrm{m}$ OD x $20 \mu \mathrm{m}$ ID; $10 \mu \mathrm{m}$ tip and a spray voltage of $2.2 \mathrm{kV}$ was applied.

33 The capillary temperature was set at $300{ }^{\circ} \mathrm{C}$. The radio frequency (RF) ion funnel was set to 40 $\%$. 
Di Sanzo, Spengler, et al.

1 Data from a subset of conditions were first acquired in data-dependent acquisition (DDA) mode

2 to contribute to a sample specific spectral library. The conditions were as follows: Full scan MS

3 spectra with mass range 350-1650 m/z were acquired in profile mode in the Orbitrap with

4 resolution of 60,000 FWHM. The filling time was set at maximum of $20 \mathrm{~ms}$ with limitation of $3 \mathrm{x}$

$510^{6}$ ions. The "Top N" method was employed to take the 15 most intense precursor ions (with an 6 intensity threshold of $4 \times 10^{4}$ ) from the full scan MS for fragmentation (using HCD normalized 7 collision energy, $27 \%$ ) and quadrupole isolation (1.6 Da window) and measurement in the 8 Orbitrap (resolution 15,000 FWHM, fixed first mass $120 \mathrm{~m} / \mathrm{z}$ ). The peptide match 'preferred' option 9 was selected and the fragmentation was performed after accumulation of $2 \times 10^{5}$ ions or after filling time of $25 \mathrm{~ms}$ for each precursor ion (whichever occurred first). MS/MS data were acquired in profile mode. Only multiply charged $(2+-5+)$ precursor ions were selected for MS/MS. Dynamic exclusion was employed with maximum retention period of $20 \mathrm{~s}$ and relative mass window of 10 ppm. Isotopes were excluded. In order to improve the mass accuracy, internal lock mass correction using a background ion (m/z 445.12003) was applied.

15 For DIA, the same gradient conditions were applied to the LC as for the DDA and the MS conditions were varied as described: Full scan MS spectra with mass range 350-1650 m/z were acquired in profile mode in the Orbitrap with resolution of 120,000 FWHM. The default charge state was set to $3+$. The filling time was set at maximum of $60 \mathrm{~ms}$ with limitation of $3 \times 10^{6}$ ions. DIA scans were acquired with 34 mass window segments of differing widths across the MS1 mass range. HCD fragmentation (stepped normalized collision energy; 25.5, 27, 30 \%) was applied and MS/MS spectra were acquired with a resolution of 30,000 FWHM with a fixed first mass of 200 $\mathrm{m} / \mathrm{z}$ after accumulation of $3 \times 10^{6}$ ions or after filling time of $40 \mathrm{~ms}$ (whichever occurred first). Data were acquired in profile mode. For data acquisition and processing of the raw data Xcalibur 4.0 and Tune version 2.9 (both Thermo Fisher) were employed.

\section{Data processing for DIA}

27 DpD (DDA plus DIA) libraries were then created by searching both the DDA runs and the DIA 28 runs using Spectronaut Pulsar (v10/11, Biognosys, Zurich, Switzerland). The data were searched against species specific protein databases (Uniprot Mus musculus or Homo sapiens, reviewed entry only, release 2016_01) with a list of common contaminants appended. The data were searched with the following modifications: carbamidomethyl $(C)$ as fixed modification, and

32 oxidation (M), acetyl (protein N-term) and carboxymethyllysine (CML) as variable modifications.

33 A maximum of 3 missed cleavages was allowed. The library search was set to $1 \%$ false discovery 34 rate (FDR) at both protein and peptide levels. This library contained 92,917 precursors, 
Di Sanzo, Spengler, et al.

corresponding to 5,393 protein groups for HUVEC, and 83,207 precursors, corresponding to 4,725 protein groups for MEF using Spectronaut protein inference. DIA data were then uploaded and searched against this spectral library using Spectronaut Professional (v.11) and default settings. Relative quantification was performed in Spectronaut for each pairwise comparison using the replicate samples from each condition using default settings, except: Major Group Quantity = Sum peptide quantity; Major Group Top N = OFF; Minor Group Quantity = Sum precursor quantity; Minor Group Top N = OFF; Data Filtering = Q value sparse; Normalization Strategy = Local normalization; Row Selection $=\mathrm{Q}$ value complete. The data (candidate tables) and protein quantity data reports were then exported and further data analyses and visualization were performed with $R$ (v.3.6.3) and $R$ studio server (v. 1.2.5042) using in-house pipelines and scripts.

\section{LC-MS/MS based on Tandem Mass Tags (TMT) for organ aging proteome and TPP}

For TMT experiments, fractions were resuspended in $10 \mu \mathrm{l}$ reconstitution buffer (5\% (v/v) acetonitrile, $0.1 \%(\mathrm{v} / \mathrm{v})$ trifluoroacetic acid in water) and $3 \mu \mathrm{l}$ were injected. Peptides were analyzed as described in (Buczak et al., 2020) using a nanoAcquity UPLC system (Waters) fitted with a trapping (nanoAcquity Symmetry C18, $5 \mu \mathrm{m}, 180 \mu \mathrm{m} \times 20 \mathrm{~mm}$ ) and an analytical column (nanoAcquity BEH C18, $2.5 \mu \mathrm{m}, 75 \mu \mathrm{m} \times 250 \mathrm{~mm}$ ), and coupled to an Orbitrap Fusion Lumos (Thermo Fisher Scientific, Waltham, MA, USA). Briefly, peptides were separated using a $130 \mathrm{~min}$ nonlinear gradient. Full scan MS spectra with mass range 375-1500 m/z were acquired in profile mode in the Orbitrap with resolution of 60,000 FWHM using the quad isolation. The RF on the ion funnel was set to $40 \%$. The filling time was set at maximum of $100 \mathrm{~ms}$ with an AGC target of $4 \mathrm{x}$ $10^{5}$ ions and 1 microscan. The peptide monoisotopic precursor selection was enabled along with relaxed restrictions if too few precursors were found. The most intense ions (instrument operated for a 3 s cycle time) from the full scan MS were selected for MS2, using quadrupole isolation and a window of 1Da. HCD was performed with collision energy of $35 \%$. A maximum fill time of 50 ms for each precursor ion was set. MS2 data were acquired with fixed first mass of $120 \mathrm{~m} / \mathrm{z}$. The dynamic exclusion list was with a maximum retention period of $60 \mathrm{sec}$ and relative mass window of $10 \mathrm{ppm}$. The instrument was not set to inject ions for all available parallelizable time. For the MS3, the precursor selection window was set to the range 400-2000 m/z, with an exclude width of $18 \mathrm{~m} / \mathrm{z}$ (high) and $5 \mathrm{~m} / \mathrm{z}$ (low). The most intense fragments from the MS2 experiment were coisolated (using Synchronus Precursor Selection=8) and fragmented using HCD (65 \%). MS3 spectra were acquired in the Orbitrap over the mass range $100-1000 \mathrm{~m} / \mathrm{z}$ and resolution set to 
Di Sanzo, Spengler, et al.

130000 . The maximum injection time was set to $105 \mathrm{~ms}$ and the instrument was set not to inject

2 ions for all available parallelizable time.

Data processing for TMT

5 TMT-10plex data from aging mouse organs were processed using Proteome Discoverer v2.0

6 (Thermo Fisher Scientific, Waltham, MA, USA). Data were searched against the fasta database

7 (Uniprot Mus musculus database, reviewed entry only, release 2016_01) using Mascot v2.5.1

8 (Matrix Science) with the following settings: Enzyme was set to trypsin, with up to 1 missed

9 cleavage. MS1 mass tolerance was set to 10ppm and MS2 to 0.5Da. Carbamidomethyl cysteine

10 was set as a fixed modification and oxidation of methionine as variable. Other modifications

11 included the TMT-10plex modification from the quantification method used. The quantification

12 method was set for reporter ions quantification with HCD and MS3 (mass tolerance, 20 ppm).

13 The false discovery rate for peptide-spectrum matches (PSMs) was set to 0.01 using Percolator

14 (Brosch et al., 2009).

15 Reporter ion intensity values for the PSMs were exported and processed with procedures written 16 in R (v.3.6.3) and R studio server (v. 1.2.5042), as described in (Heinze et al., 2018). Briefly, 17 PSMs mapping to reverse or contaminant hits, or having a Mascot score below 15, or having 18 reporter ion intensities below $1 \times 10^{3}$ in all the relevant TMT channels were discarded. TMT 19 channels intensities from the retained PSMs were then $\log _{2}$ transformed, normalized and 20 summarized into protein group quantities by taking the median value using MSnbase (Gatto and 21 Lilley, 2012). At least two unique peptides per protein were required for the identification and only 22 those peptides with no missing values across all 10 channels were considered for quantification. 23 Protein differential expression was evaluated using the limma package (Ritchie et al., 2015). Differences in protein abundances were statistically determined using the Student's $t$ test moderated by the empirical Bayes method. P values were adjusted for multiple testing using the Benjamini-Hochberg method (FDR, denoted as "adj. p") (Benjamini and Hochberg, 1995).

Data processing for TPP

For the analysis of the TPP sample data (TMT10plex, high $\mathrm{pH}$ fractionated, MS3 data acquisition), raw data files were first processed through the preMascot process of the isobarquant package (Franken et al., 2015). After the .mgf files had been generated, these were processed via Mascot decoy was created by concatenating the forward entries (Uniprot Mus musculus database, reviewed entry only, release 2016_01) to the reversed sequences of the database. Data were 
Di Sanzo, Spengler, et al.

1 then searched against the relevant database with the following settings: Enzyme $=$ trypsin, 3

2 missed cleavage allowed. Modifications: carbamidomethyl $(\mathrm{C})$ and TMT10plex (K) as fixed

3 modifications; oxidation $(\mathrm{M})$, carboxymethyllysine $(\mathrm{K})$ and TMT10plex (N-term) as variable. MS1

4 tolerance was $10 \mathrm{ppm}, \mathrm{MS} 2 ; 0.5 \mathrm{Da}$. When the .dat files for each fraction had been generated,

5 these were subjected to the postMascot process of isobarquant, combining all the outputs into a

6 single, merged, TMT10plex quantified protein output for further processing of melting point curves

7 using the TPP package in R (Childs et al., 2019).

9 Enrichment of CML modified peptides (CMLpepIP)

10 Lysates containing approximatively $1 \mathrm{mg}$ protein for HUVEC and MEF and $5 \mathrm{mg}$ for tissues were digested as described in "Sample preparation for mass spectrometry-based proteomics" with minor modifications: the digestion buffer used was 3 M Urea, $100 \mathrm{mM} \mathrm{HEPES,} 5 \%$ (v/v) acetonitrile and the ratio of LysC and Trypsin used was 1:150 enzyme to protein. The digests were then acidified with $10 \%$ (v/v) trifluoroacetic acid and then desalted with Waters Oasis $₫ H L B$ 96-well Plate $30 \mu m$ (Waters Corp., Milford, MA, USA) in the presence of a slow vacuum. In this process, the columns were conditioned with 2x $1000 \mu$ l solvent B (80\% (v/v) acetonitrile; $0.05 \%$ (v/v) formic acid) and equilibrated with $2 \times 1000 \mu$ solvent $A(0.05 \%(v / v)$ formic acid in milliQ water). The samples were loaded, washed 2 times with $1000 \mu$ solvent $A$, and then eluted with $500 \mu$ l solvent B. The eluates were dried down and dissolved in $200 \mu \mathrm{l}$ of IP buffer (50 mM MOPS, pH 7.3, 10 $\mathrm{mM} \mathrm{KPO}_{4} \mathrm{pH} 7.5,50 \mathrm{mM}$ HEPES, $2.5 \mathrm{mM}$ octyl $\beta$-D-glucopyranoside) at concentration of $5 \mu \mathrm{g} / \mu \mathrm{l}$ followed by sonication in a Bioruptor Plus (5 cycles with $1 \mathrm{~min}$ ON and $30 \mathrm{~s}$ OFF with high intensity at $20{ }^{\circ} \mathrm{C}$ ). $10 \%$ of the sample was kept and analyzed separately as input control. A pre-cleaning step was applied by incubating each sample with $10 \mu \mathrm{l}$ of Protein A magnetic beads (New England Biolabs $\mathrm{GmbH}$, Frankfurt, Germany) for $1 \mathrm{~h}$ at $4{ }^{\circ} \mathrm{C}$ in tube roller (15 rpm) (STARLAB Tube roller Mixer RM Multi-1). Samples were transferred to a magnetic rack (DynaMag ${ }^{\mathrm{TM}}-2$, Invitrogen). The supernatant was transferred into a new $1.5 \mathrm{ml}$ Eppendorf tube and incubated overnight with 30 $\mu \mathrm{g}$ of pan $(\varepsilon-\mathrm{N}) \mathrm{CML}$ antibody at $4{ }^{\circ} \mathrm{C}$ on tube roller $(15 \mathrm{rpm}$ ) (STARLAB Tube roller Mixer RM Multi-1). Subsequently, $150 \mu$ of Protein A magnetic beads were added to the samples and incubated for $1 \mathrm{~h}$ at $4^{\circ} \mathrm{C}$ on tube roller as previously. Samples were then transferred to a magnetic rack and the flow through was collected in a fresh tube, and beads were washed 3 times in 300 $\mu \mathrm{I}$ IP buffer. The enriched peptides were then eluted 3 times in $54 \mu \mathrm{l}$ of $0.1 \mathrm{M}$ glycine $\mathrm{pH}$ 2.6. The

32 fraction of elution, flow through and the input were desalted using Macro Spin Column C18 33 columns (Harvard Apparatus, Cambridge, MA, USA) following manufacturer instructions. The eluates were then dried down in a vacuum concentrator, dissolved in in $5 \%(\mathrm{v} / \mathrm{v})$ acetonitrile, 0.1 
Di Sanzo, Spengler, et al.

$\%(\mathrm{v} / \mathrm{v})$ formic acid and directly analyzed by LC-MS/MS for the MEF and HUVEC. An additional

2 step of high $\mathrm{pH}$ peptide fractionation was performed for eluates from mouse organs, as described

3 in "TMT labelling and high pH peptide fractionation for organ aging proteome and TPP". Eight

4 pooled fractions from high $\mathrm{pH}$ fractionation were measured by LC-MS/MS for each sample.

LC-MS/MS based on Data Dependent Acquisition (DDA) for CMLpepIP

7 Peptides were separated using the nanoAcquity UPLC system (Waters) fitted with a trapping 8 (nanoAcquity Symmetry C18, $5 \mu \mathrm{m}, 180 \mu \mathrm{m} \times 20 \mathrm{~mm}$ ) and an analytical column (nanoAcquity

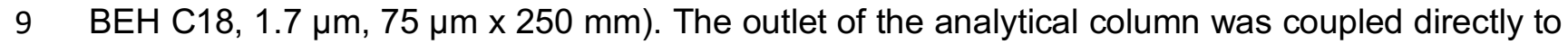
an Orbitrap Fusion Lumos (Thermo Fisher Scientific, Waltham, MA, USA) using the Proxeon nanospray source. Solvent A was water, $0.1 \%(\mathrm{v} / \mathrm{v})$ formic acid and solvent B was acetonitrile, $0.1 \%(\mathrm{v} / \mathrm{v})$ formic acid. The samples (500 $\mathrm{ng}$ ) were loaded with a constant flow of solvent $\mathrm{A}$ at $5 \mu \mathrm{l} / \mathrm{min}$ onto the trapping column. Trapping time was $6 \mathrm{~min}$. Peptides were eluted via the analytical column with a constant flow of $0.3 \mu \mathrm{l} / \mathrm{min}$. During the elution step, the percentage of solvent $B$ increased in a linear fashion from $3 \%$ to $25 \%$ in $30 \mathrm{~min}$, then increased to $32 \%$ in 5 more minutes and finally to $50 \%$ in a further $0.1 \mathrm{~min}$. Total runtime was $60 \mathrm{~min}$. The peptides were introduced into the mass spectrometer via a Pico-Tip Emitter $360 \mu \mathrm{m}$ OD x $20 \mu \mathrm{m}$ ID; 10 $\mu \mathrm{m}$ tip (New Objective) and a spray voltage of $2.2 \mathrm{kV}$ was applied. The capillary temperature was set at $300{ }^{\circ} \mathrm{C}$. The RF lens was set to $30 \%$. Full scan MS spectra with mass range $375-1500 \mathrm{~m} / \mathrm{z}$ were acquired in profile mode in the Orbitrap with resolution of 120,000 FWHM. The filling time was set at maximum of 50 ms with limitation of $2 \times 10^{5}$ ions. The "Top Speed" method was employed to take the maximum number of precursor ions (with an intensity threshold of $5 \times 10^{3}$ ) from the full scan MS for fragmentation (using HCD collision energy, $30 \%$ ) and quadrupole isolation (1.4 Da window) and measurement in the ion trap, with a cycle time of $3 \mathrm{~s}$. The MIPS (monoisotopic precursor selection) peptide algorithm was employed but with relaxed restrictions when too few precursors meeting the criteria were found. The fragmentation was performed after accumulation of $2 \times 10^{3}$ ions or after filling time of $300 \mathrm{~ms}$ for each precursor ion (whichever occurred first). MS/MS data were acquired in centroid mode, with the rapid scan rate and a fixed first mass of $120 \mathrm{~m} / \mathrm{z}$. Only multiply charged $(2+-7+)$ precursor ions were selected for MS/MS. Dynamic exclusion was employed with maximum retention period of $60 \mathrm{~s}$ and relative mass window of $10 \mathrm{ppm}$. Isotopes were excluded. Additionally, only 1 data dependent scan was performed per precursor (only the most intense charge state selected). lons were injected for all 
Di Sanzo, Spengler, et al.

1 a background ion ( $\mathrm{m} / \mathrm{z}$ 445.12003) was applied. For data acquisition and processing of the raw

2 data, Xcalibur 4.0 (Thermo Scientific, Waltham, MS, USA) and Tune version 2.1 were employed.

Data processing for DDA for CMLpepIP

5 Software MaxQuant (version 1.5.3.28) was used to search the data. The data were searched

6 against species-specific databases (Uniprot Mus musculus or Homo sapiens, reviewed entry only,

7 release 2016_01) with a list of common contaminants appended. The data were searched with

8 the following modifications: carbamidomethyl (C) as fixed modification, and oxidation (M), acetyl

9 (protein $\mathrm{N}$-term) and carboxymethyllysine $(\mathrm{CML})$ as variable modifications. The mass error

10 tolerance for the full scan MS spectra was set at $20 \mathrm{ppm}$ and for the MS/MS spectra at 0.5 Da. A

11 maximum of 3 missed cleavages were allowed. Peptide and protein level 1 \% FDR were applied

12 using a target-decoy strategy (Elias and Gygi, 2007). MaxQuant outputs were then used to 13 perform qualitative analyses. In addition, highly confident CML sites were defined using these 14 additional parameters: Posterior Error Probability $<0.05$, score $>50$, score difference $>5$, 15 localization probability $>0.75$.

Enrichment of acetylated peptides

HUVEC pellets (3 biological replicates per condition/time point) corresponding to approximately $500 \mu \mathrm{g}$ of proteins were used. Cell pellets were thawed, lysed and digested as described in the paragraph "Sample preparation for mass spectrometry-based proteomics". The digested peptides were acidified with $10 \%(\mathrm{v} / \mathrm{v})$ trifluoroacetic acid and then desalted with Waters Oasis® HLB 96well Plate $30 \mu \mathrm{m}$ following manufacturer instructions. The eluates were dried down and dissolved in $500 \mu \mathrm{l}$ of IP buffer (50 mM MOPS pH 7.3, 10 mM KPO4 pH 7.5, 50 mM NaCl, 2.5 mM Octyl $\beta$ D-glucopyranoside) to reach a peptide concentration of $1 \mu \mathrm{g} / \mu \mathrm{l}$, followed by sonication in a Bioruptor ( 5 cycles with $1 \mathrm{~min} \mathrm{ON}$ and $30 \mathrm{~s}$ OFF with high intensity at $20^{\circ} \mathrm{C}$ ). $10 \%$ of the sample was kept as it is in order to use it as input. Agarose beads coupled to antibody against acetyl lysine were washed three times with washing buffer (20 mM MOPS pH 7.4, $10 \mathrm{mM} \mathrm{KPO}_{4} \mathrm{pH} 7.5$, $50 \mathrm{mM} \mathrm{NaCl}$ ) before incubation with each sample-peptide for $1.5 \mathrm{~h}$ on a rotating well at $750 \mathrm{rpm}$ (STARLAB Tube roller Mixer RM Multi-1). Samples were transferred into Clearspin filter microtubes $(0.22 \mu \mathrm{m})$ (Dominique Dutscher SAS, Brumath, France) and centrifuged at $4{ }^{\circ} \mathrm{C}$ for 1 min at 2,000 $\mathrm{g}$. Beads were washed first with IP buffer (three times), then with washing buffer

32 (three times) and finally with $5 \mathrm{mM}$ ammonium bicarbonate (three times). Thereupon, the enriched 33 peptides were then eluted first in basic condition using $50 \mathrm{mM}$ aqueous $\mathrm{NH}_{3}$, then using $0.1 \%$ $34(\mathrm{v} / \mathrm{v})$ trifluoroacetic acid in 10\% (v/v) 2-propanol and finally with $0.1 \%(\mathrm{v} / \mathrm{v})$ trifluoroacetic acid. 
Di Sanzo, Spengler, et al.

1 Elutions were then dried down and reconstituted in MS buffer A (5\% (v/v) acetonitrile, $0.1 \%(\mathrm{v} / \mathrm{v})$

2 formic acid), acidified with $10 \%(\mathrm{v} / \mathrm{v})$ trifluoroacetic acid and then desalted with Waters Oasis ${ }^{\circledR}$

3 HLB $\mu$ Elution Plate $30 \mu \mathrm{m}$. Desalted peptides were finally dissolved in MS buffer A and analyze

4 by LC-MS/MS.

5

6 LC-MS/MS based on Data Independent Acquisition (DIA) for acetylated peptides

7 Peptides were separated using the nanoAcquity UPLC system (Waters) fitted with a trapping 8 (nanoAcquity Symmetry C18, $5 \mu \mathrm{m}, 180 \mu \mathrm{m} \times 20 \mathrm{~mm}$ ) and an analytical column (nanoAcquity BEH C18, $1.7 \mu \mathrm{m}, 75 \mu \mathrm{m} \times 250 \mathrm{~mm}$ ). The outlet of the analytical column was coupled directly to an Orbitrap Fusion Lumos (Thermo Fisher Scientific, Waltham, MA. USA) using the Proxeon nanospray source. Solvent A was water, $0.1 \%(\mathrm{v} / \mathrm{v})$ formic acid and solvent B was acetonitrile, $0.1 \%(\mathrm{v} / \mathrm{v})$ formic acid. The samples (approx. $1 \mu \mathrm{g}$ for DDA and $3 \mu \mathrm{g}$ for DIA) were loaded with a constant flow of solvent $A$ at $5 \mu \mathrm{l} / \mathrm{min}$ onto the trapping column. Trapping time was $6 \mathrm{~min}$. Peptides were eluted via the analytical column with a constant flow of $0.3 \mu \mathrm{l} / \mathrm{min}$. During the elution step, the percentage of solvent B increased in a non-linear fashion from $0 \%$ to $40 \%$ in $40 \mathrm{~min}$. Total runtime was $60 \mathrm{~min}$, including clean-up and column re-equilibration. The peptides were introduced into the mass spectrometer via a Pico-Tip Emitter $360 \mu \mathrm{m}$ OD x $20 \mu \mathrm{m}$ ID; $10 \mu \mathrm{m}$ tip (New Objective) and a spray voltage of $2.2 \mathrm{kV}$ was applied. The capillary temperature was set at $300{ }^{\circ} \mathrm{C}$. The RF lens was set to $30 \%$. Data from each sample were first acquired in DDA mode. The conditions were as follows: Full scan MS spectra with mass range $350-1650 \mathrm{~m} / \mathrm{z}$ were acquired in profile mode in the Orbitrap with resolution of 60,000 FWHM. The filling time was set at maximum of $50 \mathrm{~ms}$ with limitation of $2 \times 10^{5}$ ions. The "Top Speed" method was employed to take the maximum number of precursor ions (with an intensity threshold of $5 \times 10^{4}$ ) from the full scan MS for fragmentation (using HCD collision energy, 30 \%) and quadrupole isolation (1.4 Da window) and measurement in the Orbitrap (resolution 15,000 FWHM, fixed first mass $120 \mathrm{~m} / \mathrm{z}$ ), with a cycle time of $3 \mathrm{~s}$. The MIPS (monoisotopic precursor selection) peptide algorithm was employed but with relaxed restrictions when too few precursors meeting the criteria were found. The fragmentation was performed after accumulation of $2 \times 10^{5}$ ions or after filling time of $22 \mathrm{~ms}$ for each precursor ion (whichever occurred first). MS/MS data were acquired in centroid mode. Only multiply charged $\left(2^{+}-7^{+}\right)$precursor ions were selected for MS/MS. Dynamic exclusion was employed with maximum retention period of $15 \mathrm{~s}$ and relative mass window of $10 \mathrm{ppm}$. Isotopes were excluded. In order to improve the mass accuracy, internal lock mass correction using a background ion ( $\mathrm{m} / \mathrm{z} 445.12003$ ) was applied. For data acquisition and processing of the raw data 
Di Sanzo, Spengler, et al.

1 For the DIA data acquisition the same gradient conditions were applied to the LC as for the DDA

2 and the MS conditions were varied as described: Full scan MS spectra with mass range 350-

$31650 \mathrm{~m} / \mathrm{z}$ were acquired in profile mode in the Orbitrap with resolution of 120,000 FWHM. The

4 filling time was set at maximum of $20 \mathrm{~ms}$ with limitation of $5 \times 10^{5}$ ions. DIA scans were acquired

5 with 30 mass window segments of differing widths across the MS1 mass range with a cycle time

6 of $3 \mathrm{~s}$. HCD fragmentation (30\% collision energy) was applied and MS/MS spectra were acquired

7 in the Orbitrap with a resolution of 30,000 FWHM over the mass range $200-2000 \mathrm{~m} / \mathrm{z}$ after

8 accumulation of $2 \times 10^{5}$ ions or after filling time of $70 \mathrm{~ms}$ (whichever occurred first). lons were

9 injected for all available parallelizable time). Data were acquired in profile mode.

Data processing for DIA for acetylated peptides

12 DpD (DDA plus DIA) libraries were created by searching both DDA and DIA runs using 13 Spectronaut Pulsar (v.13), as described in "Data processing for DIA" with the following 14 modification: acetyl $(\mathrm{K})$ was included as variable modification. The library contained 17,051 15 precursors, corresponding to 3,227 protein groups using Spectronaut protein inference. DIA data 16 were then uploaded and searched against this spectral library using Spectronaut Professional 17 (v.13) and default settings. Intensities of precursors deriving from acetylated peptide were 18 obtained from the peptide report table and filtered for a localization score $>=0.75$ and further 19 processed using in house written scripts in $R$ (v.3.6.3) and $R$ studio server (v. 1.2.5042). 20 Intensities were summarized at the level of acetylation site by summing the intensities of all the 21 precursors containing a given acetylation sites. Acetylation site intensities were normalized across runs by $\log _{2}$ transformation and median centering.

Parallel Reaction Monitoring (PRM) for CML modified peptides

25 Twenty-four peptides containing CML-modification were selected among the most confident and 26 consistently identified peptides from CMLpepIP and their isotopically labelled version (heavy 27 Arginine (U-13C6;U-15N4) or Lysine (U-13C6; U-15N2) at the C-term was added) synthesized by JPT Peptide Technologies GmbH (Berlin, Germany). Peptides were delivered as lyophilized and reconstituted in $20 \%(\mathrm{v} / \mathrm{v})$ acetonitrile, $0.1 \%(\mathrm{v} / \mathrm{v})$ formic acid and further pooled together in a ratio 1:1. An aliquot of the pooled peptides, corresponding to approximatively $150 \mathrm{fmol}$ per peptide, was analyzed by both DDA and DIA LC-MS/MS and used for assay generation using

32 Spectrodive v.9 (Biognosys AG, Schlieren, Switzerland). Assays were successfully developed for 
Di Sanzo, Spengler, et al.

1 Following assay development, the heavy synthetic peptide pool was used to evaluate the limit of 2 detection (LOD) and limit of blank (LOB). Synthetic peptide pool was mixed with $200 \mathrm{ng} / \mu \mathrm{l}$ of

3 digested yeast peptides at concentration from $45 \mathrm{fmol}$ to $5760 \mathrm{fmol}$ on column and measured in

4 triplicate using PRM. Peptides were separated using a nanoAcquity UPLC M-Class system

5 (Waters, Milfors, MA, USA)) with a trapping (nanoAcquity Symmetry C18, $5 \mu \mathrm{m}, 180 \mu \mathrm{m} \times 20 \mathrm{~mm}$ )

6 and an analytical column (nanoAcquity BEH C18, $1.7 \mu \mathrm{m}, 75 \mu \mathrm{m} \times 250 \mathrm{~mm}$ ). The outlet of the

7 analytical column was coupled directly to a Q-exactive HF-X (Thermo Fisher, Waltham, MA,

8 Germany) using the Proxeon nanospray source. Solvent A was water, $0.1 \%$ (v/v) formic acid and

9 solvent B was acetonitrile, $0.1 \%(\mathrm{v} / \mathrm{v})$ formic acid. Peptides were eluted via the analytical column

10 with a constant flow of $0.3 \mu \mathrm{l} / \mathrm{min}$. During the elution step, the percentage of solvent B increased

11 in a non-linear fashion from $0 \%$ to $40 \%$ in $40 \mathrm{~min}$. Total runtime was $60 \mathrm{~min}$, including clean-up

12 and column re-equilibration. PRM acquisition was performed in a scheduled fashion for the

13 duration of the entire gradient (after instrument calibration in an unscheduled mode) using the

14 "DIA" mode with the following settings: resolution 120,000 FWHM, AGC target $3 \times 10^{6}$, maximum

15 injection time (IT) $250 \mathrm{~ms}$, isolation window $0.4 \mathrm{~m} / \mathrm{z}$. For each cycle, a "full MS" scan was acquired with the following settings: resolution 120,000 FWHM, AGC target $3 \times 10^{6}$, maximum injection

17 time (IT) $10 \mathrm{~ms}$, scan range 350 to $1650 \mathrm{~m} / \mathrm{z}$. Peak group identification and quantification was performed using SpectroDive v9. Quantification was performed using spike-in approach. Thereby, the summed height of all the identified transitions was used to estimate the quantity of each peptide. LOQ and LOB was performed using the R package MSstat (Choi et al., 2014) using non-

21 linear mode.

22 For CML site quantification in aging organs, not enriched digested peptides were spiked with 23 synthetic heavy peptides at a concentration of $144 \mathrm{fmol} / \mu \mathrm{l}$ and analyzed by scheduled PRM as described above, using the following sub-panel:

\begin{tabular}{|l|l|l|c|}
\hline Protein Access & GeneID & Peptide sequence & Charge state \\
\hline P41216 & AcsI1 & IFGQANTSLK[CML]R & $+2,+3$ \\
\hline P48036 & Anxa5 & DLVDDLK[CML]SELTGK & +2 \\
\hline Q03265 & Atp5a1 & VVDALGNAIDGK[CML]GPIGSK & $+2,+3$ \\
\hline P56480 & Atp5b & GVQK[CML]ILQDYK & +2 \\
\hline Q91VR2 & Atp5c1 & THSDQFLVSFK[CML]DVGR & +3 \\
\hline Q9CQQ7 & Atp5f1 & QIQDAIDMEK[CML]AQQALVQK & +2 \\
\hline Q9DB20 & Atp50 & VSLAVLNPYIK[CML]R & +3 \\
\hline P24270 & Cat & DAQLFIQK[CML]K & +2 \\
\hline Q8BH95 & Echs1 & AFAAGADIK[CML]EMQNR & +3 \\
\hline
\end{tabular}


Di Sanzo, Spengler, et al.

\begin{tabular}{|l|l|l|c|} 
Q9DBM2 & Ehhadh & FAQTVIGK[CML]PIEPR & $+2,+3$ \\
\hline Q8BMS1 & Hadha & FVDLYGAQK[CML]VVDR & +3 \\
\hline P01942 & Hba & FLASVSTVLTSK[CML]YR & +3 \\
\hline P62806 & Hist1h4a & TVTAMDVVYALK[CML]R & +3 \\
\hline Q7TMF3 & Ndufa12 & MELVEVLK[CML]R & +2 \\
\hline P48962 & SIc25a4 & IAK[CML]DEGANAFFK & +3 \\
\hline Q78IK2 & Usmg5 & AGAESDGQFQFTGIK[CML]K & +2 \\
\hline
\end{tabular}

Peptides quantities were normalized across samples by dividing for the integrated intensity of the Base Peak Chromatogram extracted for each sample from "full MS" scans using Xcalibur v4.1.

Immunoblot for mono and polyubiquitinated proteins of MEF cells treated with glyoxal

The same cell lysates used for proteasome activity assay were used. Lysates were thawed and centrifugated at $20817 \times \mathrm{g}$, for $15 \mathrm{~min}$ at $4{ }^{\circ} \mathrm{C}$ to remove debris and the supernatant was transferred to a new tube. Based on EZQ assay performed on it, $20 \mu \mathrm{g}$ of proteins were used. Samples were sonicated for 10 cycles ( $1 \mathrm{~min}$ ON and 30s OFF) using a Bioruptor Plus with $4 \mathrm{x}$ loading buffer (1.5 M Tris .pH 6.8, 20\% (w/v) SDS, $85 \%$ (v/v) glycerin, $5 \%$ (v/v) $\beta$ mercaptoethanol). Proteins were separated on 4-20\% Mini-Protean® TGX ${ }^{\mathrm{TM}}$ Gels (BioRad, Neuberg, Germany) by sodium dodecyl sulfate polyacrylamide gel electrophoresis (SDS-PAGE) using a Mini-Protean ${ }^{\circledR}$ Tetra Cell system (BioRad, Neuberg, Germany). Proteins were transferred to a nitrocellulose membrane (Millipore) using a Trans-Blot ${ }^{\circledR}$ Turbo ${ }^{\text {TM }}$ Transfer Starter System. Membranes were stained with PonceauS for 5 min on a shaker (Heidolph Duomax 1030), washed with milliQ water, imaged on a Molecular Imager ChemiDocTM XRS+ Imaging system (BioRad, Neuberg, Germany) and destained by 2 washes with PBS and 2 washes in TBST for 5 min (Trisbuffered saline (TBS, $25 \mathrm{mM}$ Tris, $75 \mathrm{mM} \mathrm{NaCl}$ ), with $0.5 \%$ (v/v) Tween-20). After incubation for $1 \mathrm{~h}$ in blocking buffer (3\% bovine serum albumin (w/v) in TBST), membranes were stained overnight with primary antibodies against mono- and K29-, K48-, and K63-linked mono- and polyubiquitinylated proteins or $\beta$-actin diluted in blocking buffer $(1: 5000)$ at $4{ }^{\circ} \mathrm{C}$ on a tube roller (BioCote ${ }^{\circledR}$ Stuart ${ }^{\circledR}$ SRT6). Membranes were washed 3 times with TBST for 10 min at room temperature (RT) and incubated with horse radish peroxidase coupled secondary antibodies at RT for $1 \mathrm{~h}$ (1:2000 in $0.3 \%(\mathrm{w} / \mathrm{v}) \mathrm{BSA}$ in TBST). After 3 more washes for $10 \mathrm{~min}$ in TBST, chemiluminescent signals were detected using an ECL (enhanced chemiluminescence) detection kit (Thermo Fisher Scientific, Waltham, MA, USA). Signals were acquired on the Molecular Imager ChemiDocTM XRS+ Imaging system (BioRad, Neuberg, Germany) and analyzed using the Fiji application (Schindelin et al., 2012). Membranes were stripped using stripping buffer (1\% (w/v) 
Di Sanzo, Spengler, et al.

SDS, $0.2 \mathrm{M}$ glycine, $\mathrm{pH}$ 2.5), washed 3 times with TBST, blocked and incubated with the second

2 primary antibody, if necessary.

3

$4 \quad$ Proteasome activity assay on MEF cells treated with glyoxal

5 Proteasome activity assay was performed using the 20S proteasome activity assay kit (Millipore,

6 Billerica, MA, USA) following the manufacturer instructions. Briefly, cell pellets were thawed and 7 ice-cold lysis buffer (50 mM HEPES pH 7.5, 5 mM EDTA, 150 mM NaCl, 1 \% (v/v) Triton X-100, 82 mM ATP) was added and left on ice for 30 min with quick vortex steps any 10 min. Samples 9 were centrifuged at $20817 \times \mathrm{g}$, for $15 \mathrm{~min}$ at $4^{\circ} \mathrm{C}$ to remove any debris. For protein estimation, a small aliquot was used in order to perform EZQ® Protein Quantitation Kit (Thermo Scientific,

11 Waltham, MA, USA). $50 \mu \mathrm{g}$ of protein extract were incubated with fluorophore-linked peptide substrate (LLVY-7-amino-4-methylcoumarin [AMC], from the same kit) for $60 \mathrm{~min}$ at $37^{\circ} \mathrm{C}$. Proteasome activity was measured by quantification of fluorescent units from cleaved AMC at $380 / 460 \mathrm{~nm}$ using a microplate reader m1000 (Tecan). Samples were measured together with positive control supplied with the kit.

\section{Glyoxalase 1 activity assay}

Glyoxalase 1 activity was measured using the ab241019 Glyoxalase I Assay Kit (Colorimetric,

Abcam, Cambridge, UK) following manufacturer instructions. Briefly, equal volumes of tissue homogenates (obtained as described above) from heart, liver and kidney, corresponding to an estimated protein amount of $50 \mu \mathrm{g}$ were analyzed. The substrate mix was prepared and left for 10 min at RT in the darkness to allow the formation of hemimercaptal. Afterwards, samples were transferred to a 96 well-plate and the substrate mix was added. The formation of S-Dlactoylglutathione (SLG) was monitored for $30 \mathrm{~min}$ in a kinetic mode by using a microplate reader m1000 (Tecan) at OD $240 \mathrm{~nm}$. The activity was then calculated using the formula suggested by the vendors and normalized for equal loading using immunoblot against beta-actin (as described in "Immunoblot for mono and polyubiquitinated proteins of MEF cells treated with glyoxal") performed on the same homogenates.

\section{Other data analyses}

31 Gene Ontology enrichment based on ClueGO v2.5.6 (Bindea et al., 2009) was performed using 32 the table S2 (highly confident sites) as input, and by applying the following parameters: for heart 33 (Kappa score threshold 0.4, minimum percentage $=5$ and number of genes $=3$ ), for kidney (Kappa score threshold 0.4 , minimum percentage $=2$ and number of genes $=3$ ) and for liver (Kappa score 
Di Sanzo, Spengler, et al.

1 threshold 0.4 , minimum percentage $=2$ and number of genes $=3$ ). Statistical test used $=$

2 Enrichment/depletion (Two-side hypergeometric test). For the overlap between HUVEC cells and

3 MEF cells, the following parameters were applied: Kappa score threshold 0.4, minimum

4 percentage $=4$ and number of gene $=2$ ). Statistical test used $=$ Enrichment/depletion $($ Two-side

5 hypergeometric test).

6 KEGG pathway and Gene Ontology enrichments for MEF and HUVEC total proteome were 7 performed by Gene Set Enrichment Analysis (GSEA) with WebGestalt (Liao et al., 2019) using

8 the entire lists of quantified proteins ranked on the basis of the measured log 2 fold changes.

HUVEC lysis and western blot

HUVEC were lysed in ice-cold Tris buffer (50 mM Tris (pH 7.4), 2 mM EDTA, 1 mM EGTA, 50 $\mathrm{mM} \mathrm{NaF}, 10 \mathrm{mM} \mathrm{Na}_{4} \mathrm{P}_{2} \mathrm{O}_{7}, 1 \mathrm{mM} \mathrm{Na}_{3} \mathrm{VO}_{4}, 1 \mathrm{mM}$ DTT, 1 \% Triton X-100, 0.1 \% SDS, 1 mM PMSF, $10 \mu \mathrm{l} / \mathrm{ml}$ protease inhibitor cocktail) for $15 \mathrm{~min}$ on ice, scraped and centrifuged (700 x g, $6 \mathrm{~min}$ ). Aliquots of supernatants were used for protein determination according to Lowry. Lysates were supplemented with Laemmli buffer, subjected to SDS-PAGE (25-50 $\mathrm{\mu g}$ lysate protein/lane) and blotted onto polyvinylidene difluoride (PVDF) membranes. The membranes were blocked for $1 \mathrm{~h}$ in TBST (20 mM Tris (pH 7.6), $137 \mathrm{mM} \mathrm{NaCl}, 0.1 \%$ (w/v) Tween® 20) containing $5 \%$ non-fat dried skimmed milk. Thereafter, blots were incubated with primary antibodies (diluted in TBST containing $5 \%$ BSA) overnight at $4{ }^{\circ} \mathrm{C}$ followed by incubation with horseradish peroxidaseconjugated secondary antibodies for $1 \mathrm{~h}$. Proteins were detected using the enhanced chemiluminescence (ECL) reagent (GE Healthcare, Chicago, IL, USA) or Western Lightning PlusECL reagents (Perkin Elmer, Waltham, MA, USA). The intensity of bands was quantified by densitometry using the ImageJ software (NIH, Bethesda, MD, US). Phospho- and acetylationspecific signals were normalized to the signal of the respective total proteins. For evaluation of protein expression, the signals were normalized to $\beta$-actin.

\section{5-Bromo-2'-deoxyuridine (BrdU) proliferation assay}

Glyoxal treatment of HUVEC was performed for $24 \mathrm{~h}$ in cell culture dishes and, after reseeding, for another $24 \mathrm{~h}$ in 24-well plates. Thereafter, cells were starved in starvation medium (M199, 2 $\%$ FCS, $7.5 \mathrm{U} / \mathrm{ml}$ heparin, $680 \mu \mathrm{M}$ glutamine, $100 \mathrm{U} / \mathrm{ml}$ penicillin, $100 \mu \mathrm{g} / \mathrm{ml}$ streptomycin) for $4 \mathrm{~h}$ and stimulated with bFGF for $24 \mathrm{~h}$. DNA synthesis was analyzed using the Cell Proliferation ELISA, BrdU (colorimetric) kit from Roche Diagnostics (Mannheim, Germany) according to the 
Di Sanzo, Spengler, et al.

1 BrdU-antibody (1:100) were added per well and incubated for 75 min protected from light. Cells

2 were washed three times with PBS before adding $200 \mu \mathrm{l}$ substrate solution. Reaction was stopped

3 after 5-20 min depending on the color development by adding $50 \mu \mathrm{l}$ of $1 \mathrm{M} \mathrm{H}_{2} \mathrm{SO}_{4}$ for $1 \mathrm{~min}$. The

4 solution was transferred into a 96-well plate and absorption was measured at $450 \mathrm{~nm}$.

CFSE proliferation assay

7 HUVEC were washed twice with warm $\left(37^{\circ} \mathrm{C}\right)$ HEPES buffer containing $0.25 \%$ human serum

8 albumin (HEPES/HSA) and incubated with $5 \mu \mathrm{M}$ CFSE for $15 \mathrm{~min}$ at $37^{\circ} \mathrm{C}$. After two washing

9 steps with warm HEPES/FCS, cells were incubated with glyoxal in $1 \mathrm{ml}$ experimental medium for 10 the indicated times. Thereafter, cells were washed twice with PBS, detached with $300 \mu \mathrm{l}$ 11 trypsin/EDTA and transferred to $700 \mu \mathrm{l}$ of HEPES/FCS. The cell suspension was pooled with 1 $12 \mathrm{ml} \mathrm{HEPES/FCS} \mathrm{obtained} \mathrm{after} \mathrm{rinsing} \mathrm{the} \mathrm{dish.} 10 \mathrm{ml}$ of HEPES buffer were added and samples 13 centrifuged (500 x g, $1 \mathrm{~min}$ ). Pellets were resuspended in $300 \mu \mathrm{l}$ PBS and subjected to flow 14 cytometric analysis. Median values were evaluated using the FlowJo ${ }^{\mathrm{TM}}$ software (Becton, 15 Dickinson and Company, Ashland, OR, US).

Glyoxal treatment was performed for $24 \mathrm{~h}$ in $90 \mathrm{~mm}$-cell culture dishes and, during generation of spheroids, for another $24 \mathrm{~h}$ in 96-well plates. Spheroids were prepared as previously described (Spengler et al., 2018). In brief, cells suspended in growth medium were mixed at a 4:1 ratio with methyl cellulose $(12 \mathrm{mg} / \mathrm{ml})$ and 3000 cells/well were cultured in 96-well round-bottom plates for $24 \mathrm{~h}$. The formed spheroids were collected, centrifuged (200 x g, $4 \mathrm{~min}$ ) and washed with HEPES buffer. Then, spheroids were transferred to a fibrinogen solution (1.8 $\mathrm{mg} / \mathrm{ml}$ in HEPES buffer) containing $20 \mathrm{U} / \mathrm{ml}$ aprotinin to obtain a suspension with approximately 100 spheroids per $\mathrm{ml} .300$ $\mu \mathrm{l}$ of this suspension together with $0.2 \mathrm{U}$ thrombin were added per well of a 24-well plate. The plate was incubated for $20 \mathrm{~min}$ at $37^{\circ} \mathrm{C}$ to allow the formation of a fibrin gel. To equilibrate the gel with medium, M199 containing $2 \%$ FCS, $680 \mu \mathrm{M}$ glutamine, $100 \mathrm{U} / \mathrm{ml}$ penicillin and $100 \mu \mathrm{g} / \mathrm{ml}$ streptomycin was added twice for $15 \mathrm{~min}$. Thereafter, spheroids were cultured in the same medium and stimulated with $50 \mathrm{ng} / \mathrm{ml}$ VEGF for $24 \mathrm{~h}$. Finally, spheroids were fixed on ice by adding $1 \mathrm{ml} 4 \%$ paraformaldehyde per well for $10 \mathrm{~min}$. After two washing steps with PBS, spheroid sprouting was viewed by light microscopy and pictures were taken (AxioVert 200, Carl

32 Zeiss, Oberkochen, Germany). The number of sprouts was analyzed using cellSens image analysis software (Olympus, Tokyo, Japan). 
Di Sanzo, Spengler, et al.

Cell synchronization with double thymidine block

2 Cells were synchronized as described previously (Amin and Varma, 2017). Briefly, one day after

3 seeding $2 \mathrm{mM}$ thymidine was added and incubated with cells for $18 \mathrm{~h}$. After washing (twice with

4 PBS, once with M199), cells were cultured in full growth medium for $9 \mathrm{~h}$ and subsequently

5 incubated with $2 \mathrm{mM}$ thymidine for another $18 \mathrm{~h}$. Cells were washed as described and glyoxal

6 was added in experimental medium for the indicated times.

Cell cycle analysis

9 During the last 30 min of glyoxal treatment, $10 \mu \mathrm{M}$ 5-ethynyl-2'-deoxyuridine (EdU) were added 10 to HUVEC cultured on $90 \mathrm{~mm}$-dishes. Cells were washed twice with PBS, detached with $1 \mathrm{ml}$ 11 trypsin/EDTA and transferred to $4 \mathrm{ml}$ of HEPES/FCS. The cell suspension was pooled with $4 \mathrm{ml}$ 12 HEPES/FCS obtained after rinsing the dish and samples were centrifuged. All centrifugations 13 were carried out at $500 \times \mathrm{g}$ for $3 \mathrm{~min}$ at room temperature if not otherwise stated. Cell pellets were 14 washed once in $1 \mathrm{ml}$ BSA buffer (1 \% BSA in PBS), resuspended in $100 \mu \mathrm{l}$ of the same buffer, 15 fixed with $100 \mu \mathrm{l}$ of $4 \%$ paraformaldehyde for $15 \mathrm{~min}$, centrifuged and resuspended in $300 \mu \mathrm{l}$ PBS. $700 \mu$ l of $100 \%$ ethanol were added dropwise under constant gentle shaking and samples were frozen overnight. The next day, cells were centrifuged (700 x g, $3 \mathrm{~min}, \mathrm{RT})$, washed in $1 \mathrm{ml}$ BSA buffer and permeabilized in $100 \mu$ Triton-based BSA buffer (TBB, $0.2 \%$ Triton X-100 in BSA buffer) for $30 \mathrm{~min}$. Then, cells were centrifuged, resuspended in $500 \mu \mathrm{l}$ BSA buffer, incubated for $1 \mathrm{~h}$, centrifuged again and incubated in $150 \mu$ of primary antibody solution (1:200 p-H3 (S10) antibody in TBB) for $2 \mathrm{~h}$. This was followed by another addition of $500 \mu \mathrm{l}$ TBB, centrifugation and incubation of cells in $150 \mu \mathrm{l}$ of secondary antibody solution (1:500 AF488 goat anti-rabbit antibody in TBB) for $1 \mathrm{~h}$. Next, after adding $500 \mu \mathrm{l}$ TBB, centrifugation and an additional washing with $1 \mathrm{ml}$ BSA buffer, cells were incubated in $100 \mu$ of Click-iT reaction cocktail $\left(2.5 \mathrm{mM} \mathrm{CuSO}_{4}, 1: 200\right.$ AF647 azide, $50 \mathrm{mM}$ sodium ascorbate in PBS) for $30 \mathrm{~min}$. Subsequently, another washing with $1 \mathrm{ml}$ BSA buffer was performed and cells were incubated in $300 \mu \mathrm{lSA}$ buffer containing $1 \mu \mathrm{g}$ DAPI for $30 \mathrm{~min}$. Samples were subjected to flow cytometric analysis with triple detection of AF488, AF647 and DAPI. Percentages of cells in the respective cell cycle phases were evaluated using the FlowJo ${ }^{\mathrm{TM}}$ software.

\section{Seahorse analysis of cells}

32 HUVEC were seeded into Seahorse XF96 Cell Culture Microplates (3,000 cells/well; Agilent 33 Technologies, Santa Clara, CA, USA), incubated for $24 \mathrm{~h}$ and then treated with glyoxal for $48 \mathrm{~h}$. 34 Mito stress test: Medium was replaced with Seahorse XF Base Medium (103334-100, Agilent 
Di Sanzo, Spengler, et al.

1 Technologies, pH adjusted to 7.4), supplemented with $10 \mathrm{mM} \mathrm{D-glucose,} 2 \mathrm{mM}$ L-glutamine and

$21 \mathrm{mM}$ sodium pyruvate. Cells were then cultured for another hour in a $\mathrm{CO}_{2}$-free incubator at $37^{\circ} \mathrm{C}$.

3 Oxygen consumption rates (OCR) and extracellular acidification rates (ECAR) were monitored at

4 basal conditions and after sequential injections of $2 \mu \mathrm{M}$ oligomycin to block the mitochondrial ATP

5 synthase, $2 \mu \mathrm{M}$ carbonyl cyanide-4-(trifluoromethoxy)phenylhydrazone (FCCP) to uncouple

6 oxidative phosphorylation and $2 \mu \mathrm{M}$ antimycin A to fully inhibit mitochondrial respiration.

7 Glycolysis stress test: Medium was replaced with Seahorse XF Base Medium (pH adjusted to 7.4)

8 supplemented with $2 \mathrm{mM} \mathrm{L-glutamine,} \mathrm{and} \mathrm{cells} \mathrm{were} \mathrm{cultured} \mathrm{for} \mathrm{another} \mathrm{hour} \mathrm{in} \mathrm{a} \mathrm{CO}_{2}$-free

9 incubator at $37{ }^{\circ} \mathrm{C}$. OCR and ECAR were monitored at basal conditions and after sequential

10 injections of $10 \mathrm{mM}$ D-glucose, $2 \mu \mathrm{M}$ oligomycin and $50 \mathrm{mM}$ 2-deoxy-D-glucose, an inhibitor of

11 glycolysis.

12 Measurements in both settings were performed in $3 \mathrm{~min}$ mix and $3 \mathrm{~min}$ measure cycles at $37^{\circ} \mathrm{C}$

13 in six replicates per condition on a Seahorse XFe96 Analyzer (Agilent Technologies). OCR and

14 ECAR were depicted as $\mathrm{pmol} / \mathrm{min}$ and $\mathrm{mpH} / \mathrm{min}$, respectively, and normalized to the exact cell

15 number of each well measured by high-content microscopy. Wave software (Agilent

16 Technologies) was used to analyze the datasets.

High-content microscopy

19 Cell supernatants were removed from the Seahorse XF96 microplate and cells were fixed for 10 20 min with $100 \%$ methanol at room temperature. Cells were then washed once with PBS and 21 incubated for $10 \mathrm{~min}$ with $1 \mu \mathrm{g} / \mathrm{ml} \mathrm{DAPI}$ at room temperature. After two more washing steps with 22 PBS, cell nuclei were counted on an ImageXpress Micro confocal high-content imaging system 23 (Molecular Devices, San Jose, CA, USA).

\section{ATP measurements}

The intracellular ATP content was determined using the ATP Kit SL from Biotherma (Handen, Sweden) according to the manufacturer's protocol. At the end of experimental incubations, cell proteins were denaturated by adding $500 \mu$ ethanol per dish. After evaporation of the ethanol, $250 \mu \mathrm{l}$ Tris buffer of the assay kit was added and one freezing/thawing cycle in liquid nitrogen was performed. Cells were then scraped off, centrifuged (700 x g, $5 \mathrm{~min}$ ) and supernatants subjected to ATP measurements. For normalization, cells in identically treated dishes were lysed with

32 solubilization buffer (100 mM NaOH, $\left.1.9 \mathrm{M} \mathrm{Na}_{2} \mathrm{CO}_{3}, 1 \% \mathrm{SDS}\right)$ and the protein content was 33 determined according to Lowry. 
Di Sanzo, Spengler, et al.

\section{Intracellular and mitochondrial ROS measurement}

230 min before the end of the indicated glyoxal treatment, HUVEC were washed with PBS, $600 \mu \mathrm{l}$

3 of the respective staining solution were added, glyoxal was re-added and incubation was

4 completed. The staining solutions contained $5 \mu \mathrm{M}$ CM-H2DCFDA or $3 \mu \mathrm{M}$ MitoSOX ${ }^{\mathrm{TM}}$ (both

5 Thermo Scientific, MA, Waltham, USA) diluted in HEPES/HSA for the detection of intracellular or

6 mitochondrial ROS, respectively. Cells were washed with PBS, detached with $300 \mu \mathrm{l}$

7 trypsin/EDTA and transferred to $700 \mu \mathrm{l}$ HEPES/FCS. The cell suspension was pooled with $1 \mathrm{ml}$

8 HEPES/FCS obtained from rinsing the dish, $10 \mathrm{ml}$ HEPES buffer were added and cells

9 centrifuged (500 x g, $1 \mathrm{~min}$ ). Cell pellets were resuspended in $300 \mu \mathrm{l}$ PBS and subjected to flow

10 cytometry analysis. Median values were evaluated using the FlowJo ${ }^{\mathrm{TM}}$ software.

\section{Detection of mitochondrial mass}

30 min before the end of the indicated glyoxal treatment HUVEC were washed with PBS and 600 ul of 100 nM MitoTracker ${ }^{\text {TM }}$ (Thermo Scientific, Waltham, MA, USA) diluted in HEPES/HSA were added. Glyoxal was re-added and incubation was completed. Cells were washed with PBS, detached with $300 \mu \mathrm{l}$ trypsin/EDTA and transferred to $700 \mu \mathrm{l}$ HEPES/FCS. The cell suspension was pooled with $1 \mathrm{ml}$ HEPES/FCS obtained from rinsing the dish, $10 \mathrm{ml}$ HEPES/HSA were added and cells centrifuged (500 x g, 1 min). Pellets were resuspended in $300 \mu \mathrm{l} \mathrm{PBS}$ and subjected to flow cytometry analysis. FlowJo ${ }^{\mathrm{TM}}$ software was used to evaluate the median values of MitoTracker ${ }^{\mathrm{TM}}$-positive cells

\section{SA- $\beta$-Gal staining}

After glyoxal incubation, cells were washed twice with $1 \mathrm{ml}$ cold PBS and fixed with $1 \mathrm{ml}$ of a $2 \%$ formaldehyde $/ 0.2 \%$ glutaraldehyde solution for $3 \mathrm{~min}$. SA- $\beta-$ Gal staining was performed as previously described (Debacq-Chainiaux et al., 2009). Briefly, after two washing steps with PBS, $1.5 \mathrm{ml}$ staining solution (40 mM citric acid/Na phosphate buffer, $5 \mathrm{mM} \mathrm{K}_{4}\left[\mathrm{Fe}(\mathrm{CN})_{6}\right] \cdot 3 \mathrm{H}_{2} \mathrm{O}, 5 \mathrm{mM}$ $\mathrm{K}_{3}\left[\mathrm{Fe}(\mathrm{CN})_{6}\right], 150 \mathrm{mM} \mathrm{NaCl}, 2 \mathrm{mM} \mathrm{MgCl}$, 1:20 X-Gal (20 mg/ml in DMF) in water, $\mathrm{pH}$ 6.0) was incubated with cells at $37^{\circ} \mathrm{C}$ overnight. Pictures were taken (EVOS TM FL Auto, Thermo Scientific, Waltham, MA, USA) and the number of SA- $\beta$-Gal-positive cells was counted using ImageJ and normalized to the total cell number.

33 HUVEC were washed with warm $\left(37^{\circ} \mathrm{C}\right)$ HEPES buffer, fixed in ice-cold $4 \%$ paraformaldehyde 34 for 15 min and washed twice with PBS. Cells were permeabilized in PBS containing $0.3 \%$ Triton 
Di Sanzo, Spengler, et al.

$1 \mathrm{X}-100$ for 5 min. Blocking solution (1 \% BSA-C, $5 \%$ goat serum in PBS) was added for $1 \mathrm{~h}$. After

2 two washing steps with PBS, samples were incubated in $\mathrm{yH} 2 \mathrm{~A} . \mathrm{X}$ (S139) antibody diluted in

3 blocking solution (1:400) in a humidified chamber overnight at $4{ }^{\circ} \mathrm{C}$. Cells were washed twice with

$4 \quad$ PBS and incubated with AF488-labelled goat anti-rabbit secondary antibody (1:500 in blocking

5 solution) for $2 \mathrm{~h}$. After two washing steps with PBS, DAPI (1 $\mu \mathrm{g} / \mathrm{ml}$ in PBS) was added for $10 \mathrm{~min}$

6 and cells were washed three times with PBS before mounting the coverslips on microscopic slides

7 using Fluoromount-G.

8

$9 \quad \alpha / \beta$-Tubulin and ac-Tubulin (K40) immunofluorescence staining

10 Washing, fixation and permeabilization of HUVEC were performed as described for $\mathrm{yH} 2 \mathrm{~A} . \mathrm{X}$

11 (S139) staining. Thereafter, cells were incubated for $2 \mathrm{~h}$ with primary antibodies against $\alpha / \beta-$

12 tubulin or ac-tubulin (K40) diluted in blocking solution (1:100). After two washing steps with PBS,

13 an AF488-labelled goat anti-rabbit secondary antibody (1:500 in blocking solution) was added for

$141 \mathrm{~h}$. Cells were washed three times with PBS. Then, DAPI $(1 \mu \mathrm{g} / \mathrm{ml}$ in PBS) was added for $10 \mathrm{~min}$

15 and cells were washed three times with PBS before mounting the coverslips on microscopic slides

using Fluoromount-G. For immunofluorescence, a LEICA DMi8 TCS SP8 inverted laser scanning

17 microscope was employed (Leica Biosystems, Wetzlar, Germany) and pictures were taken.

18 Evaluation was performed via a blinded approach, in which cells with strongly structured tubulin

filaments per high-power field were counted and normalized to the number of DAPI stained nuclei.

Data availability

22 The mass spectrometry proteomics data have been deposited to the ProteomeXchange 23 Consortium via the PRIDE (Perez-Riverol et al., 2019) partner repository with the dataset 24 identifiers:

TMT-10plex data for organ aging proteome: PXD021883

27 DIA for acetylated peptides: PXD021891

28 MQ searches for CMLpepIP: PXD021921

29 DIA for MEF and HUVEC cells: PXD021985

31 In addition, the proteomics data presented in this manuscript are available via a R shiny web

32 server: https://genome.leibniz-fli.de/shiny/orilab/CMLsites/ 
Di Sanzo, Spengler, et al.

\section{References}

Abbas, T., and Dutta, A. (2009). p21 in cancer: intricate networks and multiple activities. Nat Rev Cancer 9, 400-414.

Ahmad, S., Akhter, F., Shahab, U., Rafi, Z., Khan, M.S., Nabi, R., Khan, M.S., Ahmad, K., Ashraf, J.M., and Moinuddin (2018). Do all roads lead to the Rome? The glycation perspective! Semin Cancer Biol 49, 9-19. Amin, M.A., and Varma, D. (2017). Combining Mitotic Cell Synchronization and High Resolution Confocal Microscopy to Study the Role of Multifunctional Cell Cycle Proteins During Mitosis. J Vis Exp.

Ansari, N.A., Chaudhary, D.K., and Dash, D. (2018). Modification of histone by glyoxal: recognition of glycated histone containing advanced glycation adducts by serum antibodies of type 1 diabetes patients. Glycobiology 28, 207-213.

Avery, N.C., and Bailey, A.J. (2005). Enzymic and non-enzymic cross-linking mechanisms in relation to turnover of collagen: relevance to aging and exercise. Scand J Med Sci Sports 15, 231-240.

Baldensperger, T., Eggen, M., Kappen, J., Winterhalter, P.R., Pfirrmann, T., and Glomb, M.A. (2020). Comprehensive analysis of posttranslational protein modifications in aging of subcellular compartments. Sci Rep 10, 7596.

Bao, X., Liu, Z., Zhang, W., Gladysz, K., Fung, Y.M.E., Tian, G., Xiong, Y., Wong, J.W.H., Yuen, K.W.Y., and Li, X.D. (2019). Glutarylation of Histone H4 Lysine 91 Regulates Chromatin Dynamics. Mol Cell 76, 660-675 e669.

Benjamini, Y., and Hochberg, Y. (1995). Controlling the False Discovery Rate: A Practical and Powerful Approach to Multiple Testing. In Journal of the Royal Statistical Society. Series B (Methodological), pp. 289-300.

Bento, C.F., Marques, F., Fernandes, R., and Pereira, P. (2010). Methylglyoxal alters the function and stability of critical components of the protein quality control. PLoS One 5, e13007.

Berges, N., Arens, K., Kreusch, V., Fischer, R., and Di Fiore, S. (2017). Toward Discovery of Novel Microtubule Targeting Agents: A SNAP-tag-Based High-Content Screening Assay for the Analysis of Microtubule Dynamics and Cell Cycle Progression. SLAS Discov 22, 387-398.

Bierhaus, A., Fleming, T., Stoyanov, S., Leffler, A., Babes, A., Neacsu, C., Sauer, S.K., Eberhardt, M., Schnolzer, M., Lasitschka, F., et al. (2012). Methylglyoxal modification of Nav1.8 facilitates nociceptive neuron firing and causes hyperalgesia in diabetic neuropathy. Nat Med 18, 926-933.

Bilova, T., Paudel, G., Shilyaev, N., Schmidt, R., Brauch, D., Tarakhovskaya, E., Milrud, S., Smolikova, G., Tissier, A., Vogt, T., et al. (2017). Global proteomic analysis of advanced glycation end products in the Arabidopsis proteome provides evidence for age-related glycation hot spots. J Biol Chem 292, 1575815776.

Bindea, G., Mlecnik, B., Hackl, H., Charoentong, P., Tosolini, M., Kirilovsky, A., Fridman, W.H., Pages, F., Trajanoski, Z., and Galon, J. (2009). ClueGO: a Cytoscape plug-in to decipher functionally grouped gene ontology and pathway annotation networks. Bioinformatics 25, 1091-1093.

Bollong, M.J., Lee, G., Coukos, J.S., Yun, H., Zambaldo, C., Chang, J.W., Chin, E.N., Ahmad, I., Chatterjee, A.K., Lairson, L.L., et al. (2018). A metabolite-derived protein modification integrates glycolysis with KEAP1-NRF2 signalling. Nature 562, 600-604.

Boodhwani, M., and Sellke, F.W. (2009). Therapeutic angiogenesis in diabetes and hypercholesterolemia: influence of oxidative stress. Antioxid Redox Signal 11, 1945-1959.

Brings, S., Fleming, T., Freichel, M., Muckenthaler, M.U., Herzig, S., and Nawroth, P.P. (2017). Dicarbonyls and Advanced Glycation End-Products in the Development of Diabetic Complications and Targets for Intervention. Int J Mol Sci 18.

Brosch, M., Yu, L., Hubbard, T., and Choudhary, J. (2009). Accurate and sensitive peptide identification with Mascot Percolator. J Proteome Res 8, 3176-3181. 
Di Sanzo, Spengler, et al.

Brouhard, G.J., and Rice, L.M. (2018). Microtubule dynamics: an interplay of biochemistry and mechanics. Nat Rev Mol Cell Biol 19, 451-463.

Brouwers, O., Niessen, P.M., Miyata, T., Ostergaard, J.A., Flyvbjerg, A., Peutz-Kootstra, C.J., Sieber, J., Mundel, P.H., Brownlee, M., Janssen, B.J., et al. (2014). Glyoxalase-1 overexpression reduces endothelial dysfunction and attenuates early renal impairment in a rat model of diabetes. Diabetologia 57, 224-235. Brownlee, M. (1995). The pathological implications of protein glycation. Clin Invest Med 18, 275-281. Buczak, K., Kirkpatrick, J.M., Truckenmueller, F., Santinha, D., Ferreira, L., Roessler, S., Singer, S., Beck, M., and Ori, A. (2020). Spatially resolved analysis of FFPE tissue proteomes by quantitative mass spectrometry. Nat Protoc 15, 2956-2979.

Campisi, J., and d'Adda di Fagagna, F. (2007). Cellular senescence: when bad things happen to good cells. Nat Rev Mol Cell Biol 8, 729-740.

Chaudhuri, J., Bains, Y., Guha, S., Kahn, A., Hall, D., Bose, N., Gugliucci, A., and Kapahi, P. (2018). The Role of Advanced Glycation End Products in Aging and Metabolic Diseases: Bridging Association and Causality. Cell Metab 28, 337-352.

Chen, L., Cui, Y., Li, B., Weng, J., Wang, W., Zhang, S., Huang, X., Guo, X., and Huang, Q. (2020). Advanced glycation end products induce immature angiogenesis in in vivo and ex vivo mouse models. Am J Physiol Heart Circ Physiol 318, H519-H533.

Childs, D., Bach, K., Franken, H., Anders, S., Kurzawa, N., Bantscheff, M., Savitski, M.M., and Huber, W. (2019). Nonparametric Analysis of Thermal Proteome Profiles Reveals Novel Drug-binding Proteins. Mol Cell Proteomics 18, 2506-2515.

Choi, M., Chang, C.Y., Clough, T., Broudy, D., Killeen, T., MacLean, B., and Vitek, O. (2014). MSstats: an R package for statistical analysis of quantitative mass spectrometry-based proteomic experiments. Bioinformatics 30, 2524-2526.

Ciccia, A., and Elledge, S.J. (2010). The DNA damage response: making it safe to play with knives. Mol Cell 40, 179-204.

Debacq-Chainiaux, F., Erusalimsky, J.D., Campisi, J., and Toussaint, O. (2009). Protocols to detect senescence-associated beta-galactosidase (SA-betagal) activity, a biomarker of senescent cells in culture and in vivo. Nat Protoc 4, 1798-1806.

Delgado-Andrade, C. (2016). Carboxymethyl-lysine: thirty years of investigation in the field of AGE formation. Food Funct 7, 46-57.

Elias, J.E., and Gygi, S.P. (2007). Target-decoy search strategy for increased confidence in large-scale protein identifications by mass spectrometry. Nat Methods 4, 207-214.

Ferreira, L.T., Figueiredo, A.C., Orr, B., Lopes, D., and Maiato, H. (2018). Dissecting the role of the tubulin code in mitosis. Methods Cell Biol 144, 33-74.

Fornasiero, E.F., Mandad, S., Wildhagen, H., Alevra, M., Rammner, B., Keihani, S., Opazo, F., Urban, I., Ischebeck, T., Sakib, M.S., et al. (2018). Precisely measured protein lifetimes in the mouse brain reveal differences across tissues and subcellular fractions. Nat Commun 9, 4230.

Franken, H., Mathieson, T., Childs, D., Sweetman, G.M., Werner, T., Togel, I., Doce, C., Gade, S., Bantscheff, M., Drewes, G., et al. (2015). Thermal proteome profiling for unbiased identification of direct and indirect drug targets using multiplexed quantitative mass spectrometry. Nat Protoc 10, 1567-1593.

Friguet, B., Bulteau, A.L., Chondrogianni, N., Conconi, M., and Petropoulos, I. (2000). Protein degradation by the proteasome and its implications in aging. Ann N Y Acad Sci 908, 143-154.

Galligan, J.J., Wepy, J.A., Streeter, M.D., Kingsley, P.J., Mitchener, M.M., Wauchope, O.R., Beavers, W.N., Rose, K.L., Wang, T., Spiegel, D.A., et al. (2018). Methylglyoxal-derived posttranslational arginine modifications are abundant histone marks. Proc Natl Acad Sci U S A 115, 9228-9233.

Gatto, L., and Lilley, K.S. (2012). MSnbase-an R/Bioconductor package for isobaric tagged mass spectrometry data visualization, processing and quantitation. Bioinformatics $28,288-289$. 
Di Sanzo, Spengler, et al.

Giacco, F., Du, X., D'Agati, V.D., Milne, R., Sui, G., Geoffrion, M., and Brownlee, M. (2014). Knockdown of glyoxalase 1 mimics diabetic nephropathy in nondiabetic mice. Diabetes 63, 291-299.

Gimbrone, M.A., Jr., and Garcia-Cardena, G. (2016). Endothelial Cell Dysfunction and the Pathobiology of Atherosclerosis. Circ Res 118, 620-636.

Gkogkolou, P., and Bohm, M. (2012). Advanced glycation end products: Key players in skin aging? Dermatoendocrinol 4, 259-270.

Goodson, H.V., and Jonasson, E.M. (2018). Microtubules and Microtubule-Associated Proteins. Cold Spring Harb Perspect Biol 10.

Guedes, S., Vitorino, R., Domingues, M.R., Amado, F., and Domingues, P. (2011). Glycation and oxidation of histones H2B and H1: in vitro study and characterization by mass spectrometry. Anal Bioanal Chem 399, 3529-3539.

Hamelin, M., Mary, J., Vostry, M., Friguet, B., and Bakala, H. (2007). Glycation damage targets glutamate dehydrogenase in the rat liver mitochondrial matrix during aging. FEBS J 274, 5949-5961.

Heinze, I., Bens, M., Calzia, E., Holtze, S., Dakhovnik, O., Sahm, A., Kirkpatrick, J.M., Szafranski, K., Romanov, N., Sama, S.N., et al. (2018). Species comparison of liver proteomes reveals links to naked molerat longevity and human aging. BMC Biol 16, 82.

Helton, E.S., and Chen, X. (2007). p53 modulation of the DNA damage response. J Cell Biochem 100, 883896.

Hipp, M.S., Kasturi, P., and Hartl, F.U. (2019). The proteostasis network and its decline in ageing. Nat Rev Mol Cell Biol 20, 421-435.

Hodges, N.A., Suarez-Martinez, A.D., and Murfee, W.L. (2018). Understanding angiogenesis during aging: opportunities for discoveries and new models. J Appl Physiol (1985) 125, 1843-1850.

Hornbeck, P.V., Zhang. B., and Skrzypek E. (2015). PhosphoSitePlus, 2014: mutations, PTMs and recalibrations. Nucleic Acids Res. 43 (Database issue): D512-20.

Jang, J.H., Kim, E.A., Park, H.J., Sung, E.G., Song, I.H., Kim, J.Y., Woo, C.H., Doh, K.O., Kim, K.H., and Lee, T.J. (2017). Methylglyoxal-induced apoptosis is dependent on the suppression of c-FLIPL expression via down-regulation of p65 in endothelial cells. J Cell Mol Med 21, 2720-2731.

Janke, C., and Magiera, M.M. (2020). The tubulin code and its role in controlling microtubule properties and functions. Nat Rev Mol Cell Biol 21, 307-326.

Kelmer Sacramento, E., Kirkpatrick, J.M., Mazzetto, M., Baumgart, M., Bartolome, A., Di Sanzo, S., Caterino, C., Sanguanini, M., Papaevgeniou, N., Lefaki, M., et al. (2020). Reduced proteasome activity in the aging brain results in ribosome stoichiometry loss and aggregation. Mol Syst Biol 16, e9596.

Kold-Christensen, R., and Johannsen, M. (2020). Methylglyoxal Metabolism and Aging-Related Disease: Moving from Correlation toward Causation. Trends Endocrinol Metab 31, 81-92.

Kuhla, B., Boeck, K., Luth, H.J., Schmidt, A., Weigle, B., Schmitz, M., Ogunlade, V., Munch, G., and Arendt, T. (2006). Age-dependent changes of glyoxalase I expression in human brain. Neurobiol Aging 27, 815822.

Kuo, L.J., and Yang, L.X. (2008). Gamma-H2AX - a novel biomarker for DNA double-strand breaks. In Vivo 22, 305-309.

Li, P., Chen, D., Cui, Y., Zhang, W., Weng, J., Yu, L., Chen, L., Chen, Z., Su, H., Yu, S., et al. (2018). Src Plays an Important Role in AGE-Induced Endothelial Cell Proliferation, Migration, and Tubulogenesis. Front Physiol 9, 765.

Liao, Y., Wang, J., Jaehnig, E.J., Shi, Z., and Zhang, B. (2019). WebGestalt 2019: gene set analysis toolkit with revamped UIs and APIs. Nucleic Acids Res 47, W199-W205.

Liu, H., Yu, S., Zhang, H., and Xu, J. (2012). Angiogenesis impairment in diabetes: role of methylglyoxalinduced receptor for advanced glycation endproducts, autophagy and vascular endothelial growth factor receptor 2. PLoS One 7, e46720. 
Di Sanzo, Spengler, et al.

Mathieson, T., Franken, H., Kosinski, J., Kurzawa, N., Zinn, N., Sweetman, G., Poeckel, D., Ratnu, V.S., Schramm, M., Becher, I., et al. (2018). Systematic analysis of protein turnover in primary cells. Nat Commun 9, 689.

Minguez, P., Letunic, I., Parca, L., Garcia-Alonso, L., Dopazo, J., Huerta-Cepas, J., and Bork, P. (2015). PTMcode V2: a resource for functional associations of post-translational modifications within and between proteins. Nucleic Acids Res 43, D494-502.

Mir, A.R., uddin, M., Alam, K., and Ali, A. (2014). Methylglyoxal mediated conformational changes in histone H2A-generation of carboxyethylated advanced glycation end products. Int J Biol Macromol 69, 260-266.

Morcos, M., Du, X., Pfisterer, F., Hutter, H., Sayed, A.A., Thornalley, P., Ahmed, N., Baynes, J., Thorpe, S., Kukudov, G., et al. (2008). Glyoxalase-1 prevents mitochondrial protein modification and enhances lifespan in Caenorhabditis elegans. Aging Cell 7, 260-269.

Moriya, J., and Minamino, T. (2017). Angiogenesis, Cancer, and Vascular Aging. Front Cardiovasc Med 4, 65.

Navarrete Santos, A., Jacobs, K., Simm, A., Glaubitz, N., Horstkorte, R., and Hofmann, B. (2017). Dicarbonyls induce senescence of human vascular endothelial cells. Mech Ageing Dev 166, 24-32.

Nigro, C., Leone, A., Fiory, F., Prevenzano, I., Nicolo, A., Mirra, P., Beguinot, F., and Miele, C. (2019). Dicarbonyl Stress at the Crossroads of Healthy and Unhealthy Aging. Cells 8.

Nigro, C., Leone, A., Raciti, G.A., Longo, M., Mirra, P., Formisano, P., Beguinot, F., and Miele, C. (2017). Methylglyoxal-Glyoxalase 1 Balance: The Root of Vascular Damage. Int J Mol Sci 18.

Okonkwo, U.A., and DiPietro, L.A. (2017). Diabetes and Wound Angiogenesis. Int J Mol Sci 18.

Ori, A., Toyama, B.H., Harris, M.S., Bock, T., Iskar, M., Bork, P., Ingolia, N.T., Hetzer, M.W., and Beck, M. (2015). Integrated Transcriptome and Proteome Analyses Reveal Organ-Specific Proteome Deterioration in Old Rats. Cell Syst 1, 224-237.

Oya-Ito, T., Liu, B.F., and Nagaraj, R.H. (2006). Effect of methylglyoxal modification and phosphorylation on the chaperone and anti-apoptotic properties of heat shock protein 27. J Cell Biochem 99, 279-291.

Perez-Riverol, Y., Csordas, A., Bai, J., Bernal-Llinares, M., Hewapathirana, S., Kundu, D.J., Inuganti, A., Griss, J., Mayer, G., Eisenacher, M., et al. (2019). The PRIDE database and related tools and resources in 2019: improving support for quantification data. Nucleic Acids Res 47, D442-D450.

Pischetsrieder, M., Seidel, W., Munch, G., and Schinzel, R. (1999). N(2)-(1-Carboxyethyl)deoxyguanosine, a nonenzymatic glycation adduct of DNA, induces single-strand breaks and increases mutation frequencies. Biochem Biophys Res Commun 264, 544-549.

Portran, D., Schaedel, L., Xu, Z., Thery, M., and Nachury, M.V. (2017). Tubulin acetylation protects longlived microtubules against mechanical ageing. Nat Cell Biol 19, 391-398.

Queisser, M.A., Yao, D., Geisler, S., Hammes, H.P., Lochnit, G., Schleicher, E.D., Brownlee, M., and Preissner, K.T. (2010). Hyperglycemia impairs proteasome function by methylglyoxal. Diabetes 59, 670678.

Rabbani, N., and Thornalley, P.J. (2015). Dicarbonyl stress in cell and tissue dysfunction contributing to ageing and disease. Biochem Biophys Res Commun 458, 221-226.

Ravi, R., Ragavachetty Nagaraj, N., and Subramaniam Rajesh, B. (2020). Effect of advanced glycation end product on paraoxonase 2 expression: Its impact on endoplasmic reticulum stress and inflammation in HUVECs. Life Sci 246, 117397.

Ravichandran, M., Priebe, S., Grigolon, G., Rozanov, L., Groth, M., Laube, B., Guthke, R., Platzer, M., Zarse, K., and Ristow, M. (2018). Impairing L-Threonine Catabolism Promotes Healthspan through MethylglyoxalMediated Proteohormesis. Cell Metab 27, 914-925 e915.

Rayess, H., Wang, M.B., and Srivatsan, E.S. (2012). Cellular senescence and tumor suppressor gene p16. Int J Cancer 130, 1715-1725. 
Di Sanzo, Spengler, et al.

Ritchie, M.E., Phipson, B., Wu, D., Hu, Y., Law, C.W., Shi, W., and Smyth, G.K. (2015). limma powers differential expression analyses for RNA-sequencing and microarray studies. Nucleic Acids Res 43, e47. Rosca, M.G., Mustata, T.G., Kinter, M.T., Ozdemir, A.M., Kern, T.S., Szweda, L.I., Brownlee, M., Monnier, V.M., and Weiss, M.F. (2005). Glycation of mitochondrial proteins from diabetic rat kidney is associated with excess superoxide formation. Am J Physiol Renal Physiol 289, F420-430.

Ruiz-Meana, M., Minguet, M., Bou-Teen, D., Miro-Casas, E., Castans, C., Castellano, J., Bonzon-Kulichenko, E., Igual, A., Rodriguez-Lecoq, R., Vazquez, J., et al. (2019). Ryanodine Receptor Glycation Favors Mitochondrial Damage in the Senescent Heart. Circulation 139, 949-964.

Sadoul, K., and Khochbin, S. (2016). The growing landscape of tubulin acetylation: lysine 40 and many more. Biochem J 473, 1859-1868.

Saez, I., and Vilchez, D. (2014). The Mechanistic Links Between Proteasome Activity, Aging and Age-related Diseases. Curr Genomics 15, 38-51.

Sanghvi, V.R., Leibold, J., Mina, M., Mohan, P., Berishaj, M., Li, Z., Miele, M.M., Lailler, N., Zhao, C., de Stanchina, E., et al. (2019). The Oncogenic Action of NRF2 Depends on De-glycation by Fructosamine-3Kinase. Cell 178, 807-819 e821.

Santos, A.L., and Lindner, A.B. (2017). Protein Posttranslational Modifications: Roles in Aging and AgeRelated Disease. Oxid Med Cell Longev 2017, 5716409.

Sasaki, M., Kajiya, H., Ozeki, S., Okabe, K., and Ikebe, T. (2014). Reactive oxygen species promotes cellular senescence in normal human epidermal keratinocytes through epigenetic regulation of p16(INK4a.). Biochem Biophys Res Commun 452, 622-628.

Schalkwijk, C.G., van Bezu, J., van der Schors, R.C., Uchida, K., Stehouwer, C.D., and van Hinsbergh, V.W. (2006). Heat-shock protein 27 is a major methylglyoxal-modified protein in endothelial cells. FEBS Lett 580, 1565-1570.

Schindelin, J., Arganda-Carreras, I., Frise, E., Kaynig, V., Longair, M., Pietzsch, T., Preibisch, S., Rueden, C., Saalfeld, S., Schmid, B., et al. (2012). Fiji: an open-source platform for biological-image analysis. Nat Methods 9, 676-682.

Sena, C.M., Pereira, A.M., and Seica, R. (2013). Endothelial dysfunction - a major mediator of diabetic vascular disease. Biochim Biophys Acta 1832, 2216-2231.

Shaltiel, I.A., Krenning, L., Bruinsma, W., and Medema, R.H. (2015). The same, only different - DNA damage checkpoints and their reversal throughout the cell cycle. J Cell Sci 128, 607-620.

Shapiro, R., McManus, M.J., Zalut, C., and Bunn, H.F. (1980). Sites of nonenzymatic glycosylation of human hemoglobin A. J Biol Chem 255, 3120-3127.

Sharma-Luthra, R., and Kale, R.K. (1994). Age related changes in the activity of the glyoxalase system. Mech Ageing Dev 73, 39-45.

Sliman, S.M., Eubank, T.D., Kotha, S.R., Kuppusamy, M.L., Sherwani, S.I., Butler, E.S., Kuppusamy, P., Roy, S., Marsh, C.B., Stern, D.M., et al. (2010). Hyperglycemic oxoaldehyde, glyoxal, causes barrier dysfunction, cytoskeletal alterations, and inhibition of angiogenesis in vascular endothelial cells: aminoguanidine protection. Mol Cell Biochem 333, 9-26.

Smuda, M., Henning, C., Raghavan, C.T., Johar, K., Vasavada, A.R., Nagaraj, R.H., and Glomb, M.A. (2015). Comprehensive analysis of maillard protein modifications in human lenses: effect of age and cataract. Biochemistry 54, 2500-2507.

Snow, L.M., Fugere, N.A., and Thompson, L.V. (2007). Advanced glycation end-product accumulation and associated protein modification in type II skeletal muscle with aging. J Gerontol A Biol Sci Med Sci 62, 1204-1210.

Song, Y., and Brady, S.T. (2015). Post-translational modifications of tubulin: pathways to functional diversity of microtubules. Trends Cell Biol 25, 125-136.

Spengler, K., Grosse, S., Kryeziu, N., Knierim, A., and Heller, R. (2018). Studying the Role of AMPK in Angiogenesis. Methods Mol Biol 1732, 519-537. 
Di Sanzo, Spengler, et al.

Spengler, K., Kryeziu, N., Grosse, S., Mosig, A.S., and Heller, R. (2020). VEGF Triggers Transient Induction of Autophagy in Endothelial Cells via AMPKalpha1. Cells 9.

Sudnitsyna, M.V., and Gusev, N.B. (2017). Methylglyoxal and Small Heat Shock Proteins. Biochemistry (Mosc) 82, 751-759.

Sun, L., Bai, Y., and Du, G. (2009). Endothelial dysfunction--an obstacle of therapeutic angiogenesis. Ageing Res Rev 8, 306-313.

Takahashi, A., Ohtani, N., Yamakoshi, K., lida, S., Tahara, H., Nakayama, K., Nakayama, K.I., Ide, T., Saya, $\mathrm{H}$., and Hara, E. (2006). Mitogenic signalling and the p16INK4a-Rb pathway cooperate to enforce irreversible cellular senescence. Nat Cell Biol 8, 1291-1297.

Teissier, T., and Boulanger, E. (2019). The receptor for advanced glycation end-products (RAGE) is an important pattern recognition receptor (PRR) for inflammaging. Biogerontology 20, 279-301.

Thornalley, P.J. (2008). Protein and nucleotide damage by glyoxal and methylglyoxal in physiological systems--role in ageing and disease. Drug Metabol Drug Interact 23, 125-150.

Verzijl, N., DeGroot, J., Oldehinkel, E., Bank, R.A., Thorpe, S.R., Baynes, J.W., Bayliss, M.T., Bijlsma, J.W., Lafeber, F.P., and Tekoppele, J.M. (2000). Age-related accumulation of Maillard reaction products in human articular cartilage collagen. Biochem J 350 Pt 2, 381-387.

Wang, H., Liu, J., and Wu, L. (2009). Methylglyoxal-induced mitochondrial dysfunction in vascular smooth muscle cells. Biochem Pharmacol 77, 1709-1716.

Wang, Y., Hall, L.M., Kujawa, M., Li, H., Zhang, X., O'Meara, M., Ichinose, T., and Wang, J.M. (2019). Methylglyoxal triggers human aortic endothelial cell dysfunction via modulation of the KATP/MAPK pathway. Am J Physiol Cell Physiol 317, C68-C81.

Wang, Y., Yu, Y., Li, G.B., Li, S.A., Wu, C., Gigant, B., Qin, W., Chen, H., Wu, Y., Chen, Q., et al. (2017). Mechanism of microtubule stabilization by taccalonolide AJ. Nat Commun 8, 15787.

Waris, S., Winklhofer-Roob, B.M., Roob, J.M., Fuchs, S., Sourij, H., Rabbani, N., and Thornalley, P.J. (2015). Increased DNA dicarbonyl glycation and oxidation markers in patients with type 2 diabetes and link to diabetic nephropathy. J Diabetes Res 2015, 915486.

Xu, Z., Schaedel, L., Portran, D., Aguilar, A., Gaillard, J., Marinkovich, M.P., Thery, M., and Nachury, M.V. (2017). Microtubules acquire resistance from mechanical breakage through intralumenal acetylation. Science 356, 328-332.

Yamawaki, H., and Hara, Y. (2008). Glyoxal causes inflammatory injury in human vascular endothelial cells. Biochem Biophys Res Commun 369, 1155-1159.

Ye, J., Ai, X., Eugeni, E.E., Zhang, L., Carpenter, L.R., Jelinek, M.A., Freitas, M.A., and Parthun, M.R. (2005). Histone $\mathrm{H} 4$ lysine 91 acetylation a core domain modification associated with chromatin assembly. Mol Cell 18, 123-130.

Zemva, J., Fink, C.A., Fleming, T.H., Schmidt, L., Loft, A., Herzig, S., Kniess, R.A., Mayer, M., Bukau, B., Nawroth, P.P., et al. (2017). Hormesis enables cells to handle accumulating toxic metabolites during increased energy flux. Redox Biol 13, 674-686.

Zhang, Y., and Hunter, T. (2014). Roles of Chk1 in cell biology and cancer therapy. Int J Cancer 134, 10131023.

Zheng, Q., Omans, N.D., Leicher, R., Osunsade, A., Agustinus, A.S., Finkin-Groner, E., D'Ambrosio, H., Liu, B., Chandarlapaty, S., Liu, S., et al. (2019). Reversible histone glycation is associated with disease-related changes in chromatin architecture. Nat Commun 10, 1289.

Zheng, Q., Osunsade, A., and David, Y. (2020). Protein arginine deiminase 4 antagonizes methylglyoxalinduced histone glycation. Nat Commun 11, 3241. 